\title{
Giuliano Campioni
}

\section{„DIE KUNST, GUT ZU LESEN“ \\ MAZZINO MONTINARI UND DAS HANDWERK DES PHILOLOGEN}

Die Aufgabe, die ich mir in diesem Beitrag über Mazzino Montinari gestellt habe, besteht darin, mit Hilfe von unveröffentlichtem oder schwer zugänglichem Material ${ }^{1}$ einige Aspekte seiner geistig-kulturellen Physiognomie zu beleuchten und so die Leitideen zu erläutern, welche seine Arbeit als Philologe motivierten und eine neuartige "Annäherung“ an Nietzsche ermöglichten.

In seinen Aufsätzen, die er immer als „Nebenprodukte“ der Herausgebertätigkeit ansah - „sie geben gleichzeitig von dieser Rechenschaft und stammen von ihr $a b^{\prime \prime}-$, stellt Montinari „eine andere Art, Nietzsche zu lesen: historisch und nicht ideologisch, philologisch und nicht aktualisierend“ "2, vor.

Eine seiner letzten Schriften zieht gewissermaßen Bilanz der langjährigen Beschäftigung mit Nietzsche: Er spricht von ihr als einer sehr intensiven Erfahrung, die auch von den tiefstverwurzelten Mythen und Vorurteilen befreien kann, wenn man nur bereit ist, „ihm auch energisch zu widersprechen“. Im selben Sinne spricht Müller-Lauter von Nietzsches Philosophie als „ständiger Herausforderung“. Von Anfang an steht seine Bemühung um eine eigenständige Lesart Nietzsches unter diesem Aspekt.

„Wenn ich mich anschicke, die Biographie F. Nietzsches zu schreiben, scheint es mir notwendig, die Gründe für den Versuch eines solchen Unternehmens

\footnotetext{
${ }^{1}$ Diese Arbeit wurde durch die Hilfsbereitschaft und Freundschaft von Sigrid Oloff Montinari und Anna Musso Colli möglich, die mir Einsicht in unveröffentlichtes Material der beiden Gelehrten gestatteten und der Veröffentlichungen dieses Materials zugestimmt haben. Ich bin ihnen zu großem Dank verpflichtet.

Ich möchte auch Bettina Wahrig-Schmidt meinen Dank ausdrücken, die durch ihre Sorgfalt und ihre Fähigkeit als Übersetzerin die Veröffentlichung dieses Aufsatzes möglich gemacht hat.

In den vielen unveröffentlichten Briefen und Notizen, die ich zitiere, habe ich die Siglen und Abkürzungen so beibehalten wie sie im Text stehen, zumal sie leicht verständlich sind. ${ }^{2}$ M. Montinari, Su Nietzsche, Roma: Editori Riuniti, Juni 1981, Vorwort, S. IX. Für die Zitate im folgenden Absatz s. Anm. 5.
} 
zusammenzufassen; dabei schreibe ich meine Gedanken so auf, wie sie mir in den Kopf kommen, ohne eine auch nur provisorische Ordnung; ich möchte also beschreiben, welche Kriterien eine solche Biographie erfüllen muß.

$\mathrm{N}$ ist für mich ein Symbol geistiger Unordnung, $\mathrm{N}$ ist das Opfer (?) der Kontraste, die in ihm die Epoche hervorrief, in der er lebte, $\mathrm{N}$ ist weder ein poetisches Genie noch ein Philosoph noch ein ,Moralist' noch ein Psychologe. $\mathrm{N}$ ist eine Krankheit. Jedes Wort, jeder Begriff, jeder Versuch von ihm finden in mir ein persönliches Echo; $\mathrm{N}$ ist ein noch nicht gelöstes Problem, - und auch ich bin ein noch ungelöstes Problem. N fragt seine Zeit, die die meinige ist, was man tun müsse. Dann nimmt er sich vor, allein dieses Problem zu lösen; er will allein gesund werden, so wie er allein krank ist. Aber $\mathrm{N}$ will die Einsamkeit in der Krankheit. Sobald ich beschließe, mich mit meiner Krankheit zu beschäftigen, beschäftige ich mich mit seiner - und umgekehrt. Das Risiko ist groß, denn der Reichtum und die Mannigfaltigkeit der Symptome drohen zu verhindern, daß man Antwort und Heilung erlangt. Daß jemand, der sich diesem pathologischen Problem stellt, seine intellektuelle Energie verschwendete, ist dagegen keine ernstzunehmende Gefahr. (Das Risiko, oberflächlich zu verallgemeinern, stehenzubleiben, bevor ich auf den Grund gelangt bin - dieses Risiko kenne ich nicht.)

Eine neue Interpretation tut not; die biographische Mikrologie mit dem stillschweigenden oder ausdrücklichen Ziel, , uns von $\mathrm{N}$ zu befreien', nützt nur insofern, als sie uns vom $\mathrm{N}$ der Apologeten, der Modephilosophen usw. befreit. Aber als Symptom, ja als Krankheit ist $\mathrm{N}$ noch nicht beschrieben (und gelöst) worden.

$\mathrm{N}$ bewegt sich entlang der Grenzen einer ,Kultur‘. Provisorisch: $\mathrm{N}$ spürt noch die metaphysische Notwendigkeit, dem Leben eine umfassende Bedeutung zu geben, während er sich gleichzeitig - fast immer erfolgreich bemüht, die antimetaphysische Physiognomie unserer Welt zu erfassen und sie sogar zu rechtfertigen. Aber diese Rechtfertigung kommt von den Grenzen her, wo sich niemand mehr bewegt, den $N$ respektieren könnte: die gewöhnlichen Religiösen, die zu jenen Gefilden einen sonntäglichen Blick herüberwerfen; die unzeitgemäßen Religiösen, die sich an der heidnischen Tafel der Moderne nähren und doch die Moderne selbst negieren; die politischen Religiösen, die die Harmonie zwischen Metaphysik und Realität proklamieren, zum Zweck von Herrschaft und ,Ordnung."

Der Inhalt dieser unveröffentlichten Notizen (datiert 1.9.1963) von groBer stilistischer Kraft, die am Anfang eines Arbeitsheftes von Mazzino Montinari über Nietzsche ${ }^{3}$ stehen, ist nur dann überraschend, wenn man sich von

${ }^{3}$ Es handelt sich um ein Heft mit Notizen und Reflexionen, in einigen Fällen bereits in literarischer Form. Das Heft trägt den Titel Vita 1 (die Zahl wurde mit roter Tinte hinzugefügt); es hat 84 numerierte und ebensoviele nicht numerierte Seiten mit Ergänzungen und Marginalien, lose Blätter mit Stichpunkten, Entwürfen usw. Der Titel hängt zusammen mit dem Vorhaben, eine Biographie Nietzsches zu schreiben. Die letzte Notiz des Heftes ist datiert 17.3.67. In einer meiner nächsten Arbeiten, in der ich die Nietzsche-Interpretation Montinaris untersuchen möchte, habe ich vor, einen Großteil des Materials aus diesem und anderen Heften [darunter: Vita 2 - Materialien für Vorlesungen (Rom 1971) und andere Notizen Weimar 1972] zu veröffentlichen. 
seiner Arbeit als Philologe ein zu einfaches, verkürztes Bild gemacht hat. Die Notwendigkeit einer radikalen Kritik der Verkehrtheiten unserer heutigen Welt, das dringende Bedürfnis, auf eine symbolisch mit dem Namen Nietzsches bezeichnete Krankheit zu reagieren und dabei dessen eigene Fehler zu vermeiden (allein gesunden zu wollen, wie er allein krank sein will), wird klar ausgesprochen. Und doch ist das Verhältnis zu Nietzsche eines von starker, persönlicher Betroffenheit („Ns Krankheit ist die meinige“), von Herausforderung und Provokation; es ist gebunden an ein leidenschaftliches persönliches und gesellschaftliches Engagement; es ist Ausdruck einer Spannung, die nicht - und Montinari ist sich der eigenen Ausdauer sicher - auf die bequeme Weise oberflächlicher Verallgemeinerung gelöst werden soll.

Leidenschaft, Spannung, Elan sind Leitworte, um sich der komplexen Welt und Persönlichkeit Mazzino Montinaris zu nähern, um seinen Weg zu verstehen, der von einer ,weisen Radikalität" gekennzeichnet ist (dieser treffende Ausdruck stammt von der mit ihm gut befreundeten Gigliola Pasquinelli).

Bemerkenswert ist auch eine andere Notiz (datiert 30.9.63) desselben Heftes, die einen Aspekt seines permanenten Interesses für den Zarathustra erklärt:

"Im vierten Teil von $\mathrm{Zt}$ und in den Dithyramben z. B. stimmt $\mathrm{N}$ ziemlich gut mit einer Wesensart von mir überein, die ich beschreiben möchte. Es ist der Wille, sich nach vorn zu werfen, über die Grenzen des Möglichen hinweg.“

Die „weise Radikalität" Montinaris findet sich - explizit oder untergründig - auch in Schriften der letzten Jahre wieder: ich möchte hier nur seine kurze Einleitung aus dem Jahre 1984 erwähnen, in der er mit dem „Radikalismus der Genealogie der Moral" sympathisiert. Die Kraft dieses Radikalismus schreibt Montinari -

„müßte uns eigentlich verstummen machen, um in den Abgrund der wirk lichen Geschichte zu sehen (...), der sich am Ende dieser wissenschaftlichen und von gnadenlosem Radikalismus geprägten genealogischen Arbeit Nietzsches auftut. Es gibt noch heute keine authentische Antwort auf die Fragen, die in der Genealogie gestellt werden, auf diese Herausforderung durch Nietzsche." "Es gibt zwar ein paar Nietzscheanische Afterprodukte, ein paar als Löwen maskierte Affen und - auch! - den heiteren Nihilismus."

Montinaris harte Kritik gilt immer dem allzuleichten Daherreden über die Krise und der Flucht in den Mythos als Lösungsversuch:

„In den bestehenden Institutionen, die durch enorme Produktions- und Destruktionskräfte aufrechterhalten werden, wird jede Art von Protest auch der der ,Lumpen' [im Orig. dt.] - assimiliert und zur Ware gemacht, jeder Versuch, das ,Narrenschiff' zu verlassen, wird so vereitelt. Wenn Ns Methode uns heute noch helfen kann, dann insofern als die einzige Kraft, 
die uns geblieben ist, um uns gegen das Chaos zu stemmen, die Kraft der Kultur und der Vernunft ist. ${ }^{* 4}$

Die Positionen, die Montinari hier formuliert, sind so unzeitgemäß wie seine Art zu leben und zu denken: er hat die Herausforderung und den Radikalismus von Giorgio Collis „Aktion Nietzsche“ angenommen; aber er hat diese auf seine eigene Weise interpretiert und sieht sogar seine enorme philologische und historisch-kritische Arbeit als ihren konsequenten Ausdruck.

Davon zeugt auch der oben zitierte kurze Aufsatz von 1986. Die Herausgebertätigkeit vermittelte Montinari neben dem Umgang mit Nietzsches Kritik der Moderne noch einen weiteren Lernprozeß: Die Erfahrung dessen, der Jahre über Jahre an Manuskripten saß, der Entstehung und Bewegung von Texten verfolgt und nach deren Definition gefragt hat, konfiguriert jenen Nietzsche, der auf keinen Mythos und keine Ideologie zu reduzieren ist, der sich weder ästhetisch aneignen noch unmittelbar ausbeuten läßt und der dennoch zur „Befreiung“ taugt, wenngleich auf weniger sichtbare Weise, mit gedämpfter Stimme.

„Im allgemeinen zeigen die Varianten des kritischen Apparats, auch die weniger bedeutenden, wie sehr Nietzsche bewußt an der Wahl der Worte, an der Akzentuierung und Nuancierung der eigenen Gedanken arbeitete. Kein Bild, kein Wort, nicht einmal ein Interpunktionszeichen anstelle eines anderen, ist zufällig bei Nietzsche. Der Leser, der sich in Geduld übt und diesen Transformationen folgt, wird bereichert, er wird gründlicher, aufmerksamer und mißtrauischer (gegen sich selbst und gegen Nietzsche) ${ }^{\text {“5 }}$.

Die vielen Schriften, die ihn ehren und an ihn erinnern und ein rezenter internationaler Kongreß in Florenz, organisiert vom Toskanischen GramsciInstitut, haben verschiedene Aspekte der Tätigkeit und der Persönlichkeit Montinaris hervorgehoben ${ }^{6}$. Seine letzten, reifsten Ergebnisse und die durch den Tod unterbrochene Bahnung neuer Wege aber können vielleicht auch in

${ }^{4}$ Kurze Einleitung („Nota introduttiva“) zu Friedrich Nietzsche, Genealogia della morale, trad. ital. di Ferruccio Masini, PBA Milano: Adelphi 1984, S. XIX-XX.

5 L'onorevole arte di leggere Nietzsche in "Belfagor" XLI (1986), fasc. 3, S. 338.

- Istituto Gramsci Toscano: Mazzino Montinari (1928-1986) - Incontro di studio, 14. Dezember 1987 - mit Beteiligung der Facoltà di Magistero, Florenz, der Facoltà di Lettere, Pisa, der Scuola Normale Superiore di Pisa, der Verlage, mit denen Montinari zusammengearbeitet hatte sowie vieler italienischer und ausländischer Gelehrter. Vorträge: G. Mari: Apertura dei lavori, S. Romagnoli: Ricordo di Mazzino Montinari, G. Campioni: "La passione rabbiosa per la veritä", H. M. Gauger: Mazzino Montinari e la cultura tedesca, W. Müller-Lauter: Una sfida continua: il rapporto di Mazzino Montinari con Nietzsche, F. Masini: Il significato della ricerca di Mazzino Montinari, K. H. Hahn: Montinari a Weimar, N. Badaloni: Ricordo di un incontro. Außerdem haben Kurzvorträge gehalten: S. Barbera, G. Bevilacqua, G. Garritano, F. Gerratana, L. Perini, A. Venturelli, V. Vivarelli. Die Akten dieses vielstimmigen Beitrags über Person und Werk Mazzino Montinaris werden demnächst veröffentlicht. 
der Aktion jener weiterleben, die die historisch-philologische Arbeit an der Ausgabe und die Anstrengung für eine neue, ,geduldige‘ Lektüre Nietzsches fortsetzen.

1. Nach der „Weimarer Gründungszeit“ der Ausgabe („praktisch ununterbrochener Aufenthalt in Weimar von 1963 bis 1970 - während dessen wir in engem Arbeitskontakt blieben, sowohl durch die Briefe als auch persönlich in den Wochen, die Colli alljährlich in Weimar verbrachte" $)^{7}$ wurde Montinari immer mehr zum obligatorischen Bezugspunkt für jeden, der sich ernsthaft mit Nietzsche beschäftigen wollte. Sein gastfreundliches Haus in Settignano, auf den Hügeln von Florenz, war Zentrum intensiver und vielfältiger Aktivitäten. Es war ein Fokus nicht nur der Nietzsche-Forschung, sondern mannigfacher kultureller und menschlicher Beziehungen. Seine akademische Tätigkeit und die Arbeit an der Edition verteilten sich nach der Weimarer Zeit jedoch auf verschiedene Städte: Urbino, Florenz, Pisa, Berlin.

Im akademischen Jahr 1971-72 wird ihm ein Lehrauftrag für Deutsche Sprache und Literatur an der Philosophischen Fakultät der Universität Urbino erteilt. Von nun an ist das didaktische Engagement, der ,Beruf des Universitätslehrers, ein wichtiges Moment seiner Tätigkeit.

„Im Oktober 1973 wollte eine vorurteilslose und aufgeklärte Kommission (Ladislao Mittner, Marianello Marianelli, Cesare Cases, Giuliano Baioni [das fünfte Kommissionsmitglied, Francesco Delbono votierte dagegen]) meine Tätigkeit als eher atypischer Germanist auszeichnen, indem sie mich mit zwei anderen zusammen in die engere Auswahl eines zu besetzenden Lehrstuhls für Deutsche Sprache und Literatur zog“"

- so drückt sich Montinari in einem Lebenslauf aus dem November 1984 aus.

Die Zeit der außerordentlichen Professur, die in Urbino (1973-74) begann, endete an der Facoltà di Magistero (eine ursprünglich der Lehrerausbildung vorbehaltene, nach der Universitätsreform formal den anderen $\mathrm{Fa}$ kultäten gleichgestellte Fakultät) der Universität Florenz 1975-76. Von 1976 an war er Dekan dieser Fakultät.

Seine Tätigkeit als Dekan fallt in eine schwierige Zeit für die Universität und die italienische Gesellschaft; und hier zeigte sich wieder, welch große Bedeutung das soziale Engagement für Montinari hatte: Jenseits aller abstrakten Ideologie und ohne den Fehler einseitig theoretischen Handelns, der viele Intellektuelle kennzeichnet, stürzte er sich in die praktische tägliche Arbeit und fügte dabei die vielfältigen Probleme seiner Fakultät in eine allgemeine

\footnotetext{
7 M. Montinari, Ricordo di Giorgio Colli in Giorgio Colli. Incontro di Studio, hrsg. v. S. Barbera u. G. Campioni, Milano: Angeli, 1983, S. 17.
} 
Perspektive ein. Für ihn hieß im Grunde Politik nur aktive Mitarbeit: er verstand sie als Streben nach bestimmten Verbesserungen in konkreten Situationen. Jeder sollte an seinem Arbeitsplatz zur Reform der Gesellschaft beitragen - ohne Illusionen, aber in unerschütterlichem Vertrauen auf die Kraft der Demokratie und des rationalen Konsenses.

Diese Einstellung erklärt seine Praxis jener Jahre an der Universität: den Kampf gegen die demagogischen Verkürzungen und gegen ständische Privilegien, die damals häufig mit rebellischer Attitüde bemäntelt wurden, aber auch die Weigerung, den Politikern die Verantwortung der Dozenten in puncto Universitätsreform zu delegieren. Die wichtigste Konsequenz seines Politikverständnisses für die Universität war jedoch, daß er sich ständig um ihr Funktionieren kümmerte: von den Bibliotheken bis zur Organisation des Unterrichts, von den komplexen baulichen Problemen und den Beziehungen mit den lokalen Behörden bis zur Berufsausbildung der Lehrer als wichtigstem Problem einer Fakultät wie des Magistero.

Das alles findet statt in den ,heißen Jahren' des, irrationalistischen' Protests von 1977; man las, wie Montinari schreibt, an den Universitätsmauern „unter den Wandparolen" als Slogans auch Sprüche Zarathustras. Eine Art von „neuem Nietzscheanismus“ erweitert und assimiliert durch Illustrierte und Tageszeitungen, eine Modewelle, „Ausdruck des enormen kulturellen Synkretismus unserer Tage", gehörte zum ideologischen Ballast der starken und häufig antidemokratischen Protest,bewegung'. Der „Handlanger der kritischen Nietzsche-Ausgabe" ${ }^{\text {"8 }}$ mußte angesichts dieses Phänomens seine Unfähigkeit konstatieren, mit wissenschaftlicher Arbeit hier gegenzusteuern:

„Die, sagen wir, geistigen Bedürfnisse der Massen und die Erscheinungen der Kultur-Moden unserer Zeit entsprechen Gesetzen und Ursachen, gegen die der kritische Geist und der historische Sinn zur Ohnmacht verdammt sind, oder besser gesagt nichts vermögen, bis jene Ursachen verschwinden. “"

Der Intellektuelle hat die Aufgabe, diese Ursachen und Zusammenhänge zu studieren, um sie besser zu verstehen und um trotzdem mit seiner Arbeit zu einer Veränderung beizutragen.

${ }^{8}$ Delio Cantimori e Nietzsche in "Belfagor" XXXIV n. 1 (31. Januar 1979), S. 13-30.

9 L'onorevole arte die leggere Nietzsche in "Belfagor" XLI (1986), fasc. 3, S. 336.

In einer Notiz vom 16.3.78 liest man folgendes: „Der aktuelle Erfolg Nietzsches ist ein alles in allem negativ zu beurteilendes Phänomen. Er fügt sich in eine allgemeine Desorientierung ein, die ein akutes Stadium erreicht hat. Die Desorientierten glauben, daß Nietzsche Antworten für sie habe, aber das ist nicht wahr. Wahr ist dagegen, daß Nietzsche vor hundert Jahren (gerade 1978 ist der hundertste Jahrestag des ersten wirklichen N'schen Werks, MA) begonnen hat, die Krise des modernen Denkens, die „Auflösung der Werte“ (wie sie Hermann Broch genannt hat) zu beschreiben und zu analysieren. Sein Wirken im Dezennium von 1878 bis 1888 ist dieser Analyse und Beschreibung gewidmet". S. auch seinen Artikel in "Il Lavoro", Friedrich Nietzsche, attualità di un filosofo inattuale, 22.3.1978, S. 3. 
Wie andere Fakultäten in Italien war auch das Magistero lange von kämpfenden Studenten besetzt, und auf den Mauern des Klosters aus dem 15. Jahrhundert, in dem es untergebracht ist, standen Parolen: Montinari begegnete diesem Umstand nicht mit Entrüstung oder Ironie, sondern er versuchte, die Unzufriedenheit als Ausdruck der absoluten Dysfunktionalität einer Fakultät zu verstehen, die als „zweite Liga“ galt und ihre Absolventen in eine sichere Arbeitslosigkeit entließ:

„Diejenigen, die an die Mauern der Florentiner Fakultät in der Via del Parione geschrieben haben Das Magistero ist eine traurige Illusion, haben sicherlich eine falsche Methode der politischen Willensäußerung gewählt, indem sie mit dieser und anderen Parolen ihre Fakultät beschmiert haben, aber sie haben schlicht und einfach die Wahrheit gesagt"10

schreibt er für einen seiner öffentlichen Vorträge über das Problem der Universität.

Der Wille zur Verständigung und die Suche nach konkreten Antworten mündeten in vielen Initiativen zur Universitätsreform. Im April 1978 fand in San Miniato ein nationaler Kongreß über das Problem der Facoltà di Magistero statt, den er angeregt und mit großer Energie gefördert hatte. ${ }^{11}$ Die eben zitierte Rede endet mit den folgenden bedeutsamen Worten:

„Der politische Kampf für die Reform ist ohne Zweifel hart und langwierig und erfordert das Engagement aller: von Dozenten und Studenten bis zu den nichtwissenschaftlichen Mitarbeitern, die die Dramatik der Krise dieser Institution erleben. Wichtig scheint mir der Beitrag jener, die in der Universität die größte Verantwortung haben; ich denke an die ordentlichen Professoren, die sich entschließen müssen, an dem Kampf teilzunehmen ohne geistige Vorbehalte, ohne korporatives oder individualistisches Denken. Wenn einer von ihnen sagte, daß die Massenuniversität die Freiheit der Forschung bedroht, dann würde ich ihm ruhig antworten, daß jemand, der kein Vertrauen in die Vernunft und die Kultur hat und sich einem allzuleichten Kulturpessimismus überläßt, niemals frei ist und daß unsere Freiheit nichts anderes sein kann als die Freiheit aller im politischen Engagement für die Rettung, wichtiger noch als der Universität, unserer demokratischen Gesellschaft. Sonst wird sich das alte Sprichwort bewahrheiten: quos vult perdere amentit."

In diesem Handeln und Empfinden Montinaris ist meines Erachtens auch der menschliche Reichtum einer Persönlichkeit zu erkennen, die sich fern vom akademischen Elend entwickelt hatte. Bar jeder „Buckligkeit“, die auch die besten Professoren oft kennzeichnet („Vom obligaten Buckel der Profes-

${ }^{10}$ Mazzino Montinari, Due Facoltà da abolire In: „Politica e società“ II. N 10 (Oktober 1977), S. $61-62$.

11 Über die angestrengte und beispielhafte Tätigkeit Montinaris als Dekan hat auf dem Kongreß in Florenz in seinem Beitrag Ricordo di Maqzino Montinari sein Freund Sergio Romagnoli berichtet, der sein Kollege an der Facoltà di Magistero war. 
soren spüre ich noch nichts“, sagt Nietzsche) behielt er ein gewisses Mißtrauen gegen jene Welt, auch wenn er in jener reformträchtigen Zeit manchmal Illusionen über das Engagement seiner Kollegen hegte.

Den besten Ausdruck findet jedoch seine Arbeit an der Universität in den Vorlesungen für Studenten, in den Seminaren, in der direkten Vermittlung von Ergebnissen und Methoden. Vor allem aber war es das wissenschaftliche Ethos, das er weitergeben wollte. Außer an den genannten italienischen Universitäten wirkte er auch in Berlin - 1980 bis 1981 als Gastprofessor an der Freien Universität, in den folgenden Jahren als Fellow des Wissenschaftskollegs - und hielt regelmäßig Seminare mit Studenten und jungen Forschern.

Seitdem Montinari mit der Rückkehr nach Italien auch eine Lehrtätigkeit an der Universität ins Auge faßte, sah er im Lektüreseminar über Texte und Manuskripte das Modell wirksamer Vermittlung von Wissen und Forschungsmethoden. Das liest man zum Beispiel in einem Brief an den befreundeten Germanisten Paolo Chiarini ${ }^{12}$ vom 26. V. 1969. Er schlägt hier einen „freien Kurs" über den vierten Teil des Zarathustra vor. An diesem Thema lag ihm viel, es hat ihn auch während des Forschungsaufenthaltes in Paris noch beschäftigt.

„Der Kurs hätte für mich einen praktischen Nutzen, als Vorbereitung auf die Lehre. Wenn die Sache Dich interessiert und am Institut oder an der Universität abgehalten werden kann, so würde ich den etwa 20-30stündigen Kurs, dessen Thema wäre: ,Der vierte Teil von Also spracb Zaratbustra", folgendermaßen sehen:

a) Allgemeine Einleitung, die den Ort des Zarathustra im Werk Nietzsches bestimmt, allgemeine Probleme der Edition von Also sprach Zarathustra und allgemein der Ausgabe der Werke und Fragmente Nietzsches.

b) Entstehung des IV. Teils von Zarathustra, unter anderem mit ,Rückblikken' [im Orig. dt.] auf die Gedichte von Herbst 1884 und ,Vorausblicken' [im Orig. dt.] auf die Dionysos-Dithyramben.

c) Lektüre und Kommentar des Textes, auch mit Hilfe von Fotokopien (dic Entstehungsstufen sind vollständig erhalten von den ,Vorstufen' [im Orig. dt.] bis zum ,Druckmanuskript‘ [im Orig. dt.]). Dieser Teil müßte den Charakter einer Übung haben, auch im Übersetzen, wie ich es seinerzeit in Florenz gemacht habe mit dem lieben, unvergeßlichen Delio Cantimori für die Unzeitgemäße über die Geschichte - in den akademischen Jahren $1960-61$ und $1961-62 . " 13$

${ }^{12}$ Paolo Chiarini hat ein Porträt der Person und des Werks von Mazzino Montinari gezeichnet in seinem Artikel Il comunista che amava Nietzsche in „Rinascita“ 13. Dezember 1986 (n. 48), S. 22.

${ }^{13}$ In einem Brief vom 16. Februar 1970 bedankt sich Montinari bei dem Freund für die offizielle Einladung, eine Reihe von Vorlesungen an der Universität Rom im akademischen Jahr 1970/ 71 zu halten und präzisiert seine Themen und Methoden noch weiter: „Was den Inhalt der Kurse angeht, so würde ich am liebsten ,induktiv' vorgehen, d. h. von konkreten Problemen 
Gerade in den Jahren engen Kontaktes mit Delio Cantimori war in Montinari zum ersten Mal der Gedanke gereift, eine Universitätskarriere zu versuchen. So schreibt er in dieser Hinsicht an Colli, wobei er jedoch den Freund über die Wichtigkeit und den absoluten Primat der gemeinsamen, nicht-akademischen Unternehmung beruhigt:

„Die deutsche Geschichte und Literatur gut zu kennen und sie anderen vermitteln zu können ist ein achtbarer Beruf. Du weißt, daß ich großen Respekt vor der Wissenschaft oder besser gesagt der Philologie habe wie vor etwas, das ich gerne gut, d. h. systematisch lernen würde und das mir größere Befriedigung gäbe als irgendein anderer Beruf ..."

Diese Überlegungen stehen im Kontext von Montinaris langsamer und methodischer Konstruktion einer eigenen Lebensform mittels eines Berufs, der einen als noch zu leidenschaftlich und unruhig empfundenen Untergrund bändigen sollte:

„Daß ich mit systematisch eine eigene Fähigkeit schaffe, einen eigenen Beruf, scheint mir inzwischen eine Art Notwendigkeit zu sein, die Obsession zu werden droht, wenn sie bloßer Wunsch bleibt. Dafür brauche ich, auch und

der Textkritik bei Nietzsche ausgehen, zunächst in Werken, die er selbst publiziert hat, dann in druckfertig nachgelassenen Werken (wie Ecce homo, das natürlich das aufsehenerregendste Beispiel ist), schließlich die Probleme der Publikation des Nachlasses [im Original deutsch] (und hiet stellt der "Wille zur Macht" das ersichtlich größte Problem dar). Natürlich wird man alle Fragen der Auslegung und des Kommentars behandeln müssen: an erster Stelle Lektüren Nietzsches, Beziehung Biographie - Werk, das historisch-kulturelle Ambiente. Trotzdem glaube ich, daß der Akzent auf die kritische Lektüre Nietzsches gelegt werden sollte, deren ,philologischer' Bestandteil fast völlig vernachlässigt worden ist, trotz der lärmenden Diskussionen und Polemiken. Zu diesem Zweck müßten wir Texte auswählen für jede der Abteilungen a) veröffentlichte Werke b) abgeschlossene, aber von Nietzsche nicht veröffentlichte Schriften c) Nachlaß [im Original deutsch] im eigentlichen Sinne. Schließlich - gestärkt durch die während der verschiedenen Vorlesungen und Übungen gesammelten Erfahrungen - könnten wir die sogenannte, Theorie der Edition' neuzeitlicher Schriftsteller behandeln, über die, wie Du weißt, unter den Herausgebern der verschiedenen "Klassiker" der deutschen Literatur sehr viel diskutiert wird, und auch von den verschiedenen Schulen sowie - vor allem - von den wichtigen im Entstehen begriffenen Ausgaben sprechen; deren Prinzipien könnten wir diskutieren und versuchen, die Kursteilnehmer zu lehren, sie zu lesen und zu benutzen. Sag mir, was Du von dieser meiner allgemeinen Vorstellung hältst und ob Du Vorschläge oder spezielle Wünsche hast - aufgrund der Kenntnis Deiner Studenten und Graduierten." Die Verlagerung der Aufmerksamkeit vom 4. Teil des Zarathustra zu den nachgelassenen Schriften von 1888 ist wiederum dadurch bedingt, daß gerade der bedeutende Apparat für die italienische Ausgabe des VI. Bandes, 3. Teil in Vorbereitung war, der im Mai 1970 herauskam. Fr deutet Chiarini gegenüber die aufsehenerregenden Ergebnisse seiner philologischen Arbeit an: „Inzwischen habe ich weiteres Material bezüglich des berühmten unterschlagenen Abschnitts im Ecce bomo [Abschn. 3 im Kapitel „Warum ich so weise bin“ - G.C.] gefunden: wenn die vollständige Geschichte - ich meine der Veröffentlichung von 1908 - bekannt wird, so wird sie wirken wie ein Krimi. Nietzsches Schwester ist ,erbärmlich' [im Original deutsch] bis zu dem Grade, daß sie das wenig nietzscheanische Gefühl des Mitleids erregt. Aber darüber werden wir noch sprechen." 
gerade für mich, Disziplin - vielleicht weil mein Inneres eben das Gegenteil der Wissenschaftlichkeit und leider auch der Disziplin ist ... ich glaube, ich könnte lehren, und es wäre für mich mehr als die bloße Vermittlung einer Arbeitstechnik" (23. September 1962).

In seiner - schopenhauerischen - antiakademischen Attitüde spürt Colli diese Pläne des Freundes ein wenig als Gefahr, quasi als Verrat, und er antwortet etwas lakonisch:

„Ich habe Deinen Brief erhalten mit der Ankündigung Deiner Pläne hinsichtlich der Universität. Ich bin Dir dankbar, daß Du es mir offen gesagt hast; so muß ich nicht über einer Sache brüten, von der ich eine dunkle Ahnung hatte. Vielleicht muß ich eines Tages sagen:

,Nach dem Verwundbarsten, das ich besaß, schoß man den Pfeil: das waret ihr, denen die Haut einem Flaume gleich ist und mehr noch dem Lächeln, das an einem Blick erstirbt!' [im Original deutsch]

und den ganzen Rest von Zarathustras ,Grablied'. Aber vielleicht wird es auch nicht so ..."

Seine ersten Seminare hielt Montinari auf Einladung Paolo Chiarinis im Frühling 1971 im Rom. Den Notizen für die Einführungsvorlesung, die in einem Heft erhalten sind, entnimmt man folgende Hinweise auf seine Methode und seine Haltung gegenüber den Studenten:

„Unsere Sitzungen sollten den Charakter der Zusammenarbeit tragen. Der zu euch spricht, hat ein Minimum an festen Resultaten zu bieten, viele Daten und objektive Forschungsergebnisse, aber noch viel mehr ungelöste Probleme. Versuchen wir zusammen, einige von ihnen zu lösen oder der Lösung näherzubringen - “" (24.3.71)

Die Vorlesungen und Seminare Montinaris wären eine eigene Untersuchung wert; die - manchmal maschinengeschriebenen - Notizen gelten Themen wie Goethe, Mann, Broch, den deutschen Mythen und der Deutschen ,Ideologie' in den 30er Jahren, Heine, Problemen der Textkritik, und natürlich immer wieder Nietzsche in seinen verschiedenen Phasen, im kulturellen Kontext (zuletzt „die französische Literatur" seiner Zeit) und als Gegenstand der Rezeption.

Nach Florenz sollte die Universität Pisa sein Wirkungsort werden. Der Lebenslauf, den wir oben zitierten, wurde anläßlich seines Rufs nach Pisa auf einen gleichartigen Lehrstuhl in der Philosophischen Fakultät als Nachfolger des „aufgeklärten“ Kommissionsmitglieds Marianelli ${ }^{14}$ geschrieben. Marianelli war inzwischen sein enger Freund geworden.

${ }^{14}$ Marianelli hat einige Artikel von großer Sensibilität und psychologischer Einfühlung geschrieben, um Person und Schaffen des verstorbenen Freundes zu schildern: L'ultimo patriarca della grande filologia in "La Nazione" 6.1.1987, Sfidò Nietzscbe in "La Nazione" 14.12.1987, I conti del superuomo sono ancora aperti in "La Nazione" 2.8.88. - Er hat auch in Lucca an den Freund erinnert, wo am 26. März 1988 ein Treffen mit dem Titel stattfand: Mazzino 
Trotz seines methodischen Mißtrauens gegen Kongresse, die allzu oft Produkt der ,Kulturindustrie‘ sind, war er häufig Teilnehmer und manchmal auch Organisator von Arbeits- und Forschungstreffen über Themen aus den Bereichen von Germanistik, Textkritik und Philosophie in Italien, Deutschland, England, der Schweiz, Norwegen, Israel, den Niederlanden und zuletzt, 1986, den Vereinigten Staaten von Amerika.

Der Tod ereilte ihn einen Tag bevor der Unterricht in Pisa beginnen sollte: auf dem Tisch lagen die ersten Notizen für die Vorlesung Mythologie und Wabrheit: die Poetik Heinrich Heines. Die philologische Arbeit am 12. Band der kritischen Heine-Ausgabe sollte Hand in Hand gehen mit der Vermittlung der Resultate an Studenten. Dazu gesellte sich der Wunsch, Autoren, die ihm lieb waren, „lesen“" zu lehren. ${ }^{15}$

2. Mit der Rückkehr nach Italien nimmt Montinari Altes wieder auf und geht neue Verpflichtungen als Herausgeber ein. Die bedeutendste unter diesen ist seine aktive Mitarbeit im Redaktionskomitee der italienischen Ausgabe der Marx-Engels-Werke (der Opere Complete); er betreute hauptsächlich die Briefe und gab mehrere Bände heraus.

Die Ausgabe erscheint bei „Editori Riuniti“; hier hatte Anfang der 50er Jahre Montinaris Berufsleben begonnen. Er bringt in das neue Projekt seine Erfahrung als Herausgeber ein und dringt vor allem auf klare Prinzipien der Textedition. Das zeigt auch der Briefwechsel mit seinem alten Freund aus den Zeiten der Scuola Normale, Giuseppe Garritano, über die allgemeine Anlage der Ausgabe. Für die Ausgabe der Briefe revidiert und vergleicht er,

\footnotetext{
Montinari. Da Lucca a Weimar. Aus seinem ersten Artikel möchte ich hier die folgende, treffende Schilderung wiedergeben: „Die Ausstrahlung dieses sehr milden, äußerst jovialen, modernen Patriarchen der Philologie hatte etwas Seltenes und Menschliches, das jeder spürte, der ihm nahekam (...) Verlegen machten nicht seine vorsichtigen Rüffel, sondern sein betretenes Schweigen, wenn jemand etwas sagte oder machte, das ihm nicht gefiel.

Dasjenige an ihm, was man am schwersten enträtseln konnte, war das Unschuldigste: sein Lächeln: der Übergang, der in seinem großen, geröteten Gesicht vom ansteckendsten Lachen zu den schattigen Zügen der Melancholie stattfand. Ich glaube, dies war nicht nur die Melancholie, die sein Nietzsche im Antlitz jedes Philologen liest und die vom Bewußtsein herstammt, daß kein „Erraten“ des Textes die Schöpfung des Künstlers zu ersetzen vermag; ebensowenig kann es allein die Sicherheit gewesen sein, daß absolut „kein Text" existiert auch der von ihm selbst mühsam freigesetzte nicht - „der nicht neuerdings verraten würde“. Vielleicht rührte die vorsichtige Melancholie Montinaris auch daher, daß er so viele Dinge und Gefühle seinem Vorhaben opferte, oder sie war durch die Angst bedingt, es nicht zu Ende zu bringen."

15 Wer die Gelegenheit hatte, an diesen Seminaren in Florenz, Pisa oder Berlin teilzunehmen, weiß, wie leidenschaftlich Montinari seinem Engagement bei der Ausbildung seiner Studenten und Schüler, einem wichtigen Element auch der Forschung, treugeblieben ist. Über diese Aspekte haben auf dem Kongreß in Florenz Federico Gerratana und Vivetta Vivarelli berichtet.
} 
für eine Reihe von Bänden alte Übersetzungen, fertigt neue an und gibt den Anmerkungsapparat heraus. ${ }^{16}$ Die italienische Marx-Engels-Ausgabe bietet ihm die Gelegenheit, erneut mit alten Freunden von der Normale zu arbeiten, die in der Kommunistischen Partei politisch aktiv sind: Fausto Codino, Giorgio Giorgetti und als Leiter Giuseppe Garritano. ${ }^{17}$

${ }^{16}$ Er gab folgende Bände heraus: Karl Marx - Friedrich Engels, Opere complete; Lettere Ottobre 1844 - Dicembre 1851, Bd. 38, Editori Riuniti, Rom 1972, [übers. zusammen mit Mario Alighiero Manacorda]. - Lettere Gennaio 1852 - Dicembre 1855, Bd. 39, Rom 1972 [übers. zusammen mit Mario Alighiero Manacorda]. - Lettere Gennaio 1856 - Dicembre 1859, Bd. 40, Rom 1973 [übers. zusammen mit Mario Alighiero Manacorda]. - Lettere Gennaio 1860 - Dicembre 1864, Bd. 41, Rom 1973 [übers. zusammen mit Mario Alighiero Manacorda] Lettere Gennaio 1864 - Dicembre 1867, Bd. 42, Rom 1974 [übers. zusammen mit Sergio Romagnoli] - Lettere Gennaio 1868 - Dicembre 1870, Bd. 43 Rom 1975 [übers. zusammen mit Sergio Romagnoli u. Emma Cantimori Mezzomonti]. Bd. 44 erscheint demnächst.

17 Die Gefühle, die er für den wiedergefundenen Freund empfand und seine Freude über die neuerliche Zusammenarbeit finden ihren Ausdruck in einem scherzhaften Brief seines „Bruders" Giorgetti an den „verlorenen Sohn" des gemeinsamen Vaters Cantimori, bei dem beide promoviert hatten, indem sie die Philosophie mit der Geschichte vertauschten: „wir hoffen, daß Du durch die Leiden des langen Exils die Erbsünde gesühnt habest und daß die Herausgabe der heiligen Schriften endgültig die dämonischen Versuchungen besiege, die von Zarathustra [und seinem besessenen Anbeter] ausgehen. Und daß in diesem Werk der Wiedergeburt das richtige Gedenken an den Vater Dir den Weg erhelle! In diesem Geist und mit diesen Absichten gewähren wir Dir Unsere brüderliche Verzeihung“. Der vorzeitige Tod Giorgio Giorgettis (April 1976) und Fausto Codinos (1985) hatte Montinari sehr getroffen. An Giorgio Giorgetti hat er in einem kurzen, bewegten Artikel erinnert: „Mein Freund und Bruder Giorgio war eine glückliche Natur"; er war von objektiver Natur durch ein Gleichgewicht, das von jeglicher psychologistischer oder individueller (Selbst)quälerei unabhängig war und das aus der ,innigen Kohärenz seines Lebens entsprang: des Lebens eines kommunistischen Kämpfers in permanentem Kontakt mit der Basis der Partei, eines Historikers, der in täglicher, mühevoller Arbeit in den Archiven und den Bibliotheken die Probleme von ihrem Wesen her verstand, der die Eile des Schreibens um des Schreibens willen nicht kannte, der im Gegenteil wußte, daß man nur schreiben kann, was man nachgeprüft hat und auf der Ebene historischer Verallgemeinerung nur das, was ohne ideologische Dilettantismen auskommt." Es war gerade diese Praxis des "Handwerks" des Historikers, in der Montinari die tiefe Verwandtschaft mit seinem "Bruder" erkannte, auch wenn für ihn, aufgrund seiner unruhigen und leidenschaftlichen Natur, diese Entzauberung und jenes wissenschaftliche Gleichgewicht mehr einen Sieg als ein ,eigentümliches“ Faktum darstellten (Una natura felice, "Nuovo corriere senese" 15, April 1976, S. 3). Montinari hat außerdem den Band nachgelassener Schriften Giorgio Giorgettis herausgegeben: Note sulla religione nel pensiero marxista a altri scritti politici, Firenze: Guaraldi 1977, S. 156.

Fausto Codino, geboren in Lucca wie Montinari, studierte an der Scuola Normale klassische Philologie. Neben seinem Engagement als Übersetzer der Werke von Marx und Engels (unter diesen die Deutsche Ideologie) bei den Editori Riuniti möchten wir hier erinnern an seine Introduzione a Homero, Turin: Einaudi 1965 (sie ist auch ins Deutsche übersetzt worden: Einfübrung in Homer, Berlin: de Gruyter 1970) und an L'origine della storia nella Grecia antica, Rom: Editori Riuniti 1984; er gab heraus: Miti greci e romani, Bari: Laterza 1971 und übersetzte von Joseph Vogt Der Niedergang Roms (Il declino di Roma), Milano: Il saggiatore 1965. Weiterhin gab er heraus: Quando gli womini creavano gli dei. Raccolta di miti e leggende dell'antichità classica, estratti dalle opere dei maggiori poeti greci e romani dall'ottavo secolo a.c. al secondo secolo d.c. Bari: Laterza 1954. 
Anfang $1968 \mathrm{kam}$ in einer populären Reihe von hohem Niveau „I protagonisti della storia universale“ (die Großen der Weltgeschichte) ein Porträt Nietzsches heraus. Montinari entwarf hier zum ersten Mal eine Gesamtinterpretation des deutschen Philosophen. Die historische Sichtweise und die Zuverlässigkeit des reichhaltigen Quellenmaterials kennzeichneten eine völlig neuartige Annäherung an Nietzsche. Von 1968 bis zu seinem Tod hat Montinari viele Artikel und Aufsätze in italienischen, deutschen und englischen Fachzeitschriften publiziert: über Nietzsche, über die Probleme und Methoden der Edition, über Goethe, Manzoni, Thomas Mann, Wagner, Lou von Salomé, Baeumler, Hillebrand, Cantimori und schließlich Heine, von dessen in Weimar und Paris erscheinender kritischer Ausgabe er einen Band herausgeben sollte. Nach dem Tod Collis hat er Vorworte verfaßt für einzelne Bände der (italienischen) Nietzsche-Werkausgabe und für Nietzsche-Schriften, die in der Reihe „Piccola Biblioteca Adelphi“ herauskam. Für diese hatte er 1977 eine (von M. Carpitella übersetzte) Sammlung autobiographischer Jugendschriften Nietzsches (1856-1969) herausgegeben.

Von seinen weitgespannten Interessen zeugen unter anderem die Einleitungen zu Robert Musils Beitrag zur Beurteilung der Lebren Machs (Sulle teorie di Mach, Adelphi 1973), das er auch übersetzt hat, zu den Gedichten seines Dichterfreundes Reiner Kunze Sensible Wege (Sentieri Sensibili, Einaudi 1982), zum Briefwechsel Sigmund Freud - Lou Andreas-Salomé (Eros e conoscenza, Boringhieri 1983), nicht zu vergessen seine unermüdliche Tätigkeit als Übersetzer Nietzsches und vieler anderer, besonders klassischer Autoren.

1975 veröffentlichte er Nietzsche, eine stark überarbeitete Fassung seines ersten Porträts (Ubaldini, Rom). Zwei Aufsatzsammlungen, eine italienische, Su Nietzsche („Über Nietzsche“, Editori Riuniti, Rom 1981) und eine deutsche, Nietzsche lesen (de Gruyter, Berlin 1982) machen deutlich, wie ergiebig seine schriftstellerische Tätigkeit war, die parallel zur Arbeit an der kritischen Ausgabe stattfand und trotz seiner fast vollständigen Inanspruchnahme durch sie der Forschung neue Wege wies. Zuletzt widmete sich Montinari der Beziehung Nietzsches mit der ihm zeitgenössischen französischen Kultur [vgl. den Aufsatz Nietzsche e la décadence in "D'Annunzio e la cultura germanica“, Pescara 1986 und L'onorevole arte di leggere Nietzsche („Die ehrenwerte Kunst, Nietzsche zu lesen“) in „Belfagor“" 1986].

Er hielt sich im Herbst 1986 zu Studien in der Pariser Bibliothèque Nationale auf und plante auch ein internationales Forschungsseminar zu diesen Themen.

Von 1983 bis zu seinem Tode koordinierte und leitete er das von ihm vorgeschlagene und vom italienischen Bildungsministerium finanzierte nationale Forschungsprojekt „Nietzsches Bibliothek und Lektüre“. Wir werden im Abschnitt 5 auf dieses Projekt noch zu sprechen kommen. 
Unter seinen Aktivitäten als Koordinator internationaler Studien muß jedoch besonders hervorgehoben werden, daß er bei de Gruyter das internationale Jahrbuch Nietzsche-Studien und die Reihe Monograpbien und Texte zur Nietzsche-Forscbung (bis 1986 erschienen 16 Bände) mit ins Leben gerufen und vom Jahr ihrer Gründung (1972) an mit herausgegeben hat.

Schon ab Ende 1969 erwog man bei de Gruyter die Gründung einer Zeitschrift, deren Ziel die internationale Förderung und Verbreitung der Nietzsche-Forschung sein sollte. Karl Löwith, der um ein Urteil gebeten wurde, zeigte sich wenig überzeugt von den Erfolgsmöglichkeiten eines solchen Unternehmens, weil ihm die junge Generation nunmehr Nietzsche ziemlich fernzustehen schien; ihm leuchtete nur sein möglicher Nutzen für die neue Edition ein: „Etwas anderes ist es natürlich, wenn man das NietzscheJahrbuch mehr informatorisch zur Bekanntmachung und Verbreitung der großen neuen Nietzsche-Ausgabe benutzen würde." (Brief an Wenzel, 30.12. 1969) Im Frühling 1970 konkretisierte sich das Projekt in Diskussionen und Treffen, an denen Wolfgang Müller-Lauter, Karl Pestalozzi und Heinz Wenzel teilnahmen. Von Anfang an waren entscheidende Gesichtspunkte für die neue Zeitschrift ihr internationaler Charakter und die Kommunikation zwischen den Nietzsche-Forschern. So definiert Montinari die „Aufgabe des Nietzsche-Jahrbuchs" in einem Briefentwurf an Wenzel:
„Das Jahrbuch sollte genauer ,Internationales Nietzsche-Jahrbuch' heißen: damit wäre schon auf einen Aspekt seiner Aufgabe hingewiesen, nämlich ein internationales Organ für die Nietzsche-Forschung.
Es sollte allen Forschern offen sein, die sich ernstlich mit Nietzsche beschäf- tigen, ohne Rücksicht auf ihre weltanschaulichen und sonstigen Vorausset- zungen (also kein Organ für Nietzsche-Verehrer oder eine ,Nietzsche-Ge- sellschaft').
Ich sehe seine Hauptaufgabe in der Förderung der philosophischen Ausein- andersetzung mit Nietzsche, die jedoch von der historischen Forschung abhängt.
Außerdem sollte es eine möglichst vollständige Information über die ver- schiedenen Gebiete der Nietzsche-Forschung bieten. “ [2.3.1970]

Es wird hier programmatisch als Prämisse des Jahrbuchs formuliert, was, neben der Offenheit gegenüber Positionen und Weltanschauungen, eine feste Überzeugung Montinaris war: „Wenn eine Nietzsche-Interpretation nicht nur mit historisch-philologischem Arbeiten gewonnen werden kann, so kann sie doch auch keine solide Grundlage obne es haben" ${ }^{18}$.

Die Themen dieser Skizze greift Wenzel in einem Brief vom 9.3.1970 mit dem Titelvorschlag auf: ,als Name schwebt mir vor ,Internationales

\footnotetext{
${ }^{18}$ M. Montinari, Su Nietzscbe, a. a. O., S. 127.
} 
Nietzsche-Jahrbuch ' oder vielleicht auch ,Nietzsche-Studien/Internationales Jahrbuch der Nietzsche-Forschung."“

Wegen seines Engagements für Nietzsche („ohne Sie - keine NietzscheAusgabe") und wegen seiner „Beziehungen mit deutschen und ausländischen Gelehrten" schlägt Montinari Wenzel vor, selbst Herausgeber zu werden, unterstützt von einem großen internationalen wissenschaftlichen Beirat.

Für diesen nennt Montinari - außer sich selbst - seinen Freund Wolfgang Müller-Lauter: „als philosophisches ,Gegengewicht gegen meine ,historisierende Tendenz “", wie er scherzhaft formuliert.

Wenzel hielt mehr von einer mehrköpfigen, gleichberechtigten Leitung, die er selbst, Montinari und Müller-Lauter innehatten (1978 kam Ernst Behler dazu).

Aufgrund ihres internationalen und forschungsorientierten Charakters, der sich im Laufe der Jahre erhalten und weiterentwickelt hat, könnten die Nietzsche-Studien nach dem Tode Montinaris zu einem wesentlichen Organ des Austauschs und der Koordination von Projekten, Ergebnissen und Teilergebnissen werden. Sie könnten so in der Zukunft für die Fortführung der Ausgabe von zentraler Bedeutung sein.

Die vorangehenden Seiten sollten einen ersten, allgemeinen Überblick über die Arbeit Montinaris vermitteln und geben nur ein sehr kurzgefaßtes Curriculum wieder. Eine genaue und den Anspruch auf Vollständigkeit erhebende Rekonstruktion der wissenschaftlichen Biographie wäre ein schwieriges Unterfangen, und es bestünde immer die Gefahr, daß einige Aspekte seiner vielfältigen Tätigkeit sowie die wichtigen kulturellen und menschlichen Beziehungen zu kurz kämen.

Das folgende stellt daher keine umfassende und chronologische Schilderung seines intensiven und fruchtbringenden Schaffens dar; der zeitliche Abstand ist dafür zu kurz, und die mit persönlichen Eindrücken schmerzhaft durchsetzte Erinnerung trägt noch die Spuren gemeinsamer Arbeitsvorhaben, die durch seine endgültige Rückkehr als Hochschullehrer nach Pisa begünstigt worden wären. Stattdessen möchte ich interessierten Forschern sowie den Freunden Mazzino Montinaris möglichst viel Material zur Verfügung stellen; es erläutert - häufig bereits in literarischer Form - die Entscheidungen und Standpunkte, die er zur persönlichen Basis seiner täglichen Arbeit als Philologe und seiner Herausgebertätigkeit machte. Besonders die Briefe an Colli beleuchten außerdem den Alltag seines philologischen ,Handwerks'.

3. Schon die ersten Jahre seines wissenschaftlichen Werdegangs zeigen bestimmte konstante Grundeinstellungen. Das Kulturelle und das Menschliche hängen eng miteinander zusammen; auch scheinbare Schwankungen und 
Inkohärenzen der wissenschaftlichen Biographie entstehen aus einem Willen zu Moralität und Konsequenz, der keine Kompromisse kennt: Daher wird die Auseinandersetzung mit Nietzsche zur Herausforderung.

Es war mir möglich, Montinaris Arbeit in der Gründungsphase der Ausgabe mit Hilfe des - fast - vollständig erhaltenen Briefwechsels der beiden Herausgeber und über einige Hefte mit Notizen und Überlegungen zu verfolgen, die allgemeiner seiner Beschäftigung mit Nietzsche galten.

Bereits die von mir in den Nietzsche-Studien 1988 veröffentlichten Texte ${ }^{19}$ geben einen Eindruck von der minutiösen und skrupulösen Arbeit Montinaris. Sie zeigen deutlich den Weg, den er gehen wird.

Ich möchte hier, gestützt auf seine Briefe, einige konkrete Aspekte des Prozesses darstellen, den man als die "Weimarer Phase“ der Werk- und Briefausgabe bezeichnen kann.

Aus den Briefen an Colli sprechen Freundschaft und Zuneigung. In der Beziehung beider gibt es natürlich auch menschliche Krisen und Schwächen, die sich hier ebenso niederschlagen wie alltägliche Ärgernisse und Zwischenfälle, Treffen, Neuigkeiten und Wiederholungen. Auch die heiteren und scherzhaften Ereignisse des Lebens eines, der seine wissenschaftliche Arbeit nicht fern der Welt, sondern in ihr und verwickelt in ihre großen und kleinen Verhältnisse leistet, finden ihren Ausdruck. Man merkt, mit welcher Distanz, ja Feindschaft Montinari dem stummen und defensiven Hochmut philologischer Faktendienerschaft begegnet. - Seine Arbeit ist intensiv und oft nicht sehr befriedigend; man muß „vom Morgen bis zum Abend von Nietzsche und in Nietzsche und mit Nietzsche [leben, G.C.], ohne Pause, ohne eine Sekunde ,nicht philologisch' zu denken" - so schreibt er in einem Moment der Krise. Oft hat er das Gefühl, unter der Arbeitslast zu ersticken, niemals dem Schach der Zeitpläne, der drängenden Verleger und der Masse und Komplexität des Materials zu entkommen. Die Forschung ist für ihn eine Entdeckungsreise, aber auch eine Gesellenwanderung: die Werkzeuge sind keine Neutra, sondern verändern sich; sie passen sich den Umständen und den Schwierigkeiten des Augenblicks an, unterstützt und verändert durch seinen scharfen Intellekt, durch ein kulturelles Erbe, das weiter wächst, durch Ernst, Erfahrung und Humanität. Auch die langsame Entdeckung und Konsolidierung der eigenen Persönlichkeit in der immer reifer werdenden Freundschaft mit Colli findet ihren Ausdruck:

„Vielleicht ist unsere Beziehung gereift; ich fühle mich ihrer sicherer, und auch ich denke an Dich als einen Fixpunkt. Und das obwohl ich gerade in der letzten Zeit wieder gemerkt habe, daß wir unterschiedliche "Ansichten"

${ }^{19}$ G. Campioni, Mazzino Montinari in den Jabren von 1943 bis 1963 in "Nietzsche-Studien“ 17 (1988), S. XV-LX. 
haben. Aber meine Ansichten sind selbst wahrscheinlich nicht mehr jene, die ich bisher zu haben glaubte, auch wenn sie anders als Deine sind; sie müßten sich nur - durch mein Verdienst - bei Dir das Verständnis und den Respekt erwerben, den ich - durch Dein Verdienst - für die Deinigen habe." (12. Januar 1969)

Die Briefe zeugen auch von der Freundschaft und der Achtung, die den jungen italienischen Gelehrten mit dem Weimarer Ambiente und den Mitarbeitern des Goethe- und Schiller-Archivs verbinden: Helmut Holtzhauer, Direktor der nationalen Forschungs- und Gedenkstätten der klassischen deutschen Literatur; Karl Heinz Hahn, Direktor des Archivs; die „sehr tüchtige“ Archivarin Anneliese Clauss; Hans Henning, Direktor der Zentralbibliothek der deutschen Klassik. „Mazzino Montinari ... wurde civis Vimarianensis“, schreibt $\mathrm{Hahn}^{20}$ in einer bewegenden Erinnerung an jene glücklichen Jahre des täglichen Umgangs. Mit großer Liebenswürdigkeit begegnet Montinari auch den Nietzsche-Forschern, die bald das Archiv zu frequentieren beginnen, Freundschaft und Achtung bestimmen im allgemeinen seine Beziehungen zu ihnen. Montinari berichtet dem Freund zum Beispiel über die Planung und Entwicklung der bedeutenden Arbeiten von Curt Paul Janz ${ }^{21}$ und über die Begegnungen mit dem Amerikaner Frederick R. Love („von kleiner Statur, schmächtig, mit Bärtchen und Schnurrbart, dunkelhaarig wie ein Italiener; er hat ein intelligentes Gesicht und ein bescheidenes und offenes Auftreten ... er hat schon sehr viel über Gast geforscht und eine kleine Arbeit über Nietzsche und die Musik geschrieben“) (25. Juli 1966). Angesichts der japanischen Übersetzung der Ausgabe berichtet er über ein Treffen mit einem

${ }^{20}$ Karl-Heinz Hahn, Professor Mazzino Montinari 4. April 1928 - 24. November 1986 in Goethe Jahrbuch 104. Band der Gesamtfolge 1987, Weimar 1987, S. 388-390.

${ }^{21}$ „Im Archiv arbeitet, zusammen mit seiner Frau, der Schweizer, der die kritische Ausgabe der musikalischen Kompositionen Ns macht. Er wird insgesamt drei Wochen bleiben. Natürlich habe ich ihn kennengelernt. Er ist ein treuer Freund Schlechtas ... Er hat mir angekündigt, daß er ab nächstem Jahr, nach dem Erscheinen der Kompositionen, mit den Vorarbeiten für eine $\mathrm{N}$ Biographie beginnen wird ... Er wird derjenige sein, der, Blunck fortsetzend, die erste ehrliche Biographie Ns schreiben wird." (6. April 64) [F. Nietzsche, Der musikaliscbe Nacblaß, Basel 1976; C. P. Janz, Nietzsche. Biograpbie, München - Wien 1978-79] „Janz ist heute nach Basel abgereist. Er wird im Herbst 65 wieder nach Weimar kommen. Er hat mich gefragt, ob wir vorhaben, die Briefe herauszugeben, ich habe ihm mit Ja geantwortet. Er ist inzwischen fertig mit der Ausgabe der Musik und hat für seine Biographie alle Briefe Ns an Gast kollationiert; dabei hat er wenigstens fünfzig grobe Auslassungen in der bisher bekannten Ausgabe gefunden, ohne daß er einzelne ausgelassene Worte hierbei mitgezählt hätte. Er wird in einer Zeitschrift über diese seine Arbeit berichten. Ich muß sagen, daß er mir sympathisch ist, und daß er mich mit Respekt behandelt hat (häufig habe ich für ihn Wörter entziffert, die er nicht lesen konnte)“ (13. Oktober 1964) [C. P. Janz, Die Briefe F. Nietzscbes. Textprobleme und ibre Bedeutung für Biographie und Doxographie, Zürich 1972] „Ich muß sagen, daß er mit seiner Frau zusammen eine Arbeit von extremer Genauigkeit macht ..." (6. Mai 1965). 
japanischen Professor „voller Vorbehalte gegen die Zivilisation und leidenschaftlicher Nietzsche-Anhänger", der Colli gefallen hätte.

Auch Montinaris Tätigkeit als Übersetzer findet in den Briefen ihren Niederschlag. In steigendem $\mathrm{Maß}$ wird er sich der Bedeutung und der Schwierigkeit dieses, Handwerks' bewußt, das er von jungen Jahren an immer wieder ausgeübt hatte. Er sieht sich oft zu radikaler und manchmal ungerechter Selbstkritik veranlaßt:

„Ich mache gerade eine völlig neue Übersetzung der Fragmente aus IV 3, denn ich zögere nicht, diejenige, die ich für Einaudi gemacht habe, miserabel zu nennen ... .“ (1.8.1966)

„... übersetzen heißt, nach meiner neuesten Überzeugung und nach meinem eigenen Erwerb der deutschen Sprache, die Rechte beider Sprachen zu respektieren; derjenigen aus der man übersetzt und derjenigen, in die man übersetzt." (30. 5. 1966)

„Ich habe natürlich überhaupt kein Bestreben, Ecce zu übersetzen. Schon die Übersetzung des Zarathustra scheint mir, jedenfalls zur Zeit, genau das Gegenteil einer fruchtbaren Arbeit zu sein. Es handelt sich doch darum, $\mathrm{da} ß$ es gelingt, auf Italienisch das zu sagen, was Nietzsche auf Deutsch sagt, und das heißt Sich-Hineindenken und bestimmt nicht was Du nennst ,Sich auf eine höhere Ebene der Analyse begeben'. Für mich ist das Hineindenken, während ich mich langsam verdeutsche und ,vernietzsche', eine ernste Sache, die bis zum Leiden geht: für die anderen ist es das dagegen nicht. Und deshalb wird mir die Überarbeitung von Übersetzungen anderer immer mehr zur Tortur, was - wie ich sicher weiß - nicht oder nur zum allergeringsten Teil aus Unlust zur Arbeit herrührt, sondern aus der permanenten und lähmenden Wut, die mich packt, wenn ich sehe, wie die zwei elementaren Notwendigkeiten des Übersetzens unbeachtet bleiben, nämlich 1) wirklich das zu verstehen, was Nietzsche sagen will, 2) es auf italienisch nochmals zu sagen, aber wirklich! Mein Gesichtspunkt ist so radikal, daß daraus folgt: Bis auf den heutigen Tag habe ich weder eine diesen Kriterien genügende Übersetzung gelesen, noch selbst eine gemacht. Vielleicht ist das die ,platonische` Idee der Übersetzung; ich wünschte nur, ich hätte sie immer so im Kopf gehabt wie heute und unsere Übersetzer hätten sie auch. Andererseits möchte ich - da Du sie nicht machen willst - gerade aus all diesen Gründen lieber die Übersetzung des Zarathustra selbst machen als sie korrigieren zu müssen, auch wenn das keine produktive Arbeit ist, wie ich sie nötig hätte (eben im Sinne von ,sich auf eine höhere Ebene begeben').“ (13. Februar 1967)

Die Übersetzung des Zarathustra, an der er mit großer Leidenschaft arbeitet, - „,ich habe mich in ,erhabener' Unschuld in diese Arbeit versenkt, um sie auf würdige Weise zu machen" $(25.11 .68)$ - ist am 10. September 1968 fertig. Trotz seiner selbstkritischen Haltung bezeichnet Montinari sie später als „eine Arbeit von guter Qualität", „eine lesbare Fassung, die zwar nicht dem Wort aber dem Geist treu bleibt", und er hält „trotz des Sparens an Varianten“ im Verhältnis zu jenem „ewigen Apparat", an dem er ständig 
arbeitete, den Band für einen „Höhepunkt der [unserer] Ausgabe“ (28. Oktober 1968).

4. Schon der erste Kontakt mit der Weimarer Umgebung zeugt von dem Bewußtsein, daß hier etwas Endgültiges geschaffen werden soll: Das ursprüngliche Projekt der Übersetzung verwandelt sich - nach den ersten Sondierungen - in das Vorhaben einer Gesamtausgabe der Texte Nietzsches.

Die Antwort Collis auf den enthusiastischen programmatischen Brief des Freundes ${ }^{22}$ zeigt, daß die dringendsten Arbeiten angesichts der italienischen Übersetzung (Fröbliche Wissenschaft und Menschliches, Allzumenscbliches mit dem jeweiligen nachgelassenen Material) schon mit der Notwendigkeit einhergehen, „die Arbeit zu skizzieren, um die Übersetzung des W. z. M. zu machen“, d. h. einen endgültigen Text für eine kritische Ausgabe zu gewinnen.

„Deine letzten Resultate, so weit ich sie aus Deinem Brief entnehmen kann, interessieren mich sehr; Komplimente für Deine Fähigkeiten als Philologe und Graphologe - Es tut sich ein Feld für die Ausgabe auf, in der nicht nur von der Anlage her viel mehr Neues sein wird, als wir am Anfang dachten." (25. August 61)

An den ersten Bänden der Ausgabe arbeiteten ab April 1964 in Weimar und Florenz auch Sossio Giametta und Maria Ludovica Pampaloni ${ }^{23}$, die zur

${ }^{22}$ G. Campioni, Mazzino Montinari in den Jahren von 1943 bis 1963 in „Nietzsche-Studien“, S. XLV f.

${ }^{23}$ Sossio Giametta war aktiver Mitarbeiter der Enzyklopädie klassischer Autoren bei Boringhieri, die von Giorgio Colli geleitet wurde: Er hat hier unter anderen die Ethik von Spinoza (1959) und das Bellum Gallicum von Caesar (La guerra di Gallia, 1961) übersetzt. Er hat Werke von Goethe, Hegel, Schopenhauer, Nietzsche und Freud übersetzt. Seine spekulative und schriftstellerische Leidenschaft (seinen Beruf übt er in Brüssel beim Europäischen Ministerrat aus) drückt sich in vielen Studien und Erzählungen aus. Ein indirektes Zeugnis gibt der Bericht Collis in einem Brief an Montinari, in dem es um einen Kofferdiebstahl an Giametta geht, die zum Verlust ,aller seiner persönlichen Manuskripte [führte], in denen er seine Gedanken und seine literarischen Versuche gesammelt hatte". (26. Juli 1965). Montinari nimmt am Unglück des Freundes Anteil: „Ich hatte ihn so viele Male Notizen auf Blättchen machen und sie nachher mit der Maschine abschreiben sehen: er hatte mir von seinen literarischen Versuchen erzählt - es war für ihn das Allerwichtigste, eine Konstruktion, an der er, man kann sagen, Tag für Tag arbeitete ..." (2. August 1965)

Er ist Mitarbeiter zahlreicher Zeitschriften und der neapoletanischen Tageszeitung Il Mattino. Vor kurzem erschien von ihm der Band Oltre il nichilismo. Nietzsche Hölderlin Goethe. Napoli: Tempi Moderni ediz., November 1987. - Von ihm erscheint demnächst ein umfangreicher Kommentar zu Also sprach Zarathustra (Milano: Garzanti).

Maria Ludovica Pampaloni, die zur Zeit in Florenz Deutsch an Mittel- und Oberschulen lehrt, hat an der Enciclopedia di Autori classici Boringhieri mitgearbeitet; sie hat dafür übersetzt Johann J. Winckelmann, Geschichte der Kunst des Altertums (Storia dell'Arte nell'Antichità, Torino: Boringhieri 1961; diese Übersetzung erscheint, von ihr selbst überarbeitet und korrigiert, demnächst im Verlag SE in Mailand). Sie hat außerdem übersetzt Hans Richters Dada (Dada. Arte e Antiarte, Milano: Mazzotta editore 1966) und für Adelphi: Friedrich Nietzsche, Epistolario 1850-1869, ed. ital. diretta da G. Colli e M. Montinari, Bd. I 1977 und III (dieser Band ist noch nicht erschienen). 
kleinen, durch Freundschaft und Zuneigung gefestigten Schülergemeinde Collis gehörten.

"Sie erweisen sich als aufmerksam und akkurat, und ich glaube, daß Du eine gute Wahl getroffen hast, nicht nur was ihre außergewöhnlichen menschlichen Qualitäten, sondern auch was ihre Fähigkeiten betrifft" (26. August 1962).

„Die Arbeit geht gut voran. Marilù hat gerade heute die Entzifferung des Heftes M III 5 beendet. Ab Montag wird sie eine Mappe derselben Zeit bearbeiten. Sossio müht sich mit einer Mappe der Morgenröthe ab, die ziemlich schwierig ist, aber auch er wird mit der Arbeit vor seiner Abreise noch fertig (es ist die Mappe MP XV 1). Ich bin zufrieden, weil ich in der Arbeit viel Ausdauer gewonnen habe, und ich werde immer besser (!) im Entziffern. NV3 ist schon ziemlich weit und auch die anderen beiden Notizbücher werden noch von mir transkribiert: ,restlos' [im Original deutsch].*

*aber ich muß fast jede Seite vollständig neu abschreiben. Das Material noch nicht oder teilweise veröffentlichtes - wird immer größer. Ich glaube, da $B$ ein schöner Band herauskommen wird, auch wenn uns noch Monate harter Anstrengungen bevorstehen - aber ich bin guter Dinge“ (6. Oktober 1962).

„Ich für meinen Teil - und das gilt auch für die jungen Leute, soweit es sie betrifft - versichere Dir, daß ich in der Ausgabe die wichtigste, in gewisser Weise die einzige, Aufgabe meines Lebens in den nächsten drei Jahren sehe. Ihr werde ich alle meine besten Kräfte widmen ..." (15. Mai 1963).

So kommentiert Montinari die gemeinsame Arbeit im Weimarer Archiv und bestätigt seine Entschlossenheit, an diesem philologischen Projekt festzuhalten.

Die Entzifferungsarbeit an den Manuskripten stellt ihn manchmal auf harte Proben: Die Briefe zeigen, wie sehr eine solche Arbeit nicht nur von Übung und technischen Fähigkeiten abhängt. Außer dem zähen Willen, Rätsel zu lösen und befriedigende Resultate zu erlangen, hilft ihm vor allem die sichere Beherrschung der Texte Nietzsches, seiner philosophischen Themen, seiner Entwicklung, seiner Briefe, der Briefe von Personen, die mit ihm in Beziehungen standen und der genauen Vorgeschichte aller vorhergehenden Ausgaben. Die ersten Notizhefte von 1961 zeigen seine unermüdliche Arbeit in dieser Richtung und zeugen schon von einer immensen Kenntnis unveröffentlichter Briefwechsel (z. B. der wichtigen Briefe von Rohde an Overbeck) und der Gestalten um Nietzsche. Sehr häufig kann ein winziger biographischer Fakt die Zuordnung eines Fragmentes ermöglichen oder zu seiner Entzifferung beitragen. Daher rührt auch die Hochschätzung - abgesehen von seiner „destruktiven“ Forschungsrichtung - des Historikers Podach, der lange mit Quellen aus erster Hand gearbeitet hat. 
Als besonders schwierig erweisen sich die Manuskripte der letzten Jahre:

Lieber Giorgio, während ich einen Brief von Dir erwarte, um Dir länger zu schreiben, schicke ich Dir die Beschreibung von U14 mit allen Hinweisen. U14 ist voller Vs (wie man übrigens Mette entnehmen kann).

Ich habe es seit letztem Mittwoch mit den Dithyramben aufgenommen. Heute habe ich die Kollation des Dm beendet. Aber das Wichtigste ist, daß ich zwei Fragmente gefunden habe, die nach dem ersten Januar $1889 \mathrm{zu}$ datieren sind. Ich glaube, es werden die letzten in unserer Ausgabe sein. Eins der beiden habe ich restlos entziffert, das andere hat noch ein paar Lücken. Bis jetzt hat sie noch niemand gekannt: Bezüglich der Entzifferung habe ich Wunder vollbracht. [...] Es bedrückt mich, daß ich keine Nachtichten von den Meinigen habe. Sigrid geht es gut, und sie grüßt Anna und Dich ganz herzlich. Morgen hoffe ich, Deine Post zu bekommen; ich schreibe Dir gleich zurück. Es umarmt Dich

Mazzino.

„Die Tage im Archiv müssen ganz der restlosen Entzifferung des schwierigen Materials für den VIII. Band gewidmet werden. Ich habe Dir schon von den beiden Fragmenten des 2.-3. Januar erzählt, die eine wahre Neuheit sind, aber um sie zu entziffern, habe ich zwei Tage gebraucht ${ }^{24}$ ! Und hätte ich vielleicht auf die Entzifferung verzichten sollen? Die Frage ist rhetorisch, aber ich glaube, sie erklärt Dir gut die Situation. Im Moment erledige ich die Prosaseiten von W II 10, die ziemlich schwierig sind.“ (3. Juni 1965)

Auch am 9. Juni 1965 gibt es $̈$ hnnliches zu berichten:

„Meine Entzifferung des Materials von 88 geht langsam voran. Um Zeit zu gewinnen, mache ich gerade eine Gesamterkundung, aus der hervorgehen müßte, welche Fragmente aus Mp XVI-XVIII, W II 6-10, N VII 4, Z III

${ }^{24}$ Die Entzifferung ist manchmal nur der Anfang der Arbeit: am 30.6.65 schickt er die Transkription der Fragmente an den Freund. Bis zum Sommer 1969 betrachtet Montinari diese beiden Fragmente - die er so mühevoll entziffert hatte - als die letzten im Druckmanuskript der Werke Nietzsches. Dies bis zur aufsehenerregenden Entdeckung des authentischen Textes von $₫ 3$ aus "Warum ich so weise bin" in den Papieren Peter Gasts. Jetzt werden die beiden Fragmente als Varianten in den Apparat zu EH ,verbannt". (S. KSA Bd. XIV, S. 473-74). Das ist nur eine kleine Episode aus der geduldigen, langwierigen und aufmerksamen Arbeit, durch die eines der wichtigsten Resultate entsteht: die endgültige Edition der Werke von 1888, die Nietzsche selbst für den Druck vorbereitet hat und besonders von EH. Hierzu s. M. Montinari, Ein neuer Abschnitt in Nietzsches, Ecce bomo in „NietzscheStudien“, Bd. 1, 1972, S. 380-418 und außerdem die Apparate des Bandes VI,3 der italienischen Ausgabe sowie des Bandes 6 der KSA. Über die Bedeutung der Entdeckung dieses unveröffentlichten $\$ 3$ von Ecce bomo schreibt er in einem Brief vom 7. September 1969 an Wenzel: „Um Ihnen schon jetzt eine Vorstellung der Bedeutung meines Aufsatzes in der NZZ zu geben, lege ich einen Durchschlag des neuen Abschnittes 3 bei und vergleichen Sie ihn mit seinem neuen Text! Diese Schrift, die nach den Intentionen Nietzsches jedes Mißverständnis über seine Person beseitigen mußte, gewinnt mit der öffentlichen, unmißverständlichen Verdammung der Schwester erst ihre ganze Bedeutung. Es macht doch einen Unterschied ob so was nur im Nachlaß zu finden ist oder aber in einer Schrift wie Ecce bomo. Begreiflich, daß dieser explosive Text vom Nietzsche-Archiv unterdrückt wurde!" 
und verschiedenen Dm publiziert werden müssen. In den letzten Tagen habe ich Fragmente aus Z II 1 festgelegt, gestern und heute habe ich an N VII 4 gearbeitet. Das unveröffentlichte Material ist nicht sehr viel, aber die Entzifferung ist extrem schwierig; auf der anderen Seite liegt die Stärke der Ausgabe gerade hier. Was die Vs von Ecce homo usw. angeht, so muß ich sie doch über kurz oder lang lückenlos entziffern! Und diese Entzifferung kann man nicht aufschieben, weil das heißen würde, daß man nach all der Anstrengung und den Fortschritten, die man jetzt schon in dieser so komplizierten Phase gemacht hat, noch einmal von vorn anfangen müßte. Auf der anderen Seite muß ich sagen, daß ich wahre Entzifferungserfolge verzeichne, aber ich habe Angst, daß ich hier im Vergleich zur restlichen Arbeit zuviel investiere. N VII 4 enthält außer ein paar Vs von Ecce drei ziemlich heftige (unveröffentlichte) Fragmente über die Antisemiten ${ }^{25}$, vom Rest weiß ich noch nicht, was es ist. Genauso schwierig oder schlimmer sind die Blätter und Blättchen der Mappen, die auf Ende ' 88 zurückgehen. Wenn ich diese erste Kontaktaufnahme beendet habe, sind meine Vorstellungen vielleicht klarer, und ich mache mir nicht mehr so viele Sorgen. Aber die Zeit vergeht ..." „Im Archiv gehen meine ermüdenden Entzifferungen von N VII 4 weiter, die jedoch fast beendet sind“ (13. Juni 1965).

Das Duodezheft N VII 4 war in der Beschreibung von Mette als „größtenteils unleserlich" klassifiziert worden.

Im folgenden möchten wir zwei Briefe Montinaris aus dem Jahre 1967 fast vollständig wiedergeben. Sie enthalten konkrete Beispiele von Problemen und Schwierigkeiten der Entzifferung: Die Anstrengung und die Zähigkeit, die geduldige zeitaufwendige Suche, die Notwendigkeit der Intuition, die eng mit seinen breiten kulturellen Interessen, ja seiner Neugier auf diesem Gebiet zusammenhängen (der erste Brief demonstriert auch, daß eine topographische Karte und ein Führer von Nutzen sein können), eine Leidenschaft, die nur nach der Auflösung des Rätsels Ruhe gibt - all das findet hier seinen Ausdruck. Außerdem ist der erste Brief aufschlußreich für die freundschaftlichen Beziehungen mit Berlin, wo er eine außerakademische Mischung von Leben und Kultur vorfand. Den zweiten Brief vom 10. September 1967 kennzeichnet deutlich ein polemischer Ton; mit einer gewissen Gereiztheit möchte Montinari den Freund die ganze Schwere bestimmter Augenblicke spüren lassen, in denen alles ewige Wiederholung scheint und er „zu erstikken" glaubt. Der Brief steht im Kontext des offenen und rauhen Klimas einer grundsätzlichen Kontroverse („notwendige Unwetter" wird sie - im Hinblick auf die Grenzen der brieflichen Kommunikation - von Montinari definiert), die in dieser Zeit zwischen den befreundeten Herausgebern über die „Grenzen der Wissenschaftlichkeit“ und über die Kriterien der Ausgabe geführt wurde.

${ }^{25}$ Es handelt sich um die Fragmente 21[6][7][8] von Herbst 1888. Vgl. KSA Bd. 13, S. 580-82. 
Lieber Giorgio, seit vorgestern bin ich wieder in Weimar: Die Rückreise wurde durch eine Öl-Überschwemmung im Koffer überschattet; der Schaden war zum Glück nicht groß, aber ich war recht wütend: eine Stunde vor der Abfahrt von Ostberlin befand ich mich vor dem West-Bahnhof "Zoo" und betrachtete die Verwüstungen, die ein paar Liter aus einem Plastikkanister ausgelaufenes Öl im Koffer angerichtet hatten! - In Weimar, wo ich gegen fünf Uhr nachmittag ankam, hat Sigrid mich mit dem Auto vom Bahnhof abgeholt; wir kamen in dem Moment in der Lenaustraße an, als der Postbote mit den Fahnen von Luciano (drei Pakete für 377 Seiten) gerade wieder gehen wollte. So hatte ich sofort eine "Anweisung“ für die Arbeit der nächsten Tage. Ich denke, daß das Beste ist, die italienischen Fahnen sofort zu erledigen und dabei parallel den Umbruch der deutschen Fragmente zu lesen, den ich durch einen glücklichen Zufall aus den Seiten, die man mir in Berlin gab und denen, die gestern im Archiv ankamen, zusammensetzen kann (mir fehlen jedoch immer noch die Seiten 145-352 von MA). Ich möchte das Ganze Sonntag, den 2. April fertig haben und glaube, daß ich es schaffe. Die Idee, mich noch einmal mit WB und den entsprechenden Fragmenten (letztere auch in Deutsch) beschäftigen zu müssen, stimmt mich nicht fröhlich, aber deswegen werde ich es schnell machen. Zwischen gestern und heute habe ich nicht gearbeitet, einerseits weil wir einige Erledigungen für die Festtage machen mußten; andererseits hatte ich noch über bestimmte Dinge der Berlinreise und über Probleme unserer Ausgabe nachzudenken. Ich habe jedoch eine kleine Entdeckung gemacht. Sie betrifft eine Örtlichkeit in der Nähe von Naumburg, und die Hartnäckigkeit, mit der ich wochenlang auf der Suche nach einer topographischen Karte oder einem Führer von Naumburg und Umgebung war, hat gestern Früchte getragen. Es handelt sich um zwei sibyllinische Namen, die in den Fragmenten zu VM auftauchen und die leider im italienischen Text nicht mehr zu korrigieren sein werden: Windlücke (Anhöhe zwischen Naumburg und Bad Kösen) und Krumme Hufe, eine kleine Ebene am Stadtrand mit zwei Teichen, auf deren Eis Nietzsche als kleiner Junge Schlittschuh laufen ging: Es handelt sich um ein autobiographisches Fragment: 28[6]. Im Italienischen habe ich „Windlücke" mit "impressioni" übersetzt, denn, nachdem ich auch der Clauss mehrmals das Fragment zu lesen gegeben hatte, gab die Lesart „Windlücke“ [Lücke im Wind?] keinen Sinn. Da ich nicht wissen konnte, daß es sich um eine Örtlichkeit handelte (schade, weil ich zuerst richtig gelesen hatte), habe ich mit einem bißchen guten Willen dann „Eindrücke“ genommen. Nun zur Krummen Hufe: im italienischen Text findet sich „Krumme Höhe“, um das Fragment an 11[11] anzugleichen, das jedoch auch „Krumme Hufe“ heißen muß (aber es war in deutscher Schrift geschrieben, daher die Verwirrung). Ich glaube nicht, daß Du es noch verbessern kannst, aber wer weiß ...

In Berlin habe ich die gewohnte freundschaftliche Atmosphäre vorgefunden. Sonntag habe ich Pestalozzi wiedergesehen, der sich jedoch mit einer ungarischen Medizinerin verlobt hat. Auch wenn die Verlobte sehr sympathisch ist, muß ich doch sagen, daß es mir etwas ausgemacht hat, weil ich mich daran gewöhnt hatte, Pestalozzi „zu meiner Verfügung“ zu haben für die 
Abende und zum Essen, das ich diesmal allein einnehmen mußte. Zu De Gruyter bin ich Montag vormittag gegangen; während Wenzel mit drei oder vier Byzantinisten zu tun hatte, habe ich alle Arbeitsfragen mit dem "Nino“ von De Gruyter ${ }^{26}$ besprochen (auch er will sich demnächst verloben). Das Ergebnis ist, daß der Arbeitsrhythmus für mich erträglicher und realistischer geworden ist. Wenzel hat alle unsere Entscheidungen akzeptiert, und jetzt werde ich von ihm einen Brief mit den neuen Terminen bekommen (die wie bisher „annähernd“ und nicht „zwangsweise“ zu verstehen sind). Außerdem kommen auch sie mit ihrer Druckerei nicht so schnell voran, als daß die Eile des ersten Plans (IV. Band im Frühling, V. im Herbst) gerechtfertigt wäre. Wie ich Dir telefonisch gesagt habe, wird der vierte Band Ende des Sommers fertig gedruckt sein, der fünfte Ende des Jahres. Das Fräulein Schmidt, das die von Pestalozzi verpflichtete Fahnenleserin sein soll (sie ist angeblich eine wabre Scbönbeit, aber ich habe sie nicht gesehen; und außerdem soll sie beim Nietzsche-Lesen am ganzen Körper beben), hat schon lange die wartenden Fahnen der Morgenröthe und der Fröhlichen Wissenschaft mit unserem Manuskript kollationiert, jetzt kollationiert sie die Texte des sechsten Bandes, und ich habe gebeten, sie noch einmal alle von mir imprimierten Seiten (des IV. Bandes) lesen zu lassen, weil man so eine größere Sicherheit gegen Druckfehler hat. Man hat meine Bitte akzeptiert. Der vollständige Umbruch des V. Bandes wird mir nicht nach Weimar geschickt werden; ich bekomme ihn Ende Juni in Berlin, wenn ich den VII. und VIII. abgebe; auch dies geschieht so auf meine Bitte. Auch mein Vorschlag einer anderen Unterteilung des IV. Bandes (und danach des V.) ist akzeptiert worden, obwohl das bedeutet, daß alle Kolumnentitel neu gemacht werden müssen: De Gruyter wird also den IV. Band genau wie Luciano herausbringen, aber er läßt den Apparat in einem separaten Band: d. h. vier Bände werden das sein, was jetzt „IV. Abteilung“ heißt. Die fünfte Abt. wird in drei Bänden erscheinen: zwei wie die von Luciano, ein Apparatband. Ich habe Wenzel erklärt, daß es - unter anderem - im Fall des Verkaufs einzelner Bände vorteilhaft ist: Der Käufer hat immer das veröffentlichte Werk und den entsprechenden Nachlaß zusammen. Was die sechste Abteilung angeht, so habe ich vorgeschlagen, die folgenden vier Bände zu machen: $\mathrm{Za}+$ App., JGB, GM + App., WA bis NW + App., und schließlich DD + Dichtungen + Apparat. Auch hier habe ich unter anderem mit kommerziellen Gründen argumentiert: wer würde denn den sehr teuren Zarathustra bei De Gruyter kaufen, der mehr oder weniger mit den zahllosen geläufigen Ausgaben identisch ist, wenn er nicht wenigstens den Vorteil des wunderschönen Apparats hätte, den ich mache? Dasselbe gilt für die anderen Bände, vor allem jene der Werke von ' 88 mit allen ihren vertrackten Problemen und für die Diythramben und die Dichtungen, die außerdem sehr gut zusammenpassen.

${ }^{26}$ Der Hinweis im „Familienlexikon“ gilt Nino Cappelletti, der zu den engsten Mitarbeitern Collis für die Arbeit an der "Enzyklopädie klassischer Autoren“ bei Boringhieri gehörte. Cappelletti - er beschäftigte sich mit graphischer Kunst - arbeitete dann später für den im Entstehen begriffenen Verlag Adelphi. Montinari bezieht sich in den Weimarer Briefen häufig auf die Freunde Nino Cappelletti und Luciano Foà, und das nicht nur, wenn es um die Arbeit für Adelphi geht. 
Könntest Du mir schon sagen, was für eine Aufteilung für den dritten Band (d. h. für die III. Abt.) Du vorsiehst? So wie in der Planung von Luciano? Oder stellen die "Schriften" spezielle Probleme dar? Kann man eine gewisse Ausgewogenheit der Seitenzahl erreichen? Natürlich ist es von de Gruyter aus möglich, drei statt zwei Textbände zu machen, plus den Apparat - wie in den Abteilungen 4 und 5. All das hat Zeit, aber mich würde interessieren, wie es möglich ist, „harmonische“ Bände zu machen.

Dienstag abend gab es die übliche Versammlung bei Wenzel zu Hause, die inzwischen Tradition hat. Diesmal war außer Pestalozzi und Müller-Lauter ein großer Fisch der Germanistik und der ... klassischen Philologie da, ein gewisser Ernst Grumach, der den Wunsch geäußert hatte, einen der Nietzsche-Herausgeber kennenzulernen. Dieser Grumach ist ein Jude aus Königsberg, an die Siebzig. Zur Zeit der Nazis verlor er seinen Lehrstuhl.

Er hat die Goethe-Ausgabe der Akademie der Wissenschaften begründet und die ersten Bände herausgebracht. Von Beruf ist er klassischer Philologe und auch ein bißchen Ägyptologe. Bei der Akademie der Wissenschaften leitet er weiter die Publikation der Werke von Aristoteles, bei de Gruyter gibt er eine neue Ausgabe aller Gespräche Goethes heraus und leitet die Zeitschrift „Cadmos“, denn es scheint, daß sein Spezialgebiet das mykenische Zeitalter ist. Alles in allem ein interessanter und respektabler Mann, auch wenn er sehr "Professor" ist, weniger wegen seiner Meinungen als durch die Art, wie er sie vorträgt und ihnen Geltung verschafft. Er ist natürlich ein Experte der Technik kritischer Editionen und hat mich so verschiedene Dinge über unsere Ausgabe gefragt. Da ich den Prospekt mit einer Probeseite des Apparats bei mir hatte (FW über Chamfort), haben wir aufgrund dieser Probe diskutiert. Im wesentlichen hat er unseren Apparat gelobt, aber er hat empfohlen, die Zahlen und die Manuskriptsiglen nicht kursiv zu setzen und vor allem eine neue Klammer oder ein analoges Zeichen einzuführen, um nachträgliche Hinzufügungen im Kontext langer Varianten kenntlich zu machen, wenn das wichtig ist. Dann hat er auch gemeint, daß das "Lemma“ in der größten Zahl der Fälle nicht nötig ist und daß man alles überflüssige an Kommata und anderen Interpunktionszeichen im Apparat weglassen soll. Ich habe ihm mit großer Ehrerbietung zugehört, aber ich werde alles so lassen, wie wir es gemacht haben. Mit den Prinzipien der Textrekonstruktion hat er sich absolut einverstanden erklärt. Dann hat er mit seiner Kritik den Entwurf des Buchumschlags zerstört, mit dem Ergebnis, daß ein neuer Versuch gemacht wird, und anderes von dieser Art. Die Unterhaltung war lebhaft. Am Ende des Abends war Wenzel sehr zufrieden, Grumach auch. Ich habe mit ihm über Deine Arbeit zu Aristoteles geredet, vielleicht kannte er sie. Jetzt möchte er, daß ich ihn bei meiner nächsten Reise nach Berlin auf alle Fälle besuche.

Dein Telefonanruf am Morgen meiner Abreise hat mir große Freude bereitet. Das Gespräch war lang und herzlich. Danach habe ich mich seltsam traurig gefühlt, vielleicht weil ich gerne länger mit Dir reden, bei Dir sein wollte. Ich wußte nicht, daß es Anna schlecht ging. Ja, wir hatten einen schwierigen Winter, aber mir scheint, daß es jetzt neue Hoffnung gibt. Wichtig ist, daß Gallimard immer noch willens ist, die Briefe zu bringen. Den Japanern schreibe ich bald und auch Mascolò: von beiden Briefen bekommt Du eine Kopie. (...) 
Was das Geld angeht, so wäre die vage Möglichkeit, die du angedeutet hast, für mich sehr nützlich, vor allem um eine gewisse Summe in Mark an der Deutschen Notenbank zu tauschen.

Sigrid hat viel zu tun, zur Zeit haben wir noch nicht einmal die Hilfe. Aber sie schafft es. Sie grüßt Euch vielmals. Vielen Dank, daß Du meine Eltern angerufen hast.

Viele liebe Grüße an Anna und an alle Kinder. Es umarmt Dich

Ich füge die Mikrofilme der Titelseiten bei.

Mazzino

Lieber Giorgio,

Weimar 10. Sept. 1967

jetzt melde ich mich wieder bei Dir, am Ende einer Woche. Es tut mir leid, daß Du nicht hier bist wie in den vergangenen Jahren.

Heute habe ich am Zarathustra übersetzt, den ich in den letzten Tagen liegengelassen hatte. Ich habe vor mir 44 Seiten Übersetzung, die den Seiten $1-103$ der Ausgabe entsprechen (bis zur Mitte des Kapitels „Vom freien Tode"): in fünf Tagen werde ich auch die letzten 5 Seiten des ersten Teils geschrieben haben, wic aus einer genauen Kalkulation hervorgeht, und ich werde dann die erste Etappe hinter mir haben. Wie versprochen werde ich Dir die Übersetzung schicken, damit Du sie liest und mir Ratschläge gibst. ${ }^{27}$ Deinem nächsten Brief hoffe ich unter anderem etwas über die Reaktion Lucianos auf die neuerliche Änderung unserer Pläne zu entnehmen.

Leider muß ich Dir gestehen, daß der Wochenteil von Dienstag (dem Tag nach der Rückkehr aus Dornburg ${ }^{28}$ bis Samstag weder den Beginn der neuen dringenden Arbeiten noch einen Fortschritt in der Abfassung der "Großen" gesehen hat. Der Grund ist, daß ich de Gruyter gebeten habe, mir noch einmal den Umbruch des Nachlaß IV/3 zu senden, den ich im Archiv, in Bibliotheken und zu Hause kontrolliert habe. So bin ich in 27[75] zur Lesart "kalòs Sokràtes“ zurückgekehrt, nicht mit der Hilfe von Ast, aber durch Suchen in der Landesbibliothek, wo ich ein Wörterbuch griechischer Eigennamen (Pape) gefunden habe, das diese Anrede für Sokrates bei Platon, zweiter Brief 2,314c und bei Athenaios, Deipnosophistai, 5,219 nachweist: beide Bücher finden sich in Nietzsches Bibliothek, und so habe ich mir zu Hause die Passagen herausgesucht und war schließlich endgültig beruhigt über die Richtigkeit von „kalòs“. Platon spricht, wenn ich mich nicht täusche, von einem Sokrates, der "schön und jung geworden ist", Athenaios sagt direkt „o kalòs Sokràtes“. Der Ast hat mir unerwarteterweise geholfen, ein sehr viel schwierigeres Problem zu lösen, nämlich das des Fragments $33[8]^{29}$, dessen Text mich überhaupt nicht überzeugte, weil er in

${ }^{27}$ Colli urteilt über diese Übersetzung enthusiastisch und gerührt: „Ich habe vor kurzem die Übersetzung von Zarathustra I bekommen und habe in einem Atemzug das Vorwort gelesen. Ich bin gerührt: mir scheint, Du hast diese Übersetzung für mich gemacht ..." (28. Sept. 67).

${ }^{28}$ Montinari hielt sich vom 19. August bis zum 4. September 1967 in Dornburg auf; er hatte sich dorthin zurückgezogen, um sich auf die Arbeit zu konzentrieren und die knappe Nietzsche-Biographie voranzubringen. Die Notizen der Zeit sind im Heft Vita 2 erhalten.

${ }^{29}$ Die Suche nach einer Lösung für dieses Fragment ist im Brief vom 22.7.1967 dokumentiert. 
nichts dem Seelenzustand Nietzsche im Herbst 1878 entsprach. Er hieß „Giebt es ein größeres Glück als die Seele zu greifen - ein Leben ohne Poesie: ou biotós“. Ich werde Dir die dazwischenliegenden Versuche und Passagen nicht erzählen. Jedenfalls habe ich Dienstag aus Gewissenhaftigkeit unter dem Stichwort biotós im Ast nachgesehen und habe den Verweis auf die Apologia 38a gefunden, und damit genau die Stelle, die ich gesucht hatte, vorausgesetzt, man setzte "greifen“ für "prüfen“ (was ich schon im Manuskript gelesen hatte!) und das Substantiv "Prüfen" für "Poesie“. Sokrates sagt: "o de anexetatos bios ou biotós antropoo [Dativ von Anthropos]" - „ein Leben ohne prüfen ou biotós“! Ich habe auch das Exemplar der Apologie, das Nietzsche anscheinend gerade in jener Zeit - mit vielen Randglossen - wiedergelesen hat; dieser Passus ist unterstrichen und kommentiert: Glück des Sokrates. Es schien mir auch eine sehr schöne Stelle; soweit ich Griechisch noch verstehe, stimmt sie mit der Bedeutung des Fragments voll überein [wie Du Dich wohl erinnerst, hatten wir zu Urzeiten mit Shelley angefangen!!!]

Ich übergehe andere weniger wichtige Beispiele, aber ich möchte Dir noch von einem ziemlich schwerwiegenden Irrtum berichten. Das Fragment 30[182] enthielt das ziemlich seltsame Wort "Theatermetierlich“. Ich habe dieses Wort und den Rest des Fragments wenigstens eine Stunde lang aufmerksam untersucht. Die Lesart ,bestehen" schien auch unwahrscheinlich, es konnte eher „bestellen“ heißen. Die letzten Zeilen dieses Fragments stehen 30[180] gegenüber, das als im Satz abbrechend wiedergegeben war. In Wirklichkeit wurde "bestellen“ von der anderen Seite herübergeschrieben und gehört zu 30[180], was dadurch kein unvollendetes Fragment ist: ,jedes Geschlecht soll sein eignes Feld bestellen"! Theatermetierlich muß dagegen Theater-Mitleid gelesen werden, und danach gibt es eine Unterbrechung. Das Wort „bestellen“ überdeckt [oder wird überdeckt von] Theater Tassos's. Warum habe ich Dir diese Dinge erzählt? Bestimmt nicht, um mich wichtig zu machen, sondern weil ich möchte, daß Du verstehst, was ich meine, wenn ich sage, daß ich manchmal „das Gefühl habe zu ersticken“. Gerade die 136 Seiten Nachlaß IV/3 haben mich irgendwie ermüdet (auch wenn ich froh bin, die Fehler zu korrigieren und vor allem, festgestellt zu haben, daß die Schwierigkeiten unserer Arbeit objektiv groß sind: so ist z. B. in der Tat das Fragment 33[8] ein wahres Entzifferungswunder, auf das wir stolz sein können und das es sich lohnen würde zu reproduzieren). Ich habe mich von dieser „ewigen Wiederkehr des Gleichen“ erdrückt gefühlt und war vom Probieren hier und da, von den großen und kleinen Recherchen wahrhaftig "lustlos" [im Original deutsch] - wie verhext, wie das Huhn, das nicht aus dem Kreidekreis herauskann. Ich habe "schlecht" gearbeitet und mich vor allem wirklich von Dir mißsilligt gefühlt. So habe ich auch über andere Dinge wieder nachgedacht und habe schmerzlich empfunden, daß Du mir fern bist: „tüchtig als Wissenschaftler, aber eine Niete als Freund", wie Du mir während unseres Berliner Gewitters gesagt hast. Es ist die radikale Verschiedenheit meiner "Not" [im Original deutsch] von der Deinigen, die mir manchmal unüberwindbar vorkommt. Wenn diese Bände erscheinen werden, wird es eine Erleichterung sein, und vielleicht werde ich dann diese Bitterkeit vergessen. 
Ab morgen gehe ich an den Apparat von Jenseits (ich arbeite im Archiv und zu Hause von 9 bis 16.) Abends mache ich dann die "Großen“. Hoffentlich kann ich Dir Sonntag einen besseren Brief schreiben. Ich möchte Dir jedoch sagen, daß ich nicht verschlossen bin, daß ich immer offen sprechen möchte und daß ich dasselbe von Dir erwarte.

Mazzino.

5. Einen guten Einblick ermöglichen die Briefe Montinaris an Colli auch in seine wichtige Tätigkeit als Quellenforscher: Der kritische Apparat muß mit den expliziten und - häufiger - impliziten Zitaten sowie den Quellennachweisen versehen werden. Erst so ist es möglich, den Text Nietzsches zu bestimmen. (In einem Brief, den wir weiter unten zitieren, nennt Montinari das bezeichnende Beispiel der Entdeckung zweier „Aphorismen“ aus dem „Willen zur Macht", die Nietzsche zugeschrieben wurden und in Wirklichkeit nichts anderes als Übersetzungen zweier Passagen aus Tolstoi und Renan waren.)

Eines der ersten bedeutenden Ergebnisse dieser Art, was die von Nietzsche veröffentlichten Schriften angeht, ist die „Mosaikarbeit“ in Wagner in Bayreuth, die Montinari im Nacbbericht zur IV. Abteilung herausgearbeitet hat:

„... ich habe nicht geschrieben, weil ich Dir vom Abschluß dieser ewigen Revision des IV. Bandes berichten wollte. Meine Verspätung ist sehr groß. Sie wurde bedingt durch ein Intermezzo von ... Wagner. Ich habe mir in der Bibliothek alle Werke von Wagner ( 9 Bände) genommen und habe eine große Menge Zitate gefunden, einige von Nietzsche versteckt und als solche nur zu erkennen, wenn man Wagner liest. ,Wagner in Bayreuth' ist voll davon." (Weimar 25. Juni 66)

Diese Arbeit bereichert den Apparat erheblich. Welches Urteil auch immer der Interpret daraus ableiten mag, eines ist sicher: er muß in jedem Fall berücksichtigen, daß die Schrift, die Wagner, ungeheuer' nannte und in der er sich völlig wiedererkannte, auch ein gekonntes Mosaik versteckter Zitate aus den Werken - besonders den frühen - des Musikers ist.

Colli hat in seinem originär philosophischen Nachdenken über Nietzsche ein negatives Urteil darüber gefällt, daß dieser sich mit der Aktualität einließ, weil er als ,Literat' neues Material und neue Stimuli suchte: Was bei jener Suche nach Zitaten herauskommt, die Beziehung zu den Zeitgenossen, erscheint Colli als verschwendete Genialität:

"Genauer betrachtet ist es ein Mißklang, den man angesichts seiner psychologischen Methoden und seiner positivistischen Variationen über Themen aus verschiedenen $W$ issenschaften fast mit Unbehagen bemerkt. Oft scheint die Aufmerksamkeit, die er vielen literarischen und politischen Persönlichkeiten des neunzehnten Jahrhunderts widmet, unbegründet. All das ist ihm 
vorzuwerfen, denn sein Zugriff, sein Anspruch und sein Einsatz sind auch in der ,Aktualität ${ }^{\varsigma}$ - die des Philosophen, nicht des Historikers. " 30

Colli geht es von Anfang an prinzipiell um die Restitution gesicherter Nietzsche-Texte, die in der Lage sind, mit Nachdruck im Sinne der Aktion Nietzsche auf ihre Leser zu wirken: deshalb fühlt er sich nicht im Stande, die Arbeit an den Apparaten grundsätzlich zu würdigen.

Aus diesen Voraussetzungen entstehen Motive für Unstimmigkeiten über die Ziele im Zusammenhang mit Wagner in Bayreuth. Uns ist ein Briefentwurf oder -teil an G. Colli erhalten, in dem Montinari seine Ergebnisse verteidigt:

„Das wirkliche Problem ist nicht, daß $\mathrm{N}$ die Montage in WB verbergen will (und ich habe so etwas nie gesagt), sondern wie in aller Welt er 1888 sich in einer Seite wiedererkennen konnte, die 1875 an Wagner gerichtet war. ${ }^{31}$ Und das nicht in bezug auf das, was N 1888 geworden war, sondern was er 1875 war. Das heißt die Reichweite seiner Liebe zu Wagner, seines Eintauchens in einen Teil der Welt Wagners. (...) Der Apparat ist keine ,Reduktion' Ns, wie Colli fürchtet. Die ,Montage' in WB:" - fährt Montinari fort - „ich meine sie tut der Größe Nietzsches keinen Abbruch, wenn man dieses Beispiel zum Anlaß nimmt, ernsthafter $z u$ fragen, was für Nietzsche die Erfahrung mit Wagner bedeutet hat. Das ist der,Geist' meines Apparates. Aber abgesehen vom Geist sehe ich, daß auch für Dich mein Apparat wichtig ist: was wußtest Du über die Montage in WB vor meinen Forschungen? Wenn Du mit der Furcht argumentierst, Nietzsche zu beschmutzen und zu verleumden, dann begibst Du Dich mit den Verleumdern und Verbesserern Nietzsches auf eine Ebene. Für mich wenigstens _ “32

Dies ist der Ausgangspunkt von Montinaris historischen und interpretierenden Studien, die zu einer Neubestimmung des Verhältnisses Wagner-Nietzsche führten. Den meisten vorangegangenen Deutungen, die zwischen mythischer Verklärung und „allzu-menschlicher“, psychologischer Analyse geschwankt hatten, wurde damit der Boden entzogen. Die Auseinandersetzung mit Wagner und der persönlich schmerzhafte Bruch mit ihm erscheinen Nietzsche als Zeichen der Wiedergewinnung einer autonomen Perspektive. Die „Enttäuschung von Bayreuth“ bedeutet das Ende seines eigenen freiwilligen Jesuitismus: „eher noch als von Wagner ist Nietzsche enttäuscht von sich selbst“. Die Konfrontation wird zu einem Gegensatz „,von kardinaler Bedeutung für die deutsche Kultur, dessen Reichweite man bisher jedoch

30 Giorgio Colli, Nach Nietzsche. Aus dem Italienischen von Reimar Klein, Frankfurt/Main 1980, S. 78 [Dopo Nietzsche, Milano: Adelphi 1974, S. 72 f.].

$31 \mathrm{Vgl}$. EH in KSA Bd. 6, S. $313 \mathrm{f}$.

32 Diese Selbstverteidigung findet sich in einem Brief vom 4. Dezember 1967 wieder: „... Der Geist, mit dem ich den Apparat mache, ist nicht jener, der Nietzsche an den Ohren zieht oder ihn zum Schlimmeren verbessert oder ihn gar anschwärzt. Dieser Punkt ist meiner Meinung nach viel wichtiger als der andere, daß ich vielleicht mehr Varianten in den Apparat gebracht habe, als wir ursprünglich vereinbart haben ..." 
noch nicht völlig ermessen hat". Nietzsches erzwungene Treue zu den theoretischen und „revolutionären“"Werken des Musikers machen aus dieser Schrift der „Loslösung“, die voller „hinterlistiger Ambiguitäten“ ist, eine äußerste und nicht sehr überzeugt vorgetragene ,Provokation“. Der überzogene „Idealismus" Wagner gegenüber hat die Funktion, ihn auf die Probe zu stellen, um ihn zum Vergleich zu zwingen zwischen „dem Ausbund an Häßlichkeit, Karikatur und Droge" des Bayreuth von 1876 und den noblen Zielen seiner Jugendwerke ${ }^{33}$.

In einer ausführlichen Notiz (datiert 29. V. 67) skizziert Montinari schon einige Themen seiner Interpretation. In dieser Notiz ist die Auseinandersetzung mit Nietzsche freier; sie ist stärker an die Kritik der gegenwärtigen Gesellschaft gebunden, als man sonst von Montinari gewöhnt ist (die wahre Nivellierung ist Produkt der Massengesellschaft, des Konsums).

„Man könnte behaupten, daß N erst freier Geist und dann immer entschiedener anti-gemeinschaftlich und anti-gesellschaftlich geworden ist aufgrund eines falschen (oder unglücklichen?) Ausgangspunktes: Die Gesellschaftlichkeit, die er ernsthaft zu akzeptieren suchte, war diejenige Wagners [der übrigens immer die ,Unmenschlichkeit' der Antike gegenüberstand - gerade die Antike ist 1875 eine der Bruchstellen mit Wagner], also diese Gesellschaftlichkeit war schwach und heuchlerisch und hatte tausend Krankheiten [Nationalismus, Antisemitismus, Naturalismus, Dekadentismus (?)], die N allerdings zu überwinden versuchte, indem er $z$. B. von , anscheinend reaktionären Elementen' bei Wagner sprach. Aber dieser Versuch [der schon von Anfang an kompromittiert war durch die Bekanntschaft mit den Schriften Dührings, eines extremen Vulgärsozialisten, der für $\mathrm{N}$ jedoch immer das Symbol des Sozialismus geblieben ist] fühtt $\mathbf{N}$ in eine Situation, die er als unerträglich empfand und kulminierte in der Krise von Bayreuth, wo $\mathrm{N}$ sich seiner Falschheit bewußt wurde [s. Fragment aus der Zeit Za. ${ }^{34}$.] [auch

${ }^{33}$ M. Montinari, Nietzsche [Che cosa ha veramente detto], Rom: Ubaldini 1975, S. 74, 70.

Vgl. auch M. Montinari, Nietzsche und Wagner vor bundert Jabren, in "Nietzsche-Studien“ 7, 1978, S. 288-302.

${ }^{34}$ Es handelt sich um das Fragment 4[111] (N VI 1) von November 1882-Februar 1883, dessen Numerierung damals noch 2[115] war. In einer Notiz mit dem Datum 16.2.67 schreibt Montinari:

„N hat viel deutlicher als alle seine Interpreten die Gründe seines Bruches mit Wagner angegeben; man beachte, da $\beta$ das, was er so entschieden gesagt hat, sich nicht unter den Gründen findet, die er selbst anführt (Vorw. MA II und EH), sondern in einer privaten Notiz, die fast gänzlich unbekannt ist (sie wurde teilweise 1897 veröffentlicht): [geschrieben in einem weiteren Augenblick tiefer Depression? 〈Coda〉.

2[115] (N VI 1)

,Es gab eine Zeit, wo mich ein Ekel vor mir selber anfiel: Sommer 1876. Die Gefahr des Irrthums [Die Lesart "Irrthums" hat Montinari später in "Irrsinns" verbessert. G.C.] das schlechte wissenschaftliche Gewissen über die Einmischung der Metaphysik, das Gefühl der Ubertreibung, das Lächerliche im ,Richterthum ' - also die Vernunft herstellen und in der größten Nüchternheit, ohne metaphysische Voraussetzungen zu leben versuchen. ,Freigeist ${ }^{c}$ - über mich weg! ${ }^{\star}$

Vgl. übrigens auch die zahlreichen Hinweise in diesem Sinn in den Notizbüchern von VM (Sommer-Herbst 1878) - . Hier jedoch ist entscheidend: Ekel vor mir selber." 
wenn er an anderen Stellen und speziell unmittelbar nacbber von zerbrochenen Idealen spricht: in Wirklichkeit ist die Diagnose aus der Zeit Za. genauer - während jene der Vorworte zu MA schon Transfiguration, Mythisierung ist]; fast zu leicht erkennt er die soziale Inkonstistenz der wagnerischen Ideale, während er gerade die soziale Utopie [die Fragmente aus V II 9 zitieren!] auf alle erdenkliche Weise anzunehmen versucht.

$\mathrm{N}$ war folglich ehrlich gegen sich selbst, als er mit der wagnerischen UnWahrheit brach. Wenn man jetzt fragt, wie sich dieser Bruch auf seine Haltung gegenüber dem Sozialismus auswirkte, so darf man eines nicht vergessen: Auch in der Zeit des Umgangs mit Wagner - wenigstens in wagnerianischen oder utopistischen Momenten, als er sozialistischem Denken näher war als jemals später -, ging seine Art, die soziale Frage zu stellen, nie über die Perspektive des, Mitleides‘, der ,Liebe‘ gegen die Unterdrückten, eines Kultus des,Volkes' hinaus, und so etwas mußte sich gerade für einen Denker wie $N$ unter seiner eigenen Kritik [die sich auf Schopenhauer und die Religiosität im allgemeinen erstreckt] auflösen, unter der Kritik Ns, der die Wahrheit erreichen will, *** [Wort nicht zu entziffern, G.C.] [daher der große Eindruck, den auf ihn die Ps. Beob. von Rée machten]

$\mathrm{Daß}$ sich die ,Unterdrückten' das Problem ihrer Unterdrückung ganz realistisch stellen könnten, das kommt $\mathrm{N}$ nicht entfernt in den Kopf. Er reduziert die ganze ,philosophische' Komplexität des Sozialismus auf ein Schwätzchen über ,Gleichheit', ,Nivellierung' und so weiter. Nun entgeht $N$, daß die von ihm gefürchtete Gleichheit dagegen Produkt eines nivellierenden Kapitalismus ist. [Unsere gegenwärtige Wirklichkeit ist beredt in diesem Sinn! Wenn man von *** [Wort nicht zu entziffern, G.C.] reden kann - einem Begriff nicht Nietzsches aber der Nietzscheaner - dann mit größerem Recht in bezug auf die Konsumgesellschaft als auf die sozialistische!]“

Montinari weiß schon zu Beginn seiner Weimarer Arbeit, wie wichtig die Forschung über Nietzsches Lektüren ist: bereits die ersten Notizhefte zeugen vom Interesse für die Bände aus Nietzsches Bibliothek und für die Randglossen, die er zu transkribieren beginnt: Die ersten Bücher, mit denen er sich beschäftigt, sind unter anderen: Aristokratie des Geistes [1885] von einem Anonymus (Erdmann Gottreich Christaller), wo Nietzsche den Namen von Marx gefunden haben könnte (zitiert auf Seite 146; die Lesespuren enden jedoch - wie Montinari vorsichtig bemerkt - vor jener Seite), Gedanken und Thatsachen von Otto Liebmann (hier entziffert er die Randglossen), Guyau, L'irreligion de l'avenir (,viele Randglossen, leider vom Buchbinder beschädigt“). Er interessiert sich auch für die von Alfred Fouillée publizierten Randglossen in der deutschen Übersetzung von Guyau, Sittlichkeit obne, Pflicht', liest Wellhausen ("mit vielen Randglossen, die der Buchbinder ruiniert hat"), Chamfort, Dühring, Emerson usw.

Die Methode ist ausgesprochen empirisch, aber sie ist die einzig praktikable:

„Ich muß die Bücher N.s nehmen, sie durchblättern und mich anstrengen, die Zitate zu finden, die mir inzwischen alle zusammen vom IV. bis zum 
VIII. Band (außer dem VI.) durch den Kopf schwirren. Ich habe aber auch für den VI. etwas gefunden, vor allem für die GD im Journal des Goncourt: Hauptquelle N.s über das Frankreich der Decadence“ (Weimar, 21. Dezember 1964)

Ein Brief vom 23. Mai 1967 berichtet von der scheinbar zufälligen Entdeckung einer Quelle: während eines Vortrags von Hahn vor der Generalversammlung der „Goethe-Gesellschaft“, der Montinari als aktives Mitglied angehörte. - In Wirklichkeit lag auch hier die ständige Aufmerksamkeit auf noch zu lösende Probleme dem Fund zugrunde.

„Schließlich habe ich für das Fragment 11[9] ein Goethezitat ausfindig gemacht, das ich vergeblich bereits für MA I (Aph. 221) gesucht hatte. Dieses Zitat habe ich zufällig gefunden: während ich einem Vortrag von Hahn zuhörte!! Ich glaube, man kann es in die Anmerkung einfügen, die ich schon für den Vergleich mit MA 221 geschrieben haben müßte, da wo es um Goethe und die ,barbarischen Avantagen' geht, die er gebraucht haben soll, um den Faust zu dichten. Die Anmerkung zu 11[9] lautet: ,barbarische Avantagen'] vgl. Goethe, Anmerkungen über Personen und Gegenstände, deren in dem Dialog Rameau's Neffe erwäbnt wird (1805), unter dem Stichwort ,Geschmack “..."

Wir möchten noch weiter Beispiele dieser Arbeit anführen:

„Gestern und Samstag habe ich Dir nicht geschrieben: dafür habe ich (viel) an den Zitaten gearbeitet - mit mageren Ergebnissen, weil es sich - wie Du weißt - um eine Arbeit handelt, die umso schwieriger wird, je weiter sie vorangeht. Gestern, Sonntag, habe ich sieben Stunden daran gearbeitet, und ich habe ein Zitat gefunden - ein sehr verstecktes -, es ist von Doudan für die Fragmente MA sowie ... 2 auch von Doudan für die Morgenröthe ${ }^{35}$; es handelt sich um Zitate, die ,nicht zählen', aber von denen man leider sagen muß, daß wir sie besser in unsere italienische Ausgabe hätten aufnehmen sollen: 6[89] und 6[93], das letztere ist das berühmte, non consilia a casu differo', das lautet: Les volontés sont si faibles, qu'on dirait que c'est le hasard qui les pousse. Non consilia a casu differo ... Für VI - VIII habe ich 15 Anmerkungen zusammengeschrieben + alle Bezüge zu etwa vierzig Stellen aus dem Goncourt-Tagebuch, das N. in W II 3 zitiert $^{36}$. Die Zitate von Burckhardt über die Griechen sind - wenigstens für jetzt - unmöglich zu finden. Emerson ist eine Fundgrube für alle unsere Bände. Ich habe mich schon mit dem Emerson-Exemplar beschäftigt ${ }^{37}$ : alles entziffert außer einer Stelle, auf die ich zurückkommen werde" (14. Dezember 1964).

${ }^{35}$ Es handelt sich um Ximénès Doudan, Mélanges et lettres, Paris 1878 als Quelle für das Fragment 30[150] aus der Zeit von Menschliches, Allzumenschliches (MA). Das Fragment 6[89] aus dem Herbst 1880 lautet: „Der Geometer Ampère: ,Je crois que le monde extérieur a été créé tout simplement pour nous être une occasion de penser."“

36 Vgl. F. Nietzsche, Frammenti postumi 1887-1888, Werke Bd. VIII, 3, S. $322 \mathrm{ff}$ sowie die Anmerkungen, S. 471.

${ }^{37}$ Ein Exemplar der Versuche Emersons in deutscher Übersetzung (Versuche, Hannover 1858), die neben Randglossen und Lesespuren auch eine ganze Reihe Fragmente enthält (vgl. Opere Bd. V,2, S. 467-470). 
„Ich habe weitere Anmerkungen zu W II 3 [November 1887-März 1888] zusammengeschrieben; aber ich muß noch die alten Anmerkungen suchen; bevor ich die ausgeliehenen Bände abgebe, mache ich eine endgültige Bilanz. N.s Anleihen bei Büchern, die er las, übertreffen alle Vorhersagen, wenigstens die meinigen; z. B. ist die ganze Seite über das Schicksal Goethes in Deutschland in $W^{38}$ ein Ensemble von Begriffen und Daten, die er aus dem Buch von Viktor Hehn genommen und - auf geniale Weise - wieder zusammengeflickt hat. Im allgemeinen würde ich sagen, daß die Arbeit an den Zitaten für die von N. selbst veröffentlichten Werke weniger wichtig ist, da sich hier nur selten unveränderte Zitate finden; für den Nachlaß jedoch ist sie von fundamentaler Bedeutung. Aber es ist eine Arbeit, die vor uns niemand gemacht hat. Habe ich Dir zum Beispiel gesagt, daß ich zwei N. zugeschriebene ,Aphorismen' des WzM gefunden habe, die nichts anderes sind als die Übersetzung zweier Passagen aus Tolstoi und Renan? Wir müssen aufpassen."

Diese Quellenforschung hatte sich zunehmend erweitert und umfaßte alles, was sich als eine Lektüre Nietzsches herausstellte, und zwar aufgrund der expliziten und impliziten Zitate in seinen Werken, aufgrund seiner Briefe, der Briefe seiner Korrespondenzpartner, der Zeugnisse von Zeitgenossen in deren Briefen oder Schriften usw. So hat sich durch geduldige Arbeit das Bild Nietzsches langsam immer klarer und detaillierter vor dem Hintergrund seiner Epoche und seiner Reaktion auf das kulturelle Ambiente (besonders des damaligen Frankreich) herausgeschält und sich dabei gegenüber den ideologischen Vereinfachungen und den Mythisierungen der Vergangenheit verändert.

Geschichte ist Komplexität und Bewegung: Und so ist für Montinari dieser Aspekt seines Tuns weit von positivistischer Quellenforschung entfernt. Es geht ihm nicht um Reduktion - weder im Sinne positivistischer „Philologie“ noch aus bistoristischer Perspektive. In einer Notiz vom 1.4.1967 ist hierüber zu lesen:

„Keine Reduktion Ns trägt zum Verständnis seiner Persönlichkeit, seines Denkens bei - Es ist leicht, die Quelle vieler Gedanken Ns zu finden (Teichmüller z. B.), aber das formende, ordnende, auswertende Prinzip dieser Impulse bleibt N, auch wenn er sicherlich ein feines Ohr hatte, das ihm vieles mitteilen konnte, was anderen Zeitgenossen entging (Bourget, Guyau, usw. usw.)

Auf der anderen Seite ist auch für $\mathrm{N}$ die Reduktion auf die ,Klasse sinnlos, wenn sie ausschließlich sein will. Man kann sagen, daß $\mathrm{N}$ sich anbot, um vom Kampf gegen den Sozialismus ausgebeutet zu werden; aber es gibt eine begrenzte Autonomie [ein Marxist würde die Kategorie der Wechselwirkung

${ }^{38}$ Vgl. Der Fall Wagner, KSA Bd. 6, S. $18 \mathrm{f}$ sowie Kommentar KSA Bd. 14, S. 403 f; Viktor Hehn, Gedanken über Goethe, Berlin 1887, das Nietzsche im Frühling 1888 las, wie das Fragment 16[36] (KSA Bd. 13, S. 495) bezeugt. 
benutzen] des Denkens, das den Fortgang der Geschichte beschleunigt; d. h. der Determinismus gilt noch nicht einmal für $N$."

Montinari spitzt den Gedanken nochmals zu:

„Eine historistische Analyse Ns [und das sage ich, der alle Werkzeuge hat, um sie durchzuführen] kann dem Phänomen $\mathrm{N}$ keine Gerechtigkeit widerfahren lassen, wenn sie nur Reduletion - und damit antibistorisch ist." (4. 5. 67)

Montinari ist sich der Neuheit seiner Art der Quellenforschung bewußt; was Nietzsche angeht, bedeutet sie eine radikale Wende. In einer Notiz über „Nietzsches Lektüren" liest sich das folgendermaßen:

„Neu oder besser (wenn man von Andlers Versuch absieht) zum ersten Mal muß das Kapitel über Ns Lektüren geschrieben werden.

Die ,kultische' Bibliographie - angefangen von Gast - wollte sich dieser wertvollen Quellen nicht bedienen, um N nicht zu, verkleinern“.

Die ,philosophische' Bibliographie (Löwith - Jaspers? - Heidegger) hat das Thema für weniger wichtig gehalten verglichen mit gewissen, idealen 〈Entsprechungen〉, die man zwischen den Gedanken Ns und jenen von Hölderlin, Hegel usw. usf. entdeckte.

Die ,Feinde‘ Ns - allen voran die Wagnerianer - haben hartnäckigste Versuche gemacht, um die Originalität Ns zu zerstören, indem sie hier und da Autoren fanden, die er abgeschrieben haben soll (z. B. Bourget).

Ch. Andler einziger Versuch - so flach er auch ist.

Der Kultus brauchte keine ,Kritik', die Philosophie vermied das Problem, die Feinde brauchten die Kritik zu sehr ..." (26.1.67)

Das Nachdenken über Nietzsches Lektüren in ihrer Beziehung zum Text führt Montinari zu dem Versuch, diesem Begriff eine neue, allgemeinere Bedeutung zu geben. Zumindest wird er sich immer mehr dieses Problems bewußt. Wir werden auf die Überlegungen dieser letzten Zeit noch zurückkommen.

„Das wichtigste wissenschaftliche Ergebnis meiner derzeitigen Arbeit am kritischen Apparat der Ausgabe ist eine Liste von ca 200 Büchern, mit denen Nietzsche sich direkt oder indirekt zwischen Sommer 1882 und Herbst 1885 beschäftigt hat ${ }^{\text {‘ } 39}$.

Das war Montinaris positive Bilanz seiner langen Forschungen an der Abt. VII (die Apparate sind in zwei Bänden 1984 und 1986 erschienen). Im Allgemeinen haben schon die italienische Ausgabe bei Adelphi und die Kritische Studienausgabe (de Gruyter, Berlin/dtv, München) eine Unzahl von Ergebnissen auf diesem Gebiet erbracht. In den letzten Jahren hatte Montinari ein (italienisches) nationales Forschungsprojekt „Nietzsches Bibliothek und Lektüre" initiiert und geleitet. Die beteiligten Universitäten sind Pisa, Florenz und Urbino. Erstes Ziel des Projekts wat nach den Intentionen Montinaris

${ }^{39}$ L'onorevole arte di leggere Nietzische, a. a. O., S. 340. 
die Veröffentlichung eines vollständigen Katalogs der Lektüren des Philosophen, dann sollten die Randglossen der nachgelassenen Bibliothek, die in der Zentralbibliothek der deutschen Klassik in Weimar aufbewahrt werden, untersucht und publiziert werden. Nur die geduldige Rekonstruktion und eine breit angelegte kulturhistorische Arbeit geben die Möglichkeit, den definitiven Text sicher festzulegen, und es ist nach dem Ableben Montinaris wichtig, sich diesen Aspekt bei der Vervollständigung der Apparate für die Ausgabe zu vergegenwärtigen.

Wenn auch von Anfang an das Programm einer nicht-reduktivistischen Quellenforschung feststeht, so ist doch die letzte Phase seiner Durchführung besonders aufschlußreich. Mit der Entdeckung des, französischen' Nietzsche, der ab 1884 „(auf französisch) von seiner Flucht nach Cosmopolis spricht“ ${ }^{“ 40}$ entwickelt sich das Vorhaben, den Philosophen im Kontext der decadence zu lesen; das ,Phänomen Nietzsche' verdichtet und vertieft sich nochmals. Nietzsche auf die Decadence zu beziehen bedeutet, daß „unsere Sicht sowohl der Decadence als auch Ns sich ändert“.

„Die décadence ist ein integrierendes Moment der Philosophie Ns, das seinen Klassizismus und seinen Willen zur Macht relativiert; wenn diese letzteren Positionen verabsolutiert werden, hat man den $\mathrm{N}$ der Fanatiker und der Nazisten" (Notiz datiert: 21. Sept. 1984).

Die Erforschung der idealen Bibliothek, die das „philiströse Konzept der ,Originalität' zerstört'", bedeutet auch, daß die anfänglichen Perspektiven der Ausgabe weitgehend verlassen werden: Das Individuum Nietzsche löst sich auf und wird als Teil der Geschichte restituiert. Dies verdeutlicht eine undatierte, auf ein loses Blatt geschriebene Notiz:

„Wozu dient die Forschung über Ns Bibliothek? Dazu, eine Brücke zu schlagen zur Kultur in Ns Zeiten; seine Originalität hat mit dieser Konstruktion nichts zu tun, es handelt sich um die Rekonstruktion einer bomogenen, all denen gemeinsamen Atmosphäre, die im Europa jener Zeit lebten, arbeiteten und dachten. Die Erforschung von BN [Bibliothek Nietzsches, G. C.] dient nicht nur dazu, in $\mathrm{N}$ einzutreten, sondern noch mehr, aus ihm herauszukommen, um größere Zusammenhänge in der Geschichte der Philosophie, der Politik, der Literatur, der Gesellschaft im allgemeinen zu etfassen. Um das Ferment $\mathrm{N}$ zu isolieren (Thema der $\mathrm{N}$ Forschung) [N Forschung im Orig. dt.], muß man die Nährlösung kennenlernen, in der es gewirkt hat."

40 Die Zitate entstammen Notizen aus einem kleinen Heft mit schwarzem Deckel, betitelt "Pessimismus, Nibilismus décadence in Nietzsches später Pbilosopbie, angefangen am 21. November 1983 im Wissenschaftskolleg zu Berlin, e appunti zu GM“. Über diese Themen s. M. Montinari, Nietzsche in Cosmopolis. Franqüsisch-deutsche Wechselbeziebungen in der europäischen Décadence, „Frankfurter Allgemeine Zeitung“ Nr. 164, 19. Juli 1986. 
6. Die Suche nach einem deutschen Verlag spiegelt einerseits die Notwendigkeit wider, aus der paradoxen Lage herauszukommen, in der man sich durch das Unternehmen italienischer und französischer Übersetzungen befand, die auf einem kritisch rekonstruierten, aber nicht publizierten deutschen Text basierten; andererseits ist sie eng mit der „Aktion Nietzsche“ verknüpft: So erklärt sich, wie aus den Briefen hervorgeht, das Mißtrauen gegen den Beck-Verlag in München, bei dem ab 1933 die erste (unvollendete) historischkritische Ausgabe herausgekommen war:

„Ich sage Dir übrigens, daß ich sehr, sehr abgeneigt gegen Verhandlungen mit Beck bin. Wir dürfen nichts darauf geben, wenn wir nicht wollen, daß alles scheitert. Dieser Verlag ist mit dem nazistischen N.-Kult verbunden: für immer. Zumindest ist es eine Frage des guten Geschmacks, nicht die ,Fortsetzer' der alten Unternehmung zu sein“ (Weimar, 23. Oktober 1962).

Mit noch größerer Abneigung begegnet man dem Kröner-Verlag:

„,in meiner Seele herrscht ein tiefes Mißtrauen gegenüber diesem Verlag: Wenn ich daran denke, daß sie ruhigen Blutes - , weil er einen schönen Titel hat" - den Willen zur Macht drucken, packt mich die Wut“. „Eine Distanzierung von Baeumler, die wir verlangen müßten: das würden sie uns nie zusagen.“ (Weimar, 13. April 1964). Und weiter: "unsere Ausgabe ersetzt die ganz̧e Kröner-Ausgabe (d. h. Baeumler)" (23. 4.64).

Die endgültige Lösung (nach Versuchen bei Nijhoff, Rowohlt, Luchterhand und Insel) wurde mit de Gruyter gefunden, nicht zuletzt, weil sich Karl Löwith für das Projekt gewinnen ließ und bei de Gruyter vermittelte. Er hatte die Archivarbeit der beiden italienischen Gelehrten anläßlich eines internationalen Kolloquiums in Royaumont kennen- und schätzengelernt: „es ergab sich, daß Löwith sich sehr zu unseren Gunsten äußerte: er hat die Möglichkeit, daß die Ausgabe nicht erscheinen könnte, für eine , nationale Schande' erklärt!“ (14. Oktober '65) In einem Brief von März 1967 erinnert sich Montinari, wie wichtig jene gemeinsame „Schlacht“" war:

„Heute abend habe ich Lust, Dir zu schreiben, deshalb unterbreche ich die Arbeit am Zarathustra (die ziemlich gut vorangeht). Ich habe aus Paris den Band mit den Gesprächen von Royaumont erhalten ${ }^{41}$ und ihn sofort ganz durchgeblättert; mir sind viele Dinge durch den Kopf gegangen. Unser Vortrag macht eine sehr gute Figur, und unser Unternehmen wird sowohl im Vorwort als auch in den Schlußbetrachtungen des unaussprechlichen

41 „Nietzsche“, Cahiers de Royaumont. VII* colloque. 4-8 Juillet 1964 (Les Editions de minuit, Paris 1967). Der Vortrag von Giorgo Colli und Mazzino Montinari, Etat des textes de Nietzsche (frz. übs. v. H. Hildebrand und A. Lindenberg) findet sich auf S. 127-140. Von dieser Schrift existieren eine teilweise überarbeitete italienische, Stato dei testi di Nietzsche. in "Il Verri" n. 39/40 November 1972, S. 58-68 und eine spanische Übersetzung in "Eco“ Revista de la cultura de occidente, tomo XIX/5-6-7-J. 125, Sept. Okt. Nov. 1969, S. 735-753 (übers. v. Carlos Rincòn). Diese Nummer enthält auch ein Interview mit Mazzino Montinari. 
Gilles ${ }^{42}$ zitiert. Ich habe daran gedacht, wie gut wir uns gemeinsam geschlagen haben und wie entscheidend dieser Erfolg für das Schicksal der Ausgabe war. Auch unsere Tage in Paris waren schön.“

Und, nachdem er auf die Kontroversen angespielt hat, die zwischen beiden unterdessen um die Edition entstanden waren, fährt er fort:

„Die Wahrheit ist, daß wir zusammen einen schwierigen Kampf zu führen haben, der unvermeidlich zu Zusammenstößen zwischen uns führt und den wir aufgrund unseres Charakters jeder für sich und auf unterschiedliche Weise führen. Aber das Ziel ist ein gemeinsames. Und ich schätze mich glücklich, vor allem weil ich Dich zum Freund habe“" (3. März 1967)

Die Einladung zum Kolloquium von Royaumont erscheint Montinari sofort als willkommene Gelegenheit, die Arbeit an der Ausgabe und ihre Bedeutung international bekannt zu machen. Er versucht, Colli, der öffentliche Auftritte auf Kongressen wegen ihres akademischen Geruchs nach Möglichkeit vermeidet, zur Teilnahme zu überreden. Auch die offene Frage des deutschen Verlegers erklärt den großen Enthusiasmus, mit dem Montinari den Freund anstecken möchte.

In einer Situation der Isolation und der ermüdenden und enttäuschenden Suche nach einem deutschen Verleger kann es vorkommen, daß man sich mehr Feinde einbildet, als man in Wirklichkeit hat (das ist der Fall bei Karl Löwith, der sogar entscheidend für den positiven Ausgang war): Montinari denkt an den Kongreß, als sei er eine Schlacht, die man gewinnen muß und schmiedet am Schreibtisch Kriegspläne. Ich möchte ausführlich Teile dieses bedeutsamen Briefs wiedergeben, in dem auch vom angeblichen „letzten Aphorismus“ des Willens zur Macbt die Rede ist. Dieser Aphorismus datiert in Wirklichkeit aus einer Zeit, in der Nietzsche noch gar nicht beschlossen hatte, ein Werk mit diesem Titel zu schreiben:

"... Ich weiß nicht ob, wie Du an Sossio geschrieben hast, der Artikel von Löwith ${ }^{43}$ die erste Phase des Angriffs ist, den die deutsche Universität gegen die Ausgabe vorbereitet: sicher ist, daß Löwith in seiner Kritik an Podach zeigt, daß ihm das Entstehen der Ausgabe nicht lieb wäre. Natürlich! Ich habe hier und $\mathrm{da}$ in seinem Buch gelesen ${ }^{44}$ - das übrigens gar nicht $\mathrm{zu}$ verachten ist. Dessen stillschweigende Voraussetzung ist, daß man von einem Werk Nietzsches mit dem Titel WzM sprechen kann und daß im allgemeinen die vom Nietzsche-Archiv veröffentlichten Texte exakt sind. Mich hat unter anderem überrascht, daß Löwith, der am Ende des Artikels mit Bosheit über die Fehler Podachs schreibt (es gibt noch viel mehr, wie ich - leider

${ }^{42}$ Ebd.: Avant-propos, S. 7 und Gilles Deleuze, Conclusions, Sur la volonté de puissance et l'éternel retour, S. 275.

43 Es handelt sich um Karl Löwiths Rezension zweier Werke von Erich Podach: Friedrich Nietzscbes Werke des Zusammenbrucbs, Heidelberg 1961 und Ein Blick in Notizbücher Nietzscbes, Heidelberg 1963 in „Die Neue Rundschau“ 75, 1964, S. 162-168.

${ }^{44}$ K. Löwith, Nietzscbes Pbilosopbie der ewigen Wiederkebr des Gleichen, Stuttgart ${ }^{2} 1956$. 
- jetzt gerade feststellen mußte), den , letzten Aphorismus' des Willens zur Macht zitiert. Diesen , letzten' Aphorismus - dem er in seinem Buch mehrere Seiten widmet und der ständig als, letzter' zitiert wird (unter anderem hat sich auch Klages mit ihm beschäftigt) - habe ich gerade neulich kollationiert und transkribiert: seine Datierung ist ... Juli 1885 (ganz sichere Datierung). Inzwischen ist die offizielle Einladung für Royaumont angekommen; Du wirst aus der Liste der Teilnehmer entnommen haben, daß sowohl Böhm als auch Löwith anwesend sein werden. Deleuze hat der Einladung die Karte beigefügt, die ich Dir schicke. Er schlägt uns vor, eine ,table ronde über Fragen der Texte Nietzsches zu leiten, und - noch bemerkenswerter - Wahl fragt uns auf diesem Weg nach unserer persönlichen Meinung über eine Einladung an Schlechta. Mir scheint, daß wir die Teilnahme nur befürworten können, denn auch wenn unser Urteil über die Ausgabe des WzM negativ ist, so haben wir uns doch positiv geäußert über die Art, wie Schlechta in seiner Ausgabe die Briefe ediert hat; andererseits ist die Einladung an Schlechta auch eine Frage, die uns nichts angeht. Und sollte es sich auch um eine maskierte Herausforderung handeln, so könnten wir sie nur annehmen - und vielleicht müßten wir sagen, daß, wir die Einladung an Schlechta für eine gute Idee halten'! - Meine Meinung also ist: 1) wir müssen nach Royaumont kommen, auch wenn wir eine unangenehme Atmosphäre erwarten, 2) wir müssen die Leitung der ,table ronde' annehmen, 3) wir müssen einen Vortrag vorbereiten, ihn sofort Deleuze ankündigen und ihn ungefähr 14 Tage vorher hinschicken mit der Bitte, durch das Sekretariat der ,Kolloquien ' einige Kopien als Arbeitsmaterial für unsere ,table ronde' davon zu machen. Inhalt dieses Vortrags sollte meiner Meinung nach sein a) einige kurze Bemerkungen über die Ausgabe (nach Art des Berichts [Bericht im Orig. dt.]), b) das Problem des W/zM, behandelt auf der Grundlage von Texten und ausführlichen Beispielen, wobei die beiden Inhaltsverzeichnisse Nietzsches berücksichtigt werden müssen, d. h. nicht nur die Rubrik, sondern auch die 58 Zahlen, die sich in N VII 3 finden. Auf diese Weise, indem wir nur Fakten darlegen, Beispiele geben und die verschiedenen Probleme und die ,Vorgehensweise' der Redakteure der GA sowie Schlechtas diskutieren, indem wir zeigen, daß man den Namen WzM nicht einmal den Texten von WII 1-3 (Böhm) ${ }^{45}$ geben kann - auf diese Weise werden wir das Manöver Löwiths vereiteln und eine offene Diskussion erreichen. Der Vortrag müßte auf Deutsch geschrieben werden, und ich könnte - wenn Du einverstanden bist - hier eine korrigierte Fassung vorbereiten, die sowohl hier (wenn Du Beispiele für Deformationen in W I $1-2$ findest) als auch in Italien weiter ausgearbeitet werden könnte. Icb möchte, daß $D u$ einverstanden bist und daß $D u$ daran denkst, daß eine solche Aufgabe - gebt man von meinem Charakter aus - meine Arbeitskapazität nicbt verringert, sondern erböbt. Also kein Schaden für die Arbeit, die ich gerade mache, sondern größeres Engagement und eine Weiterentwicklung der Metbode, die der ,Gesamtbeit der Arbeit nur nützen kann. Unser Vortrag wird sicherlich eine Publikationsmöglichkeit finden, und von Paris aus wird auf internationaler Ebene das

45 Vgl. R. Böhm, Le problème du Wille zur Macht, Oeuvre postbume de Nietzsche. Àpropos d'une nouvelle édition ( $F$. Nietzsche, Werke in drei Bänden, hrsg. v. K. Scblechta). In: „Revue philosophique Louvain" 61, 1963, S. 403-434. 
Problem einer seriösen Nietzsche-Ausgabe gestellt werden. Für alle anderen Probleme, die anläßlich der "table ronde“ aufgebracht werden könnten, bin ich nur ein bißchen unsicher - besonders wenn Schlechta dabei sein sollte - betreffs der Jugendwerke; für den Rest haben wir unsere Bände schon fertig. Ich verspreche Dir einen extrem objektiven und philologischen Ton und werde gegenüber allen $\mathrm{Maß}$ halten, einschließlich Elisabeth und ... Löwith (...)

Von den Teilnehmern sind mir bekannt: Biser, der Priester und Freund Podachs (,Gott ist tot ${ }^{*}$ ), der Amerikaner Reichert, Freund Schlechtas, Schaeffner, der französische Herausgeber der Briefe an Gast. Massolo kenne ich nur dem Namen nach. Wer ist Vattimo?" ${ }^{46}$ (10.5.1964)

Im darauffolgenden Brief geht Montinari erneut auf das Thema ein: Er denkt besonders über die Möglichkeit nach, einen deutschen Verleger an der Arbeit in Weimar zu interessieren:

\begin{abstract}
„Zunächst möchte ich auf die Frage der Taktik in Royaumont zurückkommen. In letzter Zeit habe ich weiter nachgedacht und bin jetzt, was unseren Vortrag angeht - oder besser, den Vortrag, den ich Dir vorgeschlagen habe -, der Meinung, daß es viel besser ist, ihn nicbt vorher zu schicken, sondern ihn einfach vorzulesen, ihn während der Diskussionen über Textfragen vorzutragen. Für uns ist es nicht günstig, daß die anderen wissen, was wir sagen wollen und daß sie sozusagen im voraus immunisiert oder jedenfalls vorbehandelt und, informiert' sind über alles, was wir zu sagen haben. Wichtig scheint mir, insgesamt, daß wir die Dinge in der Hand haben, $\mathrm{da} \beta$ wir die Diskussionen über die Ausgabe inhaltlich bestimmen. Deshalb denke ich, wir sollten Deleuze einfach ankündigen, daß wir einen Vortrag über Fragen des Nachlasses [im Orig. dt.] von 1883-1888 halten werden. Ich bin immer mehr von der großen Bedeutung dieses unseres ersten Auftretens in der Öffentlichkeit überzeugt, und mich peinigt der Gedanke, $\mathrm{da} ß$ wir uns vorbereiten, daß wir diese Gelegenheit ausnutzen müssen. ... Ziel des Vortrags muß vor allem sein, an einem bedeutenden Ort die Notwendigkeit unserer Ausgabe zu zeigen und so die ,Entdeckung' eines deutschen Verlegers zu beschleunigen. Ich erwarte mit Ungeduld Deine Meinung über die ganze Angelegenheit und Deine Vorstellungen über die zu verfolgende Taktik." (Weimar, Mittwoch 13. Mai '64)
\end{abstract}

${ }^{40}$ E. Biser, "Gott ist tot". Nietzsches Destruktion des cbristlichen Bewwßtseins, München 1962. Herbert W. Reichert, der mit Karl Schlechta zusammen Autor der International Nietzsche Bibliography (Chapel Hill 1960) war, hielt auf dem Kongreß von Royaumont einen Vortrag mit dem Titel: Nietzsche et Hermann Hesse, un exemple d'influence; A. Schaeffner hat die Lettres à Peter Gast (mit einer langen Einleitung) herausgegeben, München 1957, Paris ${ }^{21981 . ~ A u s ~}$ den Akten des Kongresses geht die Teilnahme Arturo Massolos (Philosophiehistoriker an der Universität Pisa, Spezialist für Hegel, den Deutschen Idealismus und die Kultur des Existenzialismus) nicht hervor. G. Vattimo ist als Theoretiker des "pensiero debole“ [schwaches Denken] bekannt. Er ist Autor einer Reihe vielgelesener Werke über Nietzsche und über Heidegger. Auf dem Kongreß hielt er den Vortrag: Nietzsche et la Philosophie comme exercice ontologique. 
Noch 1979 gedenkt Montinari in einer Erinnerung an den verstorbenen Freund der historischen Bedeutung dieses internationalen Kongresses für die Ausgabe:

„Die Verwirklichung der Ausgabe wurde materiell möglich durch das wiedererwachende Interesse für Nietzsche in Frankreich Anfang der sechziger Jahre, aber ich erinnere mich daran, wie wir, Colli und ich, uns amüsierten, als wir eingeladen waren, auf dem Kongreß von Royaumont zu Nietzsche über unsere Arbeit zu sprechen; wir stiegen inkognito in den Bus, der uns von Paris zum Kloster bringen sollte und hörten, wie ein bekannter italienischer Universitäts-Nietzscheforscher ein paar verlegene Antworten auf die insistierenden Fragen eines französischen Kollegen stammelte; dieser wollte die unerhörte Tatsache erklärt wissen, daß zwei unbekannte Italiener sich in den Kopf gesetzt hätten, die Nietzsche-Ausgabe zu machen“. ${ }^{47}$

In dem Vortrag Etat des textes de Nietzsche zeigt sich abermals die wissenschaftliche Haltung Montinaris: Die Bedeutung der neuen Ausgabe wird weder aus einem aptioristischen, so detaillierten wie abstrakten, die allerletzten Einzelheiten berücksichtigenden Publikationsplan entwickelt, noch aus minutiös-defensiven methodologischen Kriterien, noch gar aus einer großen Grundsatzdiskussion über die Wichtigkeit oder Unwichtigkeit des Nachlasses, wie sie die ,Freunde der Nietzsche-Legende' gegen die Schlechta-Ausgabe vom Zaun gebrochen hatten. Die wenigen, triftigen methodologischen Prinzipien werden begleitet von einer Reihe konkret vorzuweisender Resultate: wichtige Auslassungen, Lesefehler, nicht veröffentlichte Fragmente, die schwerwiegende Willkür bei der Kompilation des „Hauptwerks" seitens des Archivs usw. Alle Zweifel über die Grenzen und die Unzuverlässigkeit der bisherigen Editionen für die Forschung werden beseitigt; das gilt auch für diejenige Schlechtas.

Heinz Wenzel, an einer neuen Nietzsche-Ausgabe höchst interessiert, bat Karl Pestalozzi, der sich im April 1965 im Weimarer Archiv aufhielt, Montinari doch einmal „über die Schulter zu sehen“. Pestalozzi gab bei dem deutschen Verlag die Reihe „KOMEDIA“ heraus. „Nach Weimar ist ein Dr. Pestalozzi gekommen, ein Deutschschweizer, der an der Universität in Westberlin arbeitet. Er schreibt etwas über den, Nachgesang'von JGB ... Sein Ziel ist gut eingegrenzt; er wird alle Vs dieses Gedichts veröffentlichen ..." (23. April 1965). Bereits beim ersten Zusammentreffen hat Montinari von dem Schweizer Gelehrten, mit dem ihn eine enge Freundschaft verbinden sollte, ,einen großen Eindruck von Ehrlichkeit und Frische“. Der gute Eindruck, den bei Pestalozzi die Masse und die Qualität der in Weimar geleisteten Arbeit hinterläßt, wirkt sich günstig auf die Verhandlungen aus.

${ }^{47}$ M. Montinari, Presenza della filosofia. Il significato della filosofia di Giorgio Colli. „Rinascita“ n. 7, 16. Februar 1979, S. 42. 
Der Vertrag mit dem - wissenschaftlichen - Verlag de Gruyter wird von Colli und Montinari mit großer Befriedigung aufgenommen. Heinz Wenzel, Leiter der geisteswissenschaftlichen Abteilung bei de Gruyter, ist die Person, die den Wert und die Tragweite der Ausgabe erkannt und sie mit großer Energie unterstützt hat („Gestern habe ich Wenzel wiedergesehen, der mir nochmals sagte, daß die N.-Ausgabe das wichtigste Projekt seines Verlags auf diesem Feld für die nächsten 10 Jahre ist", 6. Oktober '65) ${ }^{48}$ Während eines „denkwürdigen" Aufenthalts in Berlin diskutiert Montinari mit Wenzel und Pestalozzi über die Kriterien der Ausgabe und der Apparate und legt sie fest. „Schließlich hat Wenzel in seinem Enthusiasmus während des Abends in seinem Haus angekündigt, daß schon in einem Jahr der erste Band der De Gruyter-Ausgabe da sein wird." Mit Karl Pestalozzi und Wolfgang Müller-Lauter verbinden ihn von Anfang an nicht nur herzliche Freundschaft und Achtung, sondern auch aktive Kooperation und Beratung für die Arbeit an den deutschen Apparaten, zu denen sie ihre „Korrekturen, Zweifel, Vorschläge" beitrugen (1. August 1966).

7. In seinem Aufsatz Ricordo di Giorgio Colli bekräftigt Montinari: „Ungefähr ab 1967 betrachtet Giorgio Colli sein drittes großes ans Publikum gerichtetes Kulturunternehmen, die Aktion Nietzsche, als abgeschlossen.“ Colli wendete sich anderen großen und wichtigen philosophischen und philologischen Projekten zu, die die letzten Jahre seiner Tätigkeit bestimmten. Wie Montinari bestätigt hat, wird ihm durch Colli mit Beginn der deutschen kritischen Ausgabe die konkrete Arbeit an den Apparaten anvertraut. Die Briefe und der von seinem Sohn Enrico ${ }^{49}$ veröffentlichte Nachlaß bezeugen, $\mathrm{da} B$ in Colli der Wille zur Ausarbeitung eines eigenen philosophischen Systems heranwächst: Infolgedessen arbeitet er zwar regelmäßig an der Ausgabe weiter, aber er zeigt sich unruhig und unzufrieden über eine „endlose“ Beschäftigung mit den Apparaten, die der Freund ihm mit einem „Übermaß an Wissenschaftlichkeit" zu betreiben scheint.

48 Außerdem stellt sich auch Wenzels Aufgeschlossenheit für das Projekt der Briefe heraus: „Ich habe gesagt, daß wir natürlich die Briefe machen werden, er möchte sofort nach der Unterzeichnung des Vertrags das Projekt auf der „Donnerstagsversammlung“ vorstellen, in der bei de Gruyter über die Arbeit diskutiert wird. Ich habe ihm auch gesagt, daß wir jetzt die Möglichkeit sehen, alle Briefe zu bringen, und das hat ihn gefreut. Er hat mich schließlich gebeten, ihm einen ganz kurzen Bericht zu machen, der sich vor allem auf die Seitenzahl bezieht, denn das scheint das wichtigste Datum für diese Versammlung zu sein". In einem Zusammentreffen vom 9./10. Juli verstärkt und konkretisiert sich diese Hypothese. Im September präsentiert Montinari einen wissenschaftlichen Bericht über die, Gesamtausgabe der Briefe Nietzsches", der Wenzels volle Zustimmung findet. Dezember 1968/Januar 1969 sind die ersten beiden Bände der Briefausgabe fertig vorbereitet.

49 G. Colli, La ragione errabonda. Quaderni postumi hrsg. v. Enrico Colli, Milano: Adelphi 1982. 
Während die Arbeit an den Manuskripten vorangeht, reifen in Montinari immer adäquatere Lösungen und immer exaktere Kriterien; gleichzeitig wächst das Bewußtsein der noch zu überwindenden Schwierigkeiten. Schon im Frühling des Jahres 1964, das für das Schicksal der Ausgabe entscheidend war und das intensive Arbeit im Archiv $\mathbf{s a h}^{50}$, trifft Montinari auf die Vorarbeiten zum Zarathustra. Diese lassen ihn an die Möglichkeit eines Apparats von großer Bedeutung denken:
„Lieber Giorgio,
die erste Arbeitswoche ist beendet. Wie ich Dir schon geschrieben habe, ist die Serie Z II zu bewältigen: abgesehen von Z II 5, das ein bißchen nach- gelassenes Material enthält, sind Z II 6, 7, 8, 9 und 10 nur relevant für 1) die Gedichte (Z II 6 und 7) und für die Varianten von Zarathustra IV. Am Ende der nächsten Woche müßte ich die Serie fertig haben, da ich schon - wenn auch nur deskriptiv, d. h. ohne den Text des Apparates - mit Z II 8 begonnen habe. Die nachgelassenen Fragmente von Z II 5 sind alle kolla- tioniert. Der größte Teil des nachgelassenen Materials ist in W I (und in den Notizbüchern!!!!)) Ich bin optimistisch, und - wenn die Mappen keine Überraschungen enthalten -, dann müßte ich die Termine, die wir uns gesetzt haben, unterscbreiten. Ich habe fast den ganzen $\mathrm{Za}$ IV gelesen; er hat mich stark beeindruckt. Unser Apparat zum Za. müßte etwas „Sensationel- les" sein; aber abgesehen von der "Sensation“ glaube ich, daß es wirklich wichtig ist, ihn sehr ausführlich zu machen (das meine ich vor allem); ich möchte eine, gute Idee' für die Organisation haben. Für Za IV stehen die Dinge besser als für die anderen drei Teile, weil es auch das Dm gibt. Ich werde Dich über das, was mir hierzu durch den Kopf geht, informieren“. (14. März '64) „Der Za. IV hält mich beschäftigt mit widersprechenden Gefühlen (ich habe ihn mehrmals ganz gelesen) ...“ (24. März '64)

In einem langen und leidenschaftlichen Brief („entschuldige die Heftigkeit dieses Briefes, aber sie spiegelt nur scbwach meinen Seelenzustand und meinen Tatendrang wider") von Ostern 1964 geht Montinari mehr auf die Einzelheiten der konkreten Arbeit für die Apparate und auf die Notwendigkeit einer intensiven gemeinsamen Anstrengung ein, um zusammen die komplexen Probleme zu beherrschen, damit das "schreckliche“ Jahr - wie es Colli genannt hatte - das ,schönste" für die Ausgabe werde.

${ }^{50}$ „Vor einem Jahr, am 23. Dezember, hatten wir den IV. Band fertig. Zu denken, daß wir im vergangenen Jahr nichts abgegeben haben, ist für mich im ersten Augenblick ein unangenehmer Gedanke, aber gerade Sonntag, als ich eine Summe unserer Arbeit zog, sagte ich mir, daß wir viel gemacht haben und daß wir gut daran getan haben beide und nur wir beide zu arbeiten. Ich glaube, daß dieses Mal auch Du die Arbeit insgesamt mehr als zuvor überblickst; für mich ist es jedenfalls so. Also hat das Jahr 1964 keinen fertigen Band gesehen, aber sich bei dieser Äußerlichkeit aufzuhalten, wäre ein Irrtum. 1965 werden eine ganze Menge Bände fertig; aber die Grundlagen haben wir ' 64 gelegt." Das ist die gewissenhafte Bilanz in einem Brief vom Dezember ' 64. 
Wir geben einen Gutteil des Briefes wieder, der uns ermöglicht, in die Werkstatt eines großen „Handwerkers“ einzutreten und zu ermessen, wie erfinderisch - auch auf der praktischen Ebene - man für diese Arbeit sein mußte.

„Lieber Giorgio,

Weimar, Ostern 1964

ich hoffe, daß Du, während ich Dir aus einem ganz schneeweißen Weimar schreibe, in irgendeiner spanischen Stadt bist, vielleicht in Sevilla, ein bißchen Sonne hast und Dich an Ungewohntem und Südlichem freust. Mir, für meine Person, geht es gut, hier im kalten und gastfreundlichen Norden, in meinem Weimar ${ }^{51}$.

Was unsere Arbeit angeht, bin ich optimistisch, und ich sage Dir warum. Die Arbeit ist in diesen 18 Archiv-Tagen gut vorangegangen und alles in allem ohne große Anstrengungen. Dies sind die Ergebnisse:

1) Die Entzifferung von Z II 5-10 ist abgeschlossen. Jetzt muß ich zur Transkription übergehen, und das wird passieren, sobald ich einige chronologische Probleme gelöst habe, die für diese Manuskriptgruppe (Dichtungen von ' $84-85$ und $\mathrm{Za}$ IV) von ganz besonderer Natur sind: N hat nämlich gleichzeitig fast alle diese Hefte benutzt, die Rs fast sämtlicher Kapitel sind über sie verteilt; in allen finden sich vorhergehende, in sich geschlossene Fassungen vieler Teile von $\mathrm{Za} I V$, die natürlich ganz veröffentlicht werden - auch um den Preis von Wiederholungen - weil sie so einen Sinn haben, während sie verstümmelt, wie sie sich in GAK XII und GA XII und XIV finden, willkürliche Fragmentationen sind. Das Problem ist, ihre chronologische Reihenfolge zu sehen und - das ist das Schöne - dies ist auf alle Fälle möglich durch interne Kriterien (z. B. der „Wanderer und sein Schatten" ist in einer ganzen Reihe von Passagen der "gute Europäer" [im Orig. dt.]), oder das Kapitel „Vom Höheren Menschen“ war zuerst eine Art Finale, ein „Rundgesang“ usw.). Wahrscheinlich müßte man anstreben, zwei oder drei Fassungen des $\mathrm{Za}$ IV zu rekonstruieren und sie auf die nachgelassenen Fragmente übertragen, indem man von dem - in diesem Fall mechanischen - Kriterium des Inhalts der einzelnen Hefte ausginge. Mir scheint, wir sollten nicht so dogmatisch sein, aus Gründen der Chronologie

51 Im Briefwechsel der beiden Freunde gewinnt dieses Motiv fast philosophische und existentielle Bedeutung: der Vergleich zwischen dem Norden, mit seiner Kälte, die Montinari sozusagen als nützliche Therapie empfindet („die Temperaturen sind in Weimar bis auf 27 unter Null zurückgegangen: großartig für den polaren Teil meiner Seele!") und dem absoluten Süden (Italien, aber auch einige Reiseziele Collis: Griechenland, Spanien und Sizilien). So schreibt Colli in einem Brief vom 26.7.65: „Sizilien hat mich ziemlich angestrengt aufgrund der Wärme und der vielen Sachen, die ich gesehen habe. Ich habe jedoch intensive und verschiedenartige Eindrücke gewonnen. In diesen südlichen Ländern, wie auch in Spanien und Griechenland, spürt man stärker die Vergangenheit (und das nicht nur durch die Uberbleibsel der Antike), ja sogar die Unveränderbarkeit der Dinge. Jetzt gibt es auch in Sizilien viele Autos, aber sie erscheinen viel zufälliger und zusätzlicher als in den nördlichen Ländern. Der Antrieb zum Handeln erlischt nicht nur, sondern erscheint als Eitelkeit. Folglich ist der Süden auch eine Gefahr, wenigstens für mich. Einer der stärksten Eindrücke sind die Ruinen von Selinunte gewesen. Kolossale Tempel, die alle zusammen während eines Erdbebens eingefallen sind, ihre Säulen alle übereinander ..." 
für jedes Heft eine neue Numerierung zu beginnen und statt dessen vielleicht eine einheitliche Numerierung für die ganze Gruppe Z II vornehmen. Die Beschreibung Seite für Seite könnte dann über die Verteilung des Materials in diesen Heften Auskunft geben.

2) Ich habe zu Hause den Erstdruck von Za IV mit der Xerokopie verglichen. Die Unterschiede sind minimal. Deshalb denke ich, daß es nicht nötig ist, den Ed auf Mikrofilm zu bringen, nur um ihn dann entwickeln und wieder xerokopieren zu lassen. All das Geld können wir sparen, indem wir die GA xerokopieren und die Korrekturen des Ed eintragen. Ich habe auch den Grund für die geringen Abweichungen gefunden: $\mathrm{N}$ selbst hat das Dm von $\mathrm{Za}$ IV geschrieben, und dieses Dm ist erhalten (im Unterschied zu denen für die anderen Teile des Zarathustra). Mittlere Kollationsgeschwindigkeit 20 Seiten pro Stunde.

3) Ich habe im Archiv auch das Dm kollationiert, natürlich nach der Kollation des Ed mit Ga. Um mir die Arbeit zu erleichtern, habe ich zwei große Hefte genommen und auf jede zweite Seite eine Seite des xerokopierten Textes geklebt. Die Differenzen Ed-Ga sind rot verzeichnet, diejenigen $\mathrm{Dm}-\mathrm{Ed}$ grün. Auf den gegenüberliegenden Seiten habe ich alle Varianten des Dm transkribiert, hauptsächlich gestrichene Passagen. Die Differenzen (d. h. Interpunktion, Schreibweise, ersetzte Wörter) habe ich auf der Seite vermerkt, auf die der Text geklebt war, und zwar mit der Methode der Fahnenkorrektur. Die Kollation des Dm hat nicht mehr als 9 Stunden gebraucht.

Du wirst Dich fragen, warum ich es notwendig gefunden habe, eine Arbeit zu machen, die nicht vorgesehen war. Fakt ist, daß es unmöglich ist, an diesen Heften zu arbeiten, ohne den Za IV gut zu kennen. (Ich habe sogar gedacht, daß es alles in allem besser gewesen wäre, wenn wir auch für die anderen Bände diese Kollationen gemacht hätten, nicht weil Sossio sie schlecht gemacht hätte - Du weißt, daß er sie sehr gut gemacht hat aber: könntest Du behaupten, daß Du die Texte, an denen Du gearbeitet hast, so gut kennst wie es nötig gewesen wäre? Ich kann das wirklich überhaupt nicht sagen ...-) Außerdem wäre es ein Fehler, nicht schon ab jetzt den Apparat für die veröffentlichten Texte vorzubereiten, mit denen wir es immer wieder zu tun haben. Wenn Du daran denkst, wie wenig Zeit es braucht und wieviel ruhiger wir sein können, wenn wir die Arbeit gemacht haben, dann scheint mir, daß es sich lohnen würde, wenn auch Du die Kollation ED-GA von Za I II III machtest (die Dm gibt es nicht!). Die Karteikarten haben sich, jedenfalls für $\mathrm{Za}$ IV, als nur bedingt nützlich herausgestellt; nur bei zerstreuten Sentenzen sind sie sinnvoll. Aber jetzt habe ich vor, alle Varianten auf die gegenüberliegenden Seiten des doppelt kollationierten Textes einzutragen. Für JGB werden die Karteikarten auf alle Fälle von größerem Nutzen sein. Wenn ich zurückkomme, muß ich nur Deine Karteikarten betreffs $\mathrm{Za} \mathrm{IV} \mathrm{in} \mathrm{meine} \mathrm{Hefte} \mathrm{eintragen,} \mathrm{und} \mathrm{der} \mathrm{Apparat}$ ist fertig. Wichtig wäre, um die Arbeit nicht zweimal zu machen, die endgültige Seitennumerierung des VIII. Bandes festzulegen. Ich glaube, daß man das machen kann. Und wenn $\mathrm{Du}$ damit einverstanden bist, daß wir den Ed von Za IV nicht verfilmen, könnte ich schon die endgültigen Seitenund Zeilennummern an alle Varianten schreiben, und Du könntest das auch ..." 
Gerade über die Apparate für den Zarathustra entwickelt sich die erste Diskussion mit Colli, der seinen Gesichtspunkt in der Antwort auf diesen Osterbrief festlegt.

„Es ist mir sehr wichtig, daß Du Dein heiliges Feuer behältst, aber Du mußt mir erlauben, es ein bißchen einzudämmen und mir eine Fähigkeit zur konstruktiven Kälte in der Gesamtschau gestatten “

Die von Colli vorgeschlagene Methode ist:

„a) für die ersten Vs die Varianten bezüglich Wörtern oder auch Wendungen [im Orig. dt.] vernachlässigen, die keine neuen Elemente enthalten; die Streichungen nur in bestimmten Fällen wiedergeben, b) für die mehr entwickelten Vs, von der Art Rs, auch die weniger bedeutenden Varianten wiedergeben, sich aber davor hüten, alles anzugeben, wie im Apparat nach Vorbild der klassischen Philologie - Auch bei der Idee, nicht den einzelnen Ms einheitlich zu folgen, sondern über verschiedene Ms Fassungen zu restaurieren, muß man, scheint mir, mit etwas Vorsicht vorgehen - Häufig sind diese Vorfassungen nichts anderes als simple Vs". (12. April 64) ${ }^{52}$

Colli interessiert sich hauptsächlich für die philosophischen Inhalte des Textes, und so scheint ihm als Philologen die Eigenart der ,poetischen ${ }^{6}$ Sprache zu entgehen, wodurch für ihn auch die Varianten in Stil und Wortwahl unwichtig werden. In einem Brief vom 28. Oktober 1968, als eine Klärung bereits erfolgt und die Arbeit an der italienischen Ausgabe des Zarathustra weit fortgeschritten ist, stell Montinari kurze und interessante Überlegungen über die Varianten von Za III an.

„Lieber Giorgio, ich tauche heute aus den Visionen und Ewigkeitstaumeln des dritten Zarathustra auf: obwohl wir in der italienischen Ausgabe mit Varianten sparsam umgehen, sind meine Anmerkungen für diesen Teil 21 Seiten geworden (insgesamt hat der Apparat jetzt 52 Seiten; es fehlt noch der vierte Teil). Ich hoffe, eine brauchbare Arbeit gemacht $z u$ haben. Bestimmte lange Varianten führen vielleicht besser als der Text zu einem Verständnis von Nietzsches Leidenschaft hin. Vielleicht ist dieser Teil des Zarathustra der , lyrischste' und am wenigsten belehrende. Der vierte Zarathustra scheint mir nicht so einen inspirierten Ton zu haben (abgesehen von den ,Dithyramben' und dem ekstatischen Kapitel ,Mittags')“

Die Edition der poetischen Texte macht spezielle, neuartige Kriterien notwendig, über die sich Montinari klarwerden will:

${ }^{52}$ Die Polemik über die „Apparate“, die mit den unterschiedlichen Vorstellungen über die Ausgabe zusammenhängt, entwickelt sich und geht weiter; ab und zu kommt es zur Explosion - bis zur endgültigen Klärung. Noch im November 67 schreibt Colli an den Freund: „Jetzt nehme ich die Polemik über den ,Apparat' wieder auf: Mir scheint, daß Du Dich eher darum bemühst, Deine immer wiederkehrenden ,Zornausbrüche' gegen mich zu unterdrücken als darum, aus meinen Kritiken zu lernen. In einem Punkt jedoch wirst Du mich unnachgiebig finden: darin, $d a ß$ ich nicht in allen zukünftigen Apparaten, angefangen von $M$ und $F W$, alle Varianten akzeptiere, die wir zu seiner Zeit einig waren nicht zu bringen ..." (28. November 1967). 
"Meine Arbeit geht ziemlich gut, nach W II 10, Z II 7, Z II 5 habe ich mir jetzt Z II 6 vorgenommen; neben Z II 5 und W II 10, das wichtigste Manuskript für die Dichtungen. Parallel, nach der Arbeit im Archiv, beschäftige ich mich mit Problemen der Edition und der Apparate von Dichtungen. So habe ich wieder den Apparat der Beißnerschen HölderlinAusgabe in die Hand genommen ${ }^{53}$ und lese ein bißchen Literatur über das Thema. Auf der Grundlage der Erfahrung, die wir zusammen gemacht haben, kommt mir jetzt das ganze Gerede der Philologen sehr viel einfacher vor als damals am Anfang, als wir uns den Beißner einmal anschauten. Ohne in Kleinigkeiten übertreiben zu wollen, meine ich, daß der Apparat für die Dichtungen (und für den Zarathustra) reichhaltiger sein muß als derjenige der Aphorismen und Fragmente. Aber ich werde Dir hierzu etwas schreiben, wenn ich meine eigene Meinung über das Problem im allgemeinen und die speziellen Probleme für Nietzsche gebildet habe. Außerdem beschäftige ich mich gerne mit diesen Fragen!“ (6. Mai 1965)

Die Arbeit am „ewigen Apparat“ des Zaratbustra wird von Montinari 1967 intensiv wiederaufgenommen und parallel (neben anderen Arbeiten) zur italienischen Übersetzung fortgesetzt; das ganze Jahr 1967 und ein Teil des Jahres 1968, in dem der französische Apparat (Gallimard) erscheint, stehen in seinem Zeichen.

Und mit der Arbeit am Apparat kehrt die Polemik zurück:

"Ich arbeite weiter in einem befriedigenden Rhythmus. Für die Wiedergabe von Varianten werde ich mich aufs wesentliche beschränken (vieles ist schon in den vorangegangenen Revisionen geschehen). Der komplexe Apparat des Zarathustra nimmt Gestalt an - aber warum soll ich Dir von diesen Dingen erzählen? Im Grunde wäre es für Dich besser, wenn ich schon alles fertig hätte, für die Teile 2 und 3 eine Karteikarte nach der anderen tippen und mich für die allgemeinen Probleme irgendwie arrangieren würde, ohne mich um die verzwickten und schwierigen Verbindungen zwischen den Fragmenten und dem Veröffentlichten zu scheren ..." (25. Februar 1967).

„Die Tage vergehen und ich vertiefe mich immer mehr nicht nur in den Apparat (Neuigkeiten und Probleme über diesen verschiebe ich auf einen nächsten, philologischen Brief), sondern auch in die Gedanken und die Welt des Zarathustra. Ich muß sagen, daß mir die Arbeit an Nietzsche immer noch mehr als alles andere Lebenskraft und sogar -lust gibt. Sicher habe ich meine trüben Zeiten, aber zum Glück bin ich jetzt gerade nicht trübe. Ich habe dagegen den Eindruck, daß Du inzwischen die Arbeit an der Ausgabe als große Belastung empfindest, daß Du - aufgrund Deines starken Charakters - trotzdem mit hoher Intensität arbeitest, daß Dir vielleicht der Zustand spekulativer Begnadung von vor einigen Monaten nicht mehr zuhilfe kommt, daß Du müde und abgespannt bist“ (7. Mai 1967).

${ }^{53}$ Friedrich Beißner hatte in seiner „Stuttgarter“ Hölderlinausgabe den sogenannten genetischen Apparat eingeführt. 
Auch im Zentrum des folgenden Briefes steht die Arbeit am Apparat:

„... ich schreibe Dir nach einem weiteren Tag ganz am Zarathustra; seit ein paar Wochen beschäftige ich mich ausschließlich mit diesem Apparat, der für $\mathrm{Za} \mathrm{I}$ und II praktisch fertig ist; es sind nur noch bestimmte Sachen in den Fragmenten in Ordnung zu bringen. Ich muß jedoch sagen, daß ich inzwischen Herr der Lage bin; nur für den Za III habe ich noch keine klaren Vorstellungen. Du mußt noch ein bißchen Geduld haben - danach hoffe ich, Dir eine gute und endgültige Arbeit liefern zu können, zusammen mit allen Überlegungen und den technischen Anmerkungen. Ich arbeite immer zu Hause, auch nach dem Abendessen bis $11 \mathrm{Uhr}$, aber manchmal auch bis eins wie seit drei Tagen; das jedoch (bis eins arbeiten) darf ich nicht machen, denn sonst kann ich trotz Schlafmitteln nicht schlafen. Zum Glück bin ich wahrhaftig in Form und ganz durchdrungen von der Arbeit an diesem Apparat, der mich begeistert; ich muß mich jedoch von ihm wenigstens zum Teil für eine Woche lösen, um den Umbruch durchzusehen und den Apparat des gesamten IV. Bandes an de Gruyter zu schicken ..." (15. Mai 1967)

Die Arbeit am Apparat der IV. Abteilung der de Gruyter-Edition geht Hand in Hand mit Übersetzung und der italienischen Ausgabe des Zaratbustra: Die Nachrichten an den Freund über diese Tätigkeiten verflechten sich $^{54}$ miteinander und mit den Informationen über die persönliche, neuerliche Annäherung an dieses Werk Nietzsches:

„Das Kapitel über Zarathustra ist unvollendet geblieben. In ihm will ich zeigen, daß der ganze Zarathustra gewollte Anti-Dichtung und nicht nur Antipode eines Kunstwerks sondern auch Antipode eines, heiligen Buchs" ist. Insgesamt ein absolut persönliches und extrem gefügiges Ausdrucksmittel, das $\mathrm{N}$ sich geschmiedet hatte, um zu sagen, was er zu sagen hatte, aber ohne den "Ballast" der rationalen Demonstration. Was das Verhältnis zur sogenannten Dichtung (oder Kunst) angeht, so denke ich, daß $\mathrm{N}$ im Zarathustra bewußt jede Regel, auch die des sogenannten guten Geschmacks,

${ }^{54}$ Die leidenschaftliche philologische Vertiefung der Probleme und der Entstehung des Zarathustra, die mit dem Bewußtsein einer neuen Lektüre dieses Werks verbunden war, wird eine Konstante seiner Aktivitäten bleiben: Zusammen mit seiner langjährigen Mitarbeiterin MarieLuise Haase arbeitete er noch in den Monaten vor seinem Tod daran. Während seines Forschungsaufenthaltes in Paris im Oktober 1986, von dem er voller neuer Energie und Enthusiasmus zurückgekehrt war, hatte er viele Einsichten und zu verfolgende Spuren hinzugewonnen, viele philologische Funde gemacht, die den ,Text' Nietzsches erweitern werden und kulturelle Verbindungen entdeckt, denen er nachgehen wollte. Als ein Beispiel von vielen möglichen nennen wir die Thematik des höheren Menschen im IV. Buch des Zarathustra - einem der schwierigsten und von,Devoten' und Apokalyptikern am leichtesten mißzuverstehenden Texte. Die Notizen Montinaris zeigen, daß dieses - in der traditionellen Interpretation - , ultradeutsche' und mythische Werk nicht wenige Bezüge zur Kultur der ,französischen Psychologen' aufweist, daß, besonders der terminus technicus, höherer Mensch' in seiner Bedeutung nicht verstanden werden kann, wenn man sich nicht die zeitgenössischen Formulierungen von Taine, Renan, Bourget, Brunetière, der Goncourt usw. vor Augen hält; ebenso kann die Kritik an den vielen Masken der Decadence der höheren Menschen im $\mathrm{Za}$ IV nicht ohne diese Grundlage verstanden werden. 
zerstört hat. Alles ist ernst, schrecklich ernst, und Zarathustra ist kein Dichter (auch wenn er es vielleicht sein möchte) ..." (30.7.67)

Montinaris Zarathustra-Interpretation muß noch genauer untersucht werden. Bevor dies geschehen kann, möchte ich im Anhang jedoch bereits einige Notizen der 60er Jahre wiedergeben, die Montinari selbst zusammengestellt und auf der Maschine abgeschrieben hat; sie geben über einige Aspekte seiner Lesart des Zarathustra Auskunft.

Hinter der unnachgiebigen Haltung Collis (die „harte Schule“) kommen jedoch immer wieder die unerschütterliche Zuneigung und die große Achtung für den Jüngeren hervor, als dessen Schüler er sich häufig bezeichnete: „ich hoffe, daß Dir meine ,Beschreibung' gefällt: ich habe mich dabei angestrengt, Dein Schüler zu sein ...“ (25. Juni 1967)

Die Briefe zeigen divergente Positionen der Freunde über die Perspektiven einer kritischen Ausgabe; es findet eine offene Auseinandersetzung ohne Vorbehalte statt, die die Beziehung zwischen beiden reifen läßt. Während Montinari für die Idee einer historisch-kritischen Ausgabe mit ausführlichsten, so weit wie möglich endgültigen Apparaten Feuer fängt, beteuert Colli bereits in einem Brief vom 16. November 1965, als er gerade die Kopie des Vertrags mit de Gruyter erhalten hat ${ }^{55}$ und besorgt darüber ist, daß der Apparat die Revision der Manuskripte so verzögert ${ }^{56}$ :

55 In Wirklichkeit zogen sich die Verhandlungen, die natürlich durch die Gegenwart dreier verhandelnder Verleger (Gallimard, Adelphi, de Gruyter) kompliziert wurden, noch ein paar Monate, bis zum 6. Juni 1966 hin.

56 Diese Arbeit ist begleitet von einer ständigen Revision und Reflexion, um die Instrumente und die Prinzipien der Ausgabe zu verbessern: „Schließlich eine Menge Ideen und Probleme, die ich mit Dir diskutieren will - nicht, um alles wieder neu in Frage zu stellen (denn, trotz allem, ist unsere Arbeit gut), sondern um bestimmte Dinge zu vervollkommnen, um einiges besser auszudrücken. Unter anderem z. B. eine bessere Ausarbeitung des, bis jetzt so vagen, Begriffs der Vs“ (21. August 1965).

„Die neue Kollation ist notwendig, nicht nur wegen der Fehler im eigentlichen Sinn (von denen ich Dir eine Aufstellung machen werde), sondern auch wegen der Interpunktion, in der sich unser Text manchmal obne Not vom Manuskript entfernt. Auch hier ist es die Erfahrung der letzten Jahre, die zu einem reiferen Standpunkt geführt hat, demzufolge man sich von der originalen Interpunktion nur entfernen kann, wenn es wirklich unumgänglich ist." (30. Juli 1967)

„Mit der Interpunktion wirst Du, denke ich, zufrieden sein. Sie war schon sehr nahe am Original, aber es hat trotzdem ungerechtfertigte Kommata und Punkte gegeben, die ich eliminieren mußte, nachdem wir sie zuerst im Bann der grammatikalischen „Regeln“ übernommen hatten. Ich glaube verstanden zu haben, was Du mit Klarheit und mit „Konventionen" meinst, die man respektieren muß. Aus diesem Anlaß habe ich eine wahre Kasuistik ausgearbeitet, aus der man vielleicht ein paar Worte im „Nachbericht“ [im Orig. deutsch] veröffentlichen könnte, man könnte dabei die Probleme schildern, die ein "Herausgeber“" [im Orig, deutsch] vorfindet, wenn et die Manuskripte auf lesbare Weise publizieren will. Probleme, die für jeden Autor spezifisch sind (wie ich feststellte, als ich mit Haufe, dem Schiller-Herausgeber, sprach) und die deshalb ein wenig geschildert werden müßten. Zu 
"Und jetzt will ich Dir in aller Ruhe etwas sagen: mir scheint, daß Du unter einem Übermaß an Wissenschaftlichkeit zu leiden beginnst. Daß de Gruyter ein wissenschaftlicher Verlag ist: umso besser für uns: Aber deshalb muß unsere Ausgabe noch nicht so werden wie die Hölderlinausgabe. Das lag nicht in unseren anfänglichen Intentionen, und wenn de Gruyter anders denkt (wie man aus, historisch-kritische A.[usgabe]' schließen könnte, was besser gestrichen würde, erinnerst du Dich an unsere Ironie gegenüber der Beck-Ausgabe?), so muß man ihm das klarmachen. Dies ist die erste N.Ausgabe, und es hat keinen Sinn, daß eine erste Ausgabe historisch-kritisch auf diese Weise ist. Hüten wir uns davor, Mißverständnisse zu erzeugen!“

Die endgültige Klärung dieser Themen findet im Herbst 1967 statt wenige Wochen bevor die ersten Bände der de Gruyter-Ausgabe erscheinen. In einem Brief Montinaris vom 29. September liest man folgende Worte:

„Ich weiß, daß ich vielleicht in einigen Punkten übertrieben habe, aber ich weiß genauso sicher, daß die Übertreibung nicht mein eigentlicher Fehler ist, sondern das kraftlose Wollen, die Unfähigkeit zur Verwirklichung und zum Leiden für die Verwirklichung. Wenn der deutsche Apparat erscheinen wird, müssen wir sicher über die vernünftigen Grenzen der Wissenschaftlichkeit diskutieren, die für mich wirklich kein Fetisch ist, sondern lediglich der Wunsch, ein guter ,Arbeiter' zu sein, so wie ein tüchtiger Schuster gute Schuhe macht. Die Ensthaftigkeit des Handwerks, realistisch, zäh, ohne Angst vor der Anstrengung und vor langweiligen Dingen, weil sie einem Ergebnis gilt, das seine Rechtfertigung schon in sich selbst trägt. Deshalb kannst Du mich nicht treffen - wie ich bin oder sein möchte -, wenn Du von der unvermeidlichen Unvollkommenheit jeder wissenschaftlichen Arbeit sprichst. Und Du verletzt mich und tust mir weh, wenn Du findest, daß die französische Ausgabe so ist, wie Du die Nietzsche-Ausgabe gern gehabt

diesem Ziel habe ich in einem Heft alle Ideen gesammelt, die mir in den Kopf gekommen sind, und teilweise habe ich auch in meiner Kopie des Umbruchs mit Bleistift die Beispiele angestrichen, die man nennen könnte. Dieses Heft hatte ich in Berlin bei mir, aber ich fand keine Gelegenheit, es Dir zu zeigen." (15. August 67)

Oder er stellt sich das Problem einer besseren Aufteilung der Bände der Ausgabe: „Und jetzt eine allgemeine Frage, die mir nicht unerhebliche Pein bereitet hat und über deren Legitimität ich mindestens seit drei Wochen grüble. Seit einer denkwürdigen Nacht, in der ich nicht schlafen konnte, hat sich in mir die Überzeugung herausgeschält, daß die Aufteilung unserer "Werke“ nicht richtig ist, was die Bände VI, VII, VIII angeht. Ich finde nämlich, daß, während wir gut dran taten - vom III. Band an - Text und Nachlaß [im Orig. deutsch] zu kombinieren (und so die philologischen Vorlesungen vom "corpus" der Werke zu trennen), wir keine Rechtfertigung haben, so für einen VI. Band zu verfahren, der randvoll mit Texten von 1883 bis 1889 ist und zusätzlich - dies ist nun völlig ungerechtfertigt die sogenannten Dichtungen und poetischen Fragmente enthält; dies scheint mir also eine tadelnswürdige Abweichung von unserer Vorgehensweise ab dem III. Band, einer Vorgehensweise, die auch eine klare Stellungnahme für die Priorität der "Werke“ in bezug auf den Nachlaß [im Orig. deutsch] oder wenigstens für die Notwendigkeit, den Nachlaß [im Orig. deutsch] um die Werke herum zu gruppieren (wobei wir aber über die Frage, was wichtiger ist, keine Vorentscheidung treffen). Für uns sind die Werke, so wie Nietzsche sie gewollt hat, so wichtig, daß wir uns entschlossen haben, die späteren Vorworte von '86-87 nicht von ihnen zu trennen." (13.2.67) 
hättest, während doch die französische Ausgabe schlecht gemacht ist (schau zum Beispiel, ob die Fragmente des Emerson-Exemplars einen Sinn haben ohne die Anmerkungen).“

Auch wenn diesen Sätzen das Unrecht der Polemik anhaftet, so definieren sie doch meines Erachtens besser als andere die Arbeitsweise Mazzino Montinaris und bezeichnen auch die geistige Kontinuität gegenüber Delio Cantimori, seinem zweiten großen Lehrer aus den Zeiten der Normale, von dem er die Treue zum „historischen Sinn“ gelernt hatte. Cantimori hatte in seinen letzten Jahren für das historische „Metier“ auf dessen handwerklichem Aspekt insistiert - gegen die großen Schilderungen, gegen die großen Themen der Geschichtsphilosophie und die ideologischen Mythen, aber auch gegen die positivistischen und technizistischen Antworten auf Fragen der Historiographie.

Das ist genau Montinaris Position, wie sie sich aus dem Briefwechsel mit Colli herausschält: Der Herausgeber geht seiner Arbeit nach ohne vorbestehende Sicherheiten, ohne den Fetisch des Textes, ohne aprioristische abstrakte Vorannahmen darüber, wie man die vorbildliche Ausgabe konstruiert - er erarbeitet konkrete Lösungen konkreter Probleme in der täglichen Kleinarbeit. „Dem Theoretisieren Tatsachenbeobachtungen entgegensetzen“: Das ist die Lehre Cantimoris, der noch 1964 schrieb:

„ein Problem oder eine Frage scheinen mir inkonsistent, wenn sie nicht auf eine faktische, empirisch zu erfassende Situation antworten: $z$. B. stellt eine Villa, die verfällt, das Problem, ob es sich lohnt, sie zu rekonstruieren, sie zu restaurieren usw., während es inkonsistent ist, das Problem der Restauration im Allgemeinen zu diskutieren; das ist meine Art zu empfinden. Ich möchte sie niemandem aufzwingen, aber mir scheint, ich schade keinem, wenn ich mich entsprechend dieser Meinung verhalte ..." ${ }^{\text {"57 }}$

Montinari überläßt sich sicher nicht der schlechten Empirie oder dem wilden Pragmatismus; er setzt vielmehr kritisches Bewußtsein bis zum Äußersten und methodische Umsicht gegen die falsche Sicherheit des Apriorismus. Auch hier wird man sofort an Cantimori erinnert: Das ,kritische Bewußtsein' macht uns „mißtrauisch vor allem gegen uns selbst, $d$. h. gegen die instinktive Tendenz, sich einzubilden, die endgültige und feste, statische Erkenntnis dessen zu besitzen, was Bewegung ist" ${ }^{* 58}$.

Aber dieses Bewußtsein entsteht auch aus der Auseinandersetzung mit den Errungenschaften der deutschen Philologie der Nachkriegszeit und mit deren Diskussionen über die kritischen Editionen neuzeitlicher Autoren.

Montinari liebte sicher nicht die großen theoretischen Diskussionen, die allzuoft ins Prinzipielle oder gar in Wortklauberei abglitten: Er kannte jedoch

57 Delio Cantimori, Conversando di storia, Bari: Laterza 1967, S. 169 ff.

58 Delio Cantimori, Storici e storia, Torino: Einaudi 1971, S. 407. 
jene Reflexionen, die der Praxis der Textedition galten, auch wenn er sich selten auf diesen Boden bezog, auf dem auch die neue Nietzsche-Ausgabe gewachsen war.

Die Errungenschaft der modernen Philologie besteht darin, daß ein abgeschlossener und statischer Text erneut ins Fließen kommt, daß er offen und dynamisch wird, entsprechend einem radikal historischen Bewußtsein, das keine Sicherheiten verspricht.

„Die neue Edition verspricht nicht Sicherheit, sondern soll ,ein echtes Maß an Unsicherheit erzeugen, die Aufmerksamkeit dafür wachhalten, daß der gebotene Text die Wirklichkeit eines lebenden Textes nur unvollkommen abbildet. Der Benutzer erhält den Text nicht zu festem Besitz ausgeliefert, sondern als Aufgabe, an deren Lösung er in jedem Augenblick mitzuwirken hat.' (Karl Stackmann) ${ }^{\text {c59 }}$

Die Distanz zum Empirismus besteht jedoch in der Entwicklung von Kategorien, die die Empirie und die Komplexität der Geschichte zu bändigen vermögen: Kategorien, die indessen selbst historischen Charakter haben und historisch überwunden werden können. Letzteres gegen die Ideologien und die Mythen, die zu Erstarrung, Vereinfachung und ,Reduktion' der Zukunft führen, indem sie das Einzelne zum Allgemeinen erheben.

In einer undatierten (auf Deutsch geschriebenen) Notiz aus der letzten Zeit resümiert Montinari seine Einstellung folgendermaßen:

"Zwei Formen der niaiserie academique werden von mir bekämpft:

1. die niaiserie der sogenannten Philologen, welche ihre Arbeit als eine Auflösung des Textes betreiben, indem sie sich damit zufrieden geben, die sogenannten Quellen zu suchen und zu sammeln und so den Blick für das Ganze einer geistigen Erscheinung verlieren: z. B. Nietzsche.

2. die niaiserie der Philosophen, die einen reduzierten, ihren Nietzsche lieben und sich nie veranlaßt sehen zu fragen: was meint er, wenn er von decadence spricht? steht er mit seinen Fragen in seiner Zeit ganz allein? Welche sind seine Aktenstücke?

Ich habe eine schlechte Nachricht für beide Arten der niaiserie: wir versuchen zwar jene Aktenstücke zu eruiren (!), aber nie wissen wir uns so am Anfang unserer Arbeit, wie als wenn wir alle möglichen Quellen gesichert haben. Wir verlangen einen klaren Horizont, einen komplexen Hintergrund für unseren Nietzsche, damit er wirklich zu Worte kommen kann, aber das ist - wie gesagt - der Anfang.

Die historische Arbeit ohne philosophisches Verständnis ist blind, das philosophische Denken ohne historischen Inhalt ist leer."

${ }^{59}$ Montinari hat diese Ausführungen zitiert in: La filologia tedesca nel dopoguerra: la discussione sull'edizione critica di autori moderni. Hölderlin da Stoccarda a Francoforte, einem - sehr schönen - Vortrag von 1985 an der Pisaner Facoltà di Lettere, an die ex berufen wurde. Der historische, extrem problematische, an Sicherheiten bare, lebendige Charakter des Textes entsteht als theoretisches Bewußtsein der großen Entwicklung zeitgenössischer philologischer Praxis. 
Die vorgeblichen technizistischen oder ideologischen Entscheidungen sind nur scheinbare Abkürzungen, sie sind Kurzschlüsse angesichts der Komplexität einer Arbeit, die sich immer wieder zum Gegenstand der Diskussion machen muß, die sich mit handwerklichem Können den Falten und Unebenheiten der Praxis und der Wirklichkeit anpassen muß. ${ }^{60}$

Im Jahre 1985, anläßlich der Dankesrede bei der Überreichung des Friedrich-Gundolf-Preises - einer weiteren öffentlichen Anerkennung seiner Tätigkeit als Gelehrter und Herausgeber - hat Montinari in wenigen Sätzen den Sinn seiner historisch-philologischen Arbeit an der Nietzsche-Ausgabe formuliert.

Während Pestalozzi in seiner Laudatio auf die vielen neuen Elemente der Ausgabe und auf die zahlreichen Ergebnisse einer beeindruckenden Arbeitsleistung hinwies, schilderte Montinari die Ausgabe als Ergebnis eines langen Weges und stellte sie innerhalb einer vielschichtigen und komplexen Tradition dar:

„Tatsächlich verstehe ich heute unsere Ausgabe als ein Glied in der Geschichte der Nietzsche-Edition: wir haben auch auf den Einsichten und Bemühungen einer langen Kette von Gelehrten und Herausgebern aufgebaut, die von Peter Gast und Ernst Holzer bis hin zu Hans-Joachim Mette und Karl Schlechta - Außenseiter wie Erich F. Podach nicht zu vergessen - reicht. Vielleicht, daß die gültigen Resultate dieser fast einhundertjährigen Arbeit an Nietzsche in unserer Ausgabe ,aufgehoben" sind“.

${ }^{60}$ In einem Brief vom 25. Februar 1967 macht er diese Komponente der Pragmatik und der notwendigen selbstkritischen Achtsamkeit in einer Polemik gegen den Freund geltend, der paradoxerweise aufgrund der Unnachgiebigkeit seiner Positionen des ,Hegelianismus' bezichtigt wird:

"Lieber Giorgio,

ich habe nichts zu antworten auf die Rechtfertigungen, die Du benutzt, um bei der alten Aufteilung der Bände zu bleiben [vgl. den in Anm. 55 zitierten Brief vom 13.2. 1967, G. C.], es wäre seltsam, wenn Du meinen Vorschlag angenommen hättest, dessen Wert eben in der ,Einheitlichkeit seines Kriteriums und in seiner Geradlinigkeit' besteht, die für Dich nichts zählen. Ich wünschte nur, Du sprächest nicht von einer Aufteilung, ,die wir mühsam konstruiert haben, über verschiedene Angleichungen und Verbesserungen, die die Natur des Materials nahelegte' ... Die ,pragmatischen' Ursprünge der gegenwärtigen Aufteilung (...) sind für mich klar, für Dich hingegen ist alles Furcht einer mühsamen Ausarbeitung und nie einer Anpassung an praktische Umstände, für Dich ist ,alles was wirklich ist [d. h. was $\mathrm{Du}$ in einem bestimmten Augenblick zu tun beschlossen hast], vernünftig', und hier kann man nichts machen, außer man konstatiert meine übertriebene Tendenz zur Selbstkritik (in Wahrheit macht es mir nichts aus, etwas ,befürwortet' zu haben, wenn ich mich später davon überzeuge, daß ich mich geirrt habe oder es hätte besser machen können) und für Dich das fast völlige Fehlen der Selbstkritik festzustellen. Übrigens hat auch Nietzsche gesagt, daß man die eigenen Handlungen nicht ,im Stich lassen' soll, und Du tust das nie, ich dagegen ja, und ich werde es immer so machen, auch bei wichtigeren Fragen als es die Aufteilung der Nietzsche-Werke ist, über die ich - natürlich - die Diskussion als abgeschlossen betrachte“. 
Dies gegen seine eigene anfänglich polemische Einstellung gegen die Irrtümer der Vorläufer seiner Edition. ${ }^{61}$

Aber noch bedeutsamer sind die Worte über den Sinn der täglichen Arbeit des Philologen und dessen wachsendes kritisches Bewußtsein, fern aprioristischer und tröstlicher endgültiger Methoden:

\begin{abstract}
"Andererseits muß jeder Herausgeber einer kritischen Gesamtausgabe seine eigene Tätigkeit unter einem relativierenden Licht sehen und sie schon deshalb einer ständigen Prüfung unterziehen, weil es nach wie vor keine alleinseligmachende Editionsmethode darüber gibt. Bei einem langandauernden Unternehmen wie einer historisch-kritischen Gesamtausgabe ist er genötigt, sein philologisches Instrumentarium immer feiner und schärfer einzustellen, und zwar so, daß er gewisse, zu Anfang getroffene Entscheidungen zur Gestaltung des Textes und des kritischen Apparates später als unbefriedigend ansehen muß. In diesem Zusammenhang ist der andere Umstand, daß in der langen Periode auch Fehler von ihm begangen wurden, prinzipiell nicht so bedeutsam - man wird sie immer noch durch ErrataListen beheben können - wie die erwähnte, langsame Verschiebung der philologischen Perspektive. Die tägliche Bemühung um den Text hat auch andere Folgen: der Herausgeber sieht alles aus zu großer Nähe, die Gefahr ist nicht gering, daß er über den im Apparat wiederzugebenden Einzelheiten, etwa der handschriftlichen Überlieferung, oder über der langwierigen Suche nach versteckten Quellen, d. h. über dem Versuch, den verschlungenen Wegen seines Autors genauestens nachzugehen, gleichsam das Ziel seiner Arbeit aus den Augen verliert (zum Leidwesen des Verlegers und des Leserpublikums). In extremen Fällen kann der edierte Text gar zum Beiwerk des Apparats werden ... Hier das richtige $\mathrm{MaB}$ zu finden ist keine leichte Aufgabe. Irgendwann muß Schluß gemacht werden und - eine nicht ganz vollkommene, jedoch zu Ende geführte Ausgabe ist wahrscheinlich immer noch besser als keine". ${ }^{62}$
\end{abstract}

Colli macht seine Position in seiner Antwort auf den Brief vom 29. September deutlich (5. Oktober 1967):

"Es ist nicht wahr, daß ich die Bedeutung, das Leiden, den Wert Deiner gesamten Arbeit verkenne: wenn ich mich nicht dabei aufhalte, die glänzendsten Ergebnisse, die Du mir mitteilst, zu kommentieren (und ich möchte gern, daß Du sie mir weiter zusammen mit den detaillierten Berichten über den Fortgang Deiner Arbeit im Allgemeinen mitteilst), so liegt das auf der

${ }^{61}$ Bereits Cantimori hatte seinen Schüler in einem Brief vom 26.8.1961 nach den ersten Erfolgen seiner Arbeit in Weimar in diesem Sinne ermahnt: "Ich bin sehr neugierig auf das Ergebnis der recensio der Mskr. „Wille zur Macht“. Ich bin nicht einverstanden mit Deiner Schadenfreude [im Orig. deutsch], die Dir durch die Einsicht in die Fehler anderer Philologen entsteht; seitdem sich die Philologie von der Exegetik getrennt hat, ist es immer so mit den Philologen gegangen; folglich scheint mir, daß es die andere Seite der desinteressierten Suche nach der Wahrheit ist, die aus unserer objektiven Forschung nicht verbannt werden darf und die, wenn man sie zu kontrollieren weiß, nützlich ist, um die Sicht zu schärfen!“

${ }^{62}$ M. Montinari, Glanz und Elend der pbilologischen Arbeit. Dankrede in "Deutsche Akademie für Sprache und Dichtung“" Jahrbuch 1985, Heidelberg: Lambert Schneider, S. 56-57. 
einen Seite an der ,harten Schule', weil ich das für normal halte, auf der anderen Seite - da ein übermäßiges Geizen mit Lob nicht meinem Charakter entspricht - jedoch daran, daß ich nicht möchte, daß ein Lob für ein Ergebnis mißverstanden werde als allgemeines Lob für diese Art zu arbeiten. Du sagst mir, daß es Dir wehtut, wenn ich die französische Ausgabe im Vergleich mit der deutschen lobe. Über diesen Punkt ist eine Erklärung dienlich. Wenn ich das sage, soll es nicht heißen, daß diese französische Ausgabe, in der Anlage und mit den Fehlern von Deleuze und Foucault, für mich die ideale Nietzsche-Ausgabe ist. Aber ich möchte damit sagen, $\mathrm{da} B$ Nietzsche zu Ehren und aus meiner innersten Überzeugung heraus eine Nietzsche-Ausgabe eben eine sein müßte, die Nietzsche gefallen könnte und die sich außerdem vor allem an die, nicht wissenschaftlichen' Leser wenden würde (und Du mußt bei unserem ganzen Unternehmen, von 1958 bis heute, immer daran denken, daß für mich das Element ,Nietzsche zu ehren' zentral ist, ebenso wie das Element, ,die Wirkung Nietzsches auf die Gegenwart zu fördern'). Das erklärt Dir meine Abneigung gegen eine Ausgabe à la de Gruyter, wo der hypertrophe Apparat eine Lebensbedingung ist. Die ideale Ausgabe wäre für mich diejenige, in der der Apparat sich darauf beschränkt, neues, für die Kenntnis N.s , substantielles` Material hinzuzufügen und außerdem Erklärungen bietet für Leser, die weder Idioten noch Pedanten sind: insgesamt also eine gewisse Leichtigkeit gegenüber den Ergebnissen und den Bedürfnissen philologischer Wissenschaft - sie sollte auf fast ironische Weise undogmatisch sein. Es ist nicht gesagt, daß unsere Gesichtspunkte unvereinbar sind, weil jede Anstrengung, die Korrektheit und die Strenge des Textes zu erhöhen, für mich Respekt verdient: ich schätze die Wissenschaftlichkeit des Textes, aber ich möchte, daß der Apparat nur ein ergänzendes Instrument ist, ohne Indulgenz gegenüber der Vollständigkeit und Wissenschaftlichkeit des Apparates.“

Giorgio Collis konsequent und fest bis zur Härte durchgehaltene Position bezieht sich explizit auf die Bedeutung jener "gemeinsamen Aktion“, die beide 1958 begannen mit der Intention, Nietzsche auf die Gegenwart wirken zu lassen; Colli sieht in der entstehenden deutschen kritischen NietzscheAusgabe sozusagen den Verrat an einem Projekt. Es ist ein Glaubensbekenntnis an Nietzsche, an seinen Nietzsche, dem er treu bleiben will. Aber ebenfalls aus Treue - zum anderen Nietzsche, den er Schritt für Schritt entdeckt, zur „wütenden Leidenschaft “ der Erkenntnis, die nie versiegt - führte Mazzino Montinari seine philologische und historische Arbeit fort.

Diese, nunmehr ausgesprochene und bewußte, Distanz charakterisiert auch die unterschiedlichen Wege, die beide vor sich haben: Für Colli ${ }^{63}$ der Weg einer eigenen philosophischen Praxis in direkter Auseinandersetzung mit der „Weisheit der Griechen", mit Schopenhauer und Nietzsche, für Montinari derjenige geduldiger historischer und philologischer Arbeit, lang-

${ }^{63}$ Über dessen Tätigkeit als Philosoph, die eng mit seiner Beziehung zu Nietzsche verknüpft ist, vgl. in diesem Band: S. Barbera: Der griechische Nietzsche Giorgio Collis. 
samen Fortschreitens und allmählicher Korrosion der vorgefundenen, festgelegten und ,mythischen' Bilder.

Bezeichnend ist, daß gerade in jenen Tagen, in denen der Vertrag mit de Gruyter unterzeichnet und Montinaris ,Schicksal' als Philologe besiegelt wird, auch die Vereinbarung über seine erwähnte Nietzsche-Monographie in der populärwissenschaftlichen Reihe fällt.

„Wenn es mir gelingen würde, etwas Bedeutendes zu sagen, wenn auch nur an einem unbedeutenden Ort vor einem Publikum, das voller historizistischer Vorurteile steckt, wenn mir das gelänge, könnte man beginnen, auf eine neue Weise über Nietzsche zu denken ..." (14. Oktober 65).

Als er 1967 die Fahnen des Bändchens liest und seine eigene Distanz zum „griechischen“ Nietzsche Giorgio Collis erkennt, bekräftigt er - in der begründeten Angst, das Resultat könnte dem „unwiderlegbaren“ Freund mißfallen, den Primat der persönlichen Beziehung und der Freundschaft:

„für mich gibt es keinen Platon, Schopenhauer, N. oder sonstwen, der Dir gegenüber auch nur im geringsten zählte oder an meinen Gefühlen Dir gegenüber etwas ändern könnte“" (4. 12.1967).

Es ist dieser Primat des wirklichen Lebens, der auch ein gewisses Mißtrauen gegen die ,Kopflastigkeit' des Vivisektors Nietzsche, gegen dessen „Pathos der Distanz“ motiviert und den Willen zu ihrer Überwindung bedingt. Dieser Sinn der Fülle und der Unmittelbarkeit des Lebens drückt sich in einer Notiz aus, die zur Erinnerung an den Menschen Mazzino Montinari beitragen mag:

„Das Glück ist etwas, das man schon hat (oder nicht hat), es ist nicht erreichbar, man muß sich seines Glücks bewußt werden." ${ }^{\prime 64}$

\section{ANHANG \\ Mazzino Montinari: Notizen aus dem Jabre 1967 \\ zu "Also sprach Zaratbustra“}

Nietzsches Irrtum in bezug auf seinen Zarathustra ist, daß er glaubte, der Menschheit ein neues heiliges Buch zu geben. Dieser Irrtum wurde durch die Blindheit seines ersten „Schülers“, Peter Gast, begünstigt. Sein zweiter Irrtum war, an die Unverständlichkeit des Zarathustra zu glauben, ja sich darüber zu freuen. Zarathustra ist kein heiliges Buch, Zarathustra ist kein unverständliches Buch, kein Buch für Eingeweihte, wofür es sehr schnell

${ }^{64}$ Eine Notiz, „gedacht am 21. September 1984, 6 Uhr (Herbstanfang)“, die sich im bereits zitierten Heft Pessimismus, Nibilismus, décadence findet. 
gehalten wurde von denen, die - wie Gast - sich unkritisch selbst als „Ausnahmen", als Eingeweihte betrachten konnten. Zarathustra ist gerade ein Buch „für alle“ - wenn es gelesen werden muß; sonst ist es ein Buch für keinen und müßte nicht gelesen werden.

Zarathustra ist keine Musik - er ist es noch weniger in einer Übersetzung. Das ist aber der Vorteil einer Übersetzung: den Leser wachzuhalten und ihn nicht mit den falschen Schönheiten der Töne einzulullen. Außerdem ist Zarathustra in Wirklichkeit noch nicht einmal schön, und nur der beträchtliche Verfall des Geschmacks in der Epoche der Moderne - oder besser das Ende des Geschmacks! - konnte dieses Werk des Gedankens in ein Vademecum der Ästheten verwandeln. Um klar zu sein: wenn wir Dichtung sagen, dann meinen wir: Faust, Anna Karenina, Rot und Schwarz usw. $\mathrm{N}$ hat die Dichtung zerstört, $\mathrm{N}$ konnte und wollte kein Dichter sein. Vielleicht hat er geglaubt, es zu sein - wider Willen - aber es ist ihm nie gelungen. Keine einzige der wenigen (?) Seiten von ihm, die als Dichtungen gepriesen werden, kann uns überzeugen. Wenn die Schönheit - wie N auf den Spuren Stendhals glaubte - ein Glücksversprechen ist, wenn die Dichtung mit der Schönheit zu tun hat - wie jedenfalls $\mathrm{N}$ meinte - dann ist $\mathrm{Za}$ keine Dichtung.

Rohde: Das Herz zerspringt usw. und dann das Urteil über Za

$\mathrm{Za}$ ist dasjenige Werk, das am engsten mit dem Problem von Ns „fortune“ zusammenhängt und das deshalb a limine die Beseitigung einer großen Reihe von Mißverständnissen erfordert. Vieles aus dem $\mathrm{Za}$ ist in den Büchern vor ihm enthalten - genauer ab $M A$ (nicht ab GT und UB!).

Den positiven Inhalt des Zarathustra beschreiben, um allmählich eine Negation zu erreichen: die Negation eines endgültigen metaphysischen Inhalts - vielmehr [geht es um, d. Übs] eine Einstellung nach dem Tod Gottes. Und zum Schluß Za als Musik und Dichtung negieren. Zum Glück Übersetzung! Für alle: also muß er gelesen werden, d. h. er ist verständlich. Für keinen: also ist es nutzlos, ihn zu lesen.

[handschriftliche Hinzufügung, G.C.]:

Wie Za sagt: das Gehirn ist der Magen des Herzens - Man muß einen guten Magen haben. Man muß Zarathustra verdauen - mit dem Gehirn

Es ist keine geringe Sache, das Blut anderer $\mathrm{zu}$ fordern: ich hasse die Tagediebe, die lesen. [eingefügt mit Pfeil:] Jedoch ist Sich-Hineinversetzen notwendig - mit $\mathrm{N}$ leiden -

Scbluß: (S.) [Za] ist ein Fehltritt Ns - mit traditionellen Mitteln eine neue Sache: das „Nichts“! die Antimetaphysik! vielleicht ist $N$ seiner Seinsweise treugeblieben - dem Aphorismus -

[N und die Deutschen]

R. M. Mayer - Institutionalisator Ns mit nicht zu verachtenden Ideen, z. B. über Za als „Krönung“ - er hat gesagt: „Wir haben das Reich, die Erfindungen und $\mathrm{N}$ erlebt"! 
[Za]

„Es gibt nichts, das dich bewegt, du selbst bist das Rad, das von selbst rollt und keine Ruhe hat" - sagt Angelus Silesius (1624-1677), und Nietzsche: „Das ist der Mensch: eine neue Kraft, eine erste Bewegung, ein aus sich rollendes Rad; wenn er stark genug wäre, würde er die Sterne zwingen, daß sie sich um ihn drehen“"

[Za]

Za ist ambivalent: 1) kann man sagen, daß er eine "schlechte Tat" Ns war, weil er so Propaganda für sich selbst gemacht hat - Propaganda im modernsten Sinn dieses Wortes, d. h. etwas extrem Negatives und Liturgisches; 2) und nichtsdestotrotz - wenn man über die Ebene der Propaganda und ihre narkotisch-musikalische Faszination hinausgeht - ein Werk ganz aus Gedanken; das, was andere als Grenze Za's empfunden haben (z. B. Hofmiller), daß es nämlich keine Dichtung, sondern eine Sentenzensammlung sei - ist in Wirklichkeit sein eigentlicher Wert. Sicher sind es "Gedanken“ Nietzsches. Fakten.

[Za]

Der Übermensch, die ewige Wiederkehr sind - wenn wir uns eines unsympathischen Wortes bedienen wollen - die Mythen einer Epoche ohne Mythen. Übermensch ist kein biologisch-rassisches Konzept; soviel ist wahr: wenn $\mathrm{N}$ sich mit „biologisch-rassischen“ Problemen beschäftigt, benutzt er nie dieses Wort. Ewige Wiederkehr ist nichts anderes als die Sanktion der „Treue zur Erde“, des irdischen Lebens als oberstem Wert, die, wenn man so will, auf religiöse Weise erlebt wird. $\mathrm{Daß}$ der Za so trocken ist und das Herz nicht erwärmt (Löwith) findet hier seine Erklärung.

An Goethe erinnern: der nicht religiöse Mensch ist kein Künstler, sondern Wiederholer und Imitator.

[Za]

Das Problem der Herkunft Za's ist noch heute unlösbar. Man könnte an das erinnern, was ein Iranist - dessen gewichtiges Werk $\mathrm{N}$ im fernen Jahr 1878 in Händen hielt -, Spiegel (3.234) sagt: Ihm zufolge war die Entstehung der Legende von Zarathustra auf Seiten der iranischen Priester weitgehend durch den „Haß gegen den Buddhismus" bedingt. Nun kann man auch für den Nietzscheschen Zarathustra von einem $\mathrm{Ha}$ gegen den modernen Buddhismus sprechen, d. h. vom Kampf gegen Schopenhauer.

[Za]

Im Za findet sich auch das für $\mathrm{N}$ bereits alte $(1875,5[11])$ Element des Kampfes gegen den Zufall (und gegen die Notwendigkeit). 
$[\mathrm{Za}]$

Der IV. Teil des Zarathustra kann auch als eine Art allegorische innere Biographie Zarathustras verstanden werden.

Im ersten Teil des Zarathustra sind in anderer Form - die wir versuchen wollen, kurz zu analysieren - Gedanken dargelegt, die zum „System Nietzsche" gehören, so wie es sich ab 1876 entwickelt hatte. Es ist zum Beispiel sehr bezeichnend, daß die Grundlage der Polemik gegen die „Meta-Physiker“ „historistischen“ Ursprungs ist: ebenso ist bekannt, daß Nietzsche schon in VM den Begriff „Hinterweltler" gebraucht hatte.

[über Nietzsche Arbeitsweise]

Die Notizbücher Beethovens - alle Großen waren große Arbeiter, unermüdlich nicht nur im Erfinden, sondern auch im Zurückweisen, Durchsieben, Neustrukturieren, Ordnen.

[Später Nietzsche]

Nietzsche hat, speziell in der Spätphase seines schöpferischen Daseins, Begriffe benutzt, die leer und fast blutlos, beinahe nichtssagend scheinen (z. B. der Begriff „höhere Menschen"): man muß sich folglich aller vorhergehenden Bedeutungen erinnern, mit denen er sie angefüllt hat. Diese Begriffe sind sozusagen Siglen: sie sollen uns immer an das denken machen, was vorher gewesen ist. Sicher kann es sein, daß man auf diesem Weg entdeckt, daß Nietzsches Denken eine allmähliche Entleerung (Auflösung) von Inhalten ist und keine Anreicherung. Es versteht sich, daß wir uns auf alles beziehen, was der wahre und eigentliche Nietzsche ist: $d . h$. den Nietzsche ab MA sowie das, was er vorher geschrieben hat, insoweit es diesen Nietzsche vorbereitet.

[Za]

Wenige Zuckerkörnchen machen Zuckerwatte - Zarathustra! Wir haben es nicht mit der dichterischen Einfachheit zu tun, wie wenn man zum Beispiel sagen würde, daß der Faust auf einer ausgesprochen linearen dichterischen Konzeption beruht. Es handelt sich um etwas, das wir direkt als Armut an Ideen (an Leben?) bezeichnen könnten.

[Za]

N sagt - im Dezember 1882: „Ich will das Leben nicht wieder. Wie habe ich's ertragen? Schaffend. Was macht mich den Anblick aushalten? der Blick auf den Übermenschen, der das Leben bejabt. Ich habe versucht, es selber zu bejahen - Ach!“ [KSA 10 4[81], G. C.] Folglich fühlte sich N selbst vom Gedanken der ewigen Wiederkehr überwältigt; er hatte nicht die Kraft, sich zur Bejahung, zur Annahme zu erheben, zu dem, was er "Ja Sagen“ zum Leben nannte. Das Fragment zeigt uns, abgesehen von der biographischen 
Einfärbung, eine bedeutsame Verbindung, nämlich die zwischen den beiden Vorstellungen der „ewigen Wiederkehr" und des „Übermenschen“. Viele haben einen Widerspruch zwischen diesen beiden Begriffen gesehen. In Wirklichkeit gibt es keinen Widerspruch - wenigstens, und hierauf kommt es natürlich an - im Denken Nietzsches selbst, also in der Art, wie $\mathrm{N}$ beides betrachtete. Die ewige Wiederkehr, weit davon entfernt, den Übermenschen auszuschließen, benötigt ihn im Gegenteil sogar, um ertragen zu werden. Insofern als dieser die übermenschliche Kraft hat, ja zum Leben zu sagen. Der Widerspruch, oder besser der Konflikt, ist stattdessen bei $\mathrm{N}$ selbst zu suchen, der sich nicht als Übermensch fühlt. Wenn man dieses Wort hört, müßte man immer an die Bedeutung denken, die $\mathrm{N}$ ihm gab: der Übermensch, der ja zu Leben sagt, einem Leben, das immer wiederkehrt.

[Za]

Man könnte den Zarathustra als eine Art „Religion“ der Freiheit des Geistes bezeichnen, als den Versuch, eine "heroische“ Moral jenseits von Gut und Böse theoretisch zu entwickeln. Das Wort „heroisch“ ist heute fast diskreditiert, aber gerade die Urheber dieser Diskreditierung sind es, die es dann verwenden. Warum?

[Za]

Es ist seltsam, daß N, der sich mit den Idealisten und den Religiösen im Allgemeinen anlegt, weil sie behaupten, daß das Leben nicht erträglich wäre ohne die "metaphysische Bedeutung" oder ohne "Gott", danach selbst das Argument verwendet "man könnte nicht ertragen" wie in diesem Fragment zum Zarathustra 2[219] VII [KGW VII, 34 [212], G.C.]

Auf der anderen Seite ist gerade der Übermensch derjenige, der das Leben, das immer wiederkehrt, nicht nur erträgt, sondern auch will.

[Za]

Zarathustra ist weniger der Prolog von Nietzsches neuer Philosophie als vielmehr die Krönung seines Denkens zwischen 1876 und 1882. Jedes Kapitel des Zarathustra kann auch als "langer“ dithyrambischer Aphorismus gesehen werden, in dem - ausgehend von einem zentralen Thema - aufgrund der besonderen, Abschweifungen erlaubenden Darstellungsform zahlreiche Variationen und Sentenzen über das Thema Platz finden. Dies ist auch daraus ersichtlich, wie die einzelnen Teile des $\mathrm{Za}$ entstanden. [So daß es keinen wirklichen Sinn ergibt, von $\mathrm{Za}$ als einem mystifizierenden Werk zu sprechen. In Wirklichkeit hat $\mathrm{N}$ nach einem neuen Ausdrucksmittel gesucht, um seine Gedanken mitzuteilen. [Man könnte sogar sagen, daß zwischen dem aphoristischen $\mathrm{N}$ und dem $\mathrm{N}$ des $\mathrm{Za}$ überhaupt kein Unterschied besteht - und daß auch in formaler Hinsicht der Unterschied nicht so groß ist.] Es gibt im $\mathrm{Za}$ keine unverständlichen oder dunklen Behauptungen. Selbst die Idee der 
„Wiederkehr des Gleichen“ ist ein Gedanke, der der Sphäre der Rationalität angehört, sie ist keine mystische Intuition. Sicher hat $\mathrm{N}$ vor Enthusiasmus und Furcht gezittert. Aber für ihn waren die Gedanken Ereignisse; wie wir schon gesagt haben, waren sie sein ganzes Leben.

[Za]

Das Genie ist etwas ganz anderes als det Übermensch. Das Genie ist in der romantischen Konzeption derjenige, dem die Produktivität „von Natur“ gegeben ist, dagegen ist der Übermensch einfach nur derjenige, der Ja zum Leben sagt, obwohl er die Ewige Wiederkehr kennt.

(Aus dem Italienischen übersetzt von Bettina Wahrig-Schmidt) 